\title{
Normal and Neoplastic Growth Suppression by The Extended Myc Network
}

\author{
Edward V. Prochownik ${ }^{1,2,3,4,5}$ and Huabo Wang ${ }^{1}$
}

Key words: ChREBP, L-Myc, Max, Mga, Mlx, Mnt, MondoA, Mxd, N-Myc, tumor suppressor

${ }^{1}$ Division of Hematology/Oncology and The Department of Pediatrics, UPMC Children's Hospital of Pittsburgh; ${ }^{2}$ The Department of Microbiology and Molecular Genetics. UPMC; ${ }^{3}$ The Hillman Cancer Center of UPMC; ${ }^{4}$ The Pittsburgh Liver Research Center, Pittsburgh PA 15224

${ }^{5}$ Corresponding author:

Edward V. Prochownik, M.D., Ph.D.

Division of Hematology/Oncology

Department of Pediatrics

UPMC Childrens Hospital of Pittsburgh

Rangos Research Center, Room 5124

4401 Penn Ave.

Pittsburgh, PA 15224

Tel: 412-692-6795

Email:procev@chp.edu

Abstract 


\section{Abstract}

Among the first discovered and most prominent cellular oncogenes is MYC, which encodes a bHLH-ZIP transcription factor (Myc) that both activates and suppresses numerous genes involved in proliferation, energy production, metabolism and translation. Myc belongs to a small group of bHLH-ZIP transcriptional regulators (the Myc Network) that includes its obligate heterodimerization partner Max and six "Mxd proteins" (Mxd1-4, Mnt and Mga) each of which heterodimerizes with Max and largely oppose Myc's functions. More recently, a second group of bHLH-ZIP proteins (the Mlx Network) has emerged. It is comprised of the Myc-like factors ChREBP and MondoA, which, in association with the Max-like member Mlx, regulate smaller and more functionally restricted sets of target genes, some of which are shared with Myc. Opposing ChREBP and MondoA are heterodimers comprised of Mlx and Mxd1, Mxd4 and Mnt, which also structurally and operationally link the two Networks. We discuss here the functions of these "Extended Myc Network" members with particular emphasis on the roles played by Max, Mlx and Mxd proteins in suppressing normal and neoplastic growth. These roles are complex due to the temporally-and tissue-restricted expression of Extended Myc Network proteins in normal cells, their regulation of both common and unique target genes and, in some cases, their functional redundancy.

Keywords: ChREBP; L-Myc; Max; Mga; Mlx; Mnt; MondoA; Mxd; N-Myc; tumor suppressor 


\section{Introduction}

The Myc and Mlx Networks. 2021 marked the 30th anniversary of the discovery of Max, the obligate heterodimerization partner of the c-Myc (Myc) bHLH-ZIP transcription factor, which had itself been identified nearly a decade earlier as the evolutionarily conserved cellular homolog of the avian v-myc retroviral oncogene [1-5]. Shortly thereafter, it became clear that Max was necessary for Myc-mediated target gene activation and cellular transformation but that, at higher Max:Myc ratios, it also repressed these functions in a dose-dependent manner [611]. This initially suggested a simple model whereby Myc-Max heterodimers, which contain a transactivation domain (TAD) contributed by Myc, and Max homodimers, which lack a TAD, alternatively activate or suppress transcription in accord with their relative abundance $[12,13]$. This balance was believed to be maintained by the competitive binding of these dimers to so-called "E-box" elements that are typically located in proximity to the transcriptional start sites of target genes (Fig. 1). The model immediately implied that Max could serve dual functions; on the one hand, it could activate target genes and drive transformation by virtue of its obligate association with Myc. As a homodimer, on the other hand, it could outcompete Myc-Max binding, repress target gene expression and serve as a tumor suppressor (TS).

Max's discovery soon paved the way for the rapid identification of six additional bHLH-ZIP Max partners that currently comprise the so-called "Myc Network" of which Max remains the central member (Fig. 1). These proteins, Mxd1-4, Mnt and Mga (hereafter referred to collectively as "Mxd proteins") (Fig. 1), necessitated a revision of the above model as did the finding that, in mammalian cells, Max's high level of phosphorylation, maintained by casein kinase II, prevents its binding to DNA as a homodimer but not as a heterodimer [14-16]. Transcriptional repression by Max was thus deemed to be mediated not simply by passive exclusion of Myc-Max heterodimers from binding E-boxes by Max homodimers. Rather it was now seen as an active process that required Max's heterodimerization with Mxd proteins, the association with obligate transcriptional co-repressors such as mSin3 proteins and the ensuing transcriptionally suppressive modification of chromatin via altered patterns of histone acetylation and methylation [17-22]. Collectively, these six Mxd proteins, which show distinct tissue-, developmental- and age-dependent patterns of expression, antagonize Myc's broad impact on transcription and its highly pleiotropic effects on both normal and neoplastic growth [6-8,21,23-32].

By the turn of the $21^{\text {st }}$ century, the existence of a second network, parallel to that of the Myc Network, and possessing significant structural and functional similarities, had emerged. This "Mlx Network", also comprised of bHLH-ZIP factors, contained the positively-acting Myc-like proteins ChREBP ('carbohydrate response element binding protein') and MondoA and their own dedicated heterodimerization partner, the Max-related Mlx, which together formed the Network's positively-acting arm [33-36] (Fig. 1). Unlike Myc and Max, which are nuclear proteins, ChREBP, MondoA and Mlx are cytoplasmic but translocate to the nucleus in response to the binding of metabolites such as glucose, glucose-6-phosphate, fructose 2,6-bisphosphate, lactate and adenosine [33,34,37-55]. In fact, the cytosolic location of MondoA and ChREBP is not random; rather amphipathic helical domains in the C-termini of these factors allow them to interact with intracytoplasmic lipid droplets and presumably serve as sensors of intracellular lipid content [56]. Lipid droplet depletion and the loss of cytoplasmic sequestration signal allows MondoA and ChREBP to translocate to the nucleus and activate genes involved in glucose metabolism. The negative arm of the Mlx Network shares three factors from the Myc Network, namely Mxd1, Mxd4 and Mnt, along with mSin3-histone deacetylase complexes [33,35,57]. These three negative regulators link the two Networks both structurally and functionally and provide a means of crosstalk for more refined and coordinated regulation of both common and unique targets.

Mlx Network heterodimers recognize E-Box-related binding sites termed "carbohydrate response elements" (ChoREs) (Fig. 1). Both E-boxes and ChoREs, but particularly the latter, can be quite variable and cross-binding of one Network's members to the other Network's sites is likely more common than previously appreciated [35,58-63]. Binding by ChREBP may also facilitate promiscuous, non-E-box-dependent binding by Myc at nearby sites [64]. Mlx Network 
target genes, while overlapping with those regulated by the Myc Network, are both fewer in number and have been reported to be more functionally restricted [65-67]. They tend to encode enzymes involved in carbohydrate and lipid metabolism; mitochondrial and ribosomal proteins and factors that regulate translational initiation, elongation and termination [21,33,50,57-60,63,65-78]. Together these findings indicate that, via selective, cytoplasmic-nuclear partitioning, sharing of $\mathrm{Mxd1}, 4$ and Mnt and binding to both common and unique target genes, this "Extended Myc Network" cross-talks, while simultaneously communicating with and responding to the metabolic cues needed to support energy-intensive processes such as translation and proliferation [43,50-52,56,77-85].

The Extended Myc Network and tumor suppression. Given the number of Mxd proteins and their crucial roles, particularly with regard to limiting Myc signaling, proliferation and metabolism (Fig. 1), it is reasonable to surmise that, at some level, they, and perhaps Max as well, behave as TSs. We discuss below the evidence to support this, the findings that the inactivation of these factors is often confined to certain tumor types and the implications of Mxd member haplo-insufficiency, which is a common theme in many tumors. It is also important to consider these factors in their proper biological context. In other words, do they behave as "classical" TSs such TP53, RB and BRCA1/2, whose germ line or somatic inactivation predispose to spontaneous neoplasms such as leukemias, lymphomas, retinoblastomas, osteosarcomas, and breast, ovarian and prostate cancer [86-91]? Or, does the inactivation of these factors simply accelerate the growth of pre-existing tumors without otherwise contributing directly to their initiation?

All Mxd members, as well as the central players Max and Mlx, have been implicated as TSs based on bioinformaticsbased surveys of large populations of human tumors [92,93]. However, to our knowledge, neither comprehensive summaries nor intragroup comparisons of the consequences of copy number variations (CNVs) and mutations described in these reports have been published. By way of introduction to the more detailed discussions presented in the following sections, we too surveyed all tumors from The Cancer Genome Atlas (TCGA) to identify those associated with CNVs of Extended Myc Network genes (Fig. 2). This survey revealed several interesting findings. First, and in keeping with the known role of MYC as a bona fide oncogene and the presumptive roles of CHREBP and MONDOA in supporting transformation and rapid proliferation, these genes showed the highest frequency of amplification $[20,43,67,92,93]$. Second, recurrent deletions of all other Extended Myc Network members were quite frequent across many tumor types, in keeping with their presumptive role as TS genes (TSGs). Third, none of the genes was exclusively amplified or deleted across all tumor types or, in many cases, even within the same tumor type [93]. Fourth, among the "oncogenes", high-level gene amplification, defined as $>4.4$ copies/cell [94], was seen only with MYC and tended to be associated with subgroups of certain cancers such as breast, ovary, liver and lung as previously reported [95-98]. Fifth, more often than not, amplifications or deletions of more than one Extended Myc Network gene was associated with particular tumor types and was most obvious in breast, ovarian and squamous cell lung cancers. This suggests that oncogenic activation of the Extended Myc Network can be achieved via multiple pathways that are cooperative rather than mutually exclusive. Sixth, despite its relatively high incidence of genomic instability, thyroid cancer was the only tumor in which CNV of any Extended Myc Network member was never observed (Fig. 2). This may partly reflect their high incidence of BRAF, PIK3CA and PTEN mutations, which likely circumvent Myc Network activation $[93,99]$. In keeping with the theme that high level MYC amplification tends to be confined to certain tumor types (Fig. 2) [93], deletion of presumptive TSGs tend to cluster as well, particularly in those instances associated with two copy deletion as seen with $M L X$ and $M N T$ in ovarian cancer, $M X D 2$ in prostate cancer and $M X D 3$ in squamous cell lung cancer (Fig. 2) [93]. Finally, the inactivation of TSG-like members of the Extended Myc Network by frame-shift and truncating mutations is rare, typically accounting for $<1 \%$ of inactivated alleles, except in the case of $M G A$ where this approaches 4\% [93]. Thus, as discussed more fully in the following sections, rather than the traditional bi-allelic inactivation/deletion of classical TSGs seen in both hereditary and sporadic cancers, hemizygous inactivation of $M X D$ genes is a recurrent theme [87-91].

As was generally true for oncogenic members of the Extended Myc Network, the correlation between MXD TSG expression and survival is variable. Fig. 3 summarizes these relationships among all tumors from TCGA and Fig.4 shows 
several specific examples of survival differences. Interestingly, survival correlated with the expression of as many as 11-12 of the individual Extended Myc Network members and in the case of low-grade gliomas (LGGs), with all 13 members, although not necessarily in the same way. This supports the points mentioned above that perturbing the delicate balance among Extended Myc Network members may have oncogenic consequences that are additive or complementary rather than mutually exclusive. The connections among tumor aggressiveness, survival and the expression of individual members of the Extended Myc Network are thus complex, inter-dependent and tumor typespecific.

The relationships among Extended Myc Network gene CNV, mutation, expression and survival are in many cases thus far only correlative. Indeed, this cautionary note applies even to an oncogene as unassailable as MYC whose role in tumorigenesis mandated a direct demonstration of its actual causality [100-102]. Yet, recent work has indicated that, at least for some tumor types, Myc may function more as a facilitator of tumor growth than as an actual initiator. Hepatoblastoma (HB) in mice, induced via the ectopic expression of mutant forms of $\beta$-catenin and the Hippo pathway effector protein YAP, is associated with Myc over-expression $[66,103,104]$. Yet, the rate of tumor induction in livers with hepatocyte-specific knockout of Myc is identical to that seen in wild-type livers $[66,67]$ although tumor growth is slowed. Similarly, tumors induced with different $\beta$-catenin mutants express widely different levels of Myc that roughly correlate with growth rates even though they too are initiated at identical frequencies [104]. These results, strongly indicate that the role of Myc in actual tumor induction versus facilitation is quite nuanced and may reflect both the levels at which it is expressed and the tissue environment [105].

A somewhat analogous situation, discussed in greater detail below, occurs with Max. While there is no evidence that MAX is an actual oncogene, it could be viewed as being another tumor facilitator that collaborates with Myc (Fig. 1). Yet, the recurrent loss of Max in pheochromoctytomas, parganglioneuromas and several other tumors supports its role as a potent TS [106-112]. Similarly, $M L X$ loss dramatically impairs normal hepatocyte proliferation while at the same time serving as a potent suppressor of benign hepatic adenomatosis [63].

Given the well-accepted role of Extended Myc Network members in tumorigenesis, either directly as oncogenes or as tumor facilitators, we have focused here on their roles in tumor suppression and discuss each member in turn. As mentioned above and discussed in greater detail below, the functions of these members may differ, even in the same tissue. Where necessary, background information on the oncogenic function of these factors or their role in normal cell proliferation is provided as a way of furnishing context. We hope this review provides a much-needed source of information regarding this emerging function for the Extended Myc Network and how it impacts the balance between normal and neoplastic growth and the functions that support them.

\section{Myc}

Like RAS and PI3K, MYC is a classic example of a dominantly acting oncogene although, unlike the former two, it is seldom mutated in tumors. Rather, its oncogenicity commonly derives from gene amplification, where, along with CCND1 and EGFR, it is among the top three amplified genes across a broad range of cancers (Fig. 2) [94]. Such frequent, pronounced and uni-directional changes in gene copy number emphasize this pro-oncogenic role and are rivaled, albeit only modestly so, by similar changes in CHREBP (Fig. 2). In other tumors, such as Burkitt's lymphoma and subsets of diffuse large B-cell lymphoma (DLBCL) and multiple myeloma, MYC's over-expression is a result of its translocation into immunoglobulin gene loci [113-116]. Yet these examples, involving alterations in chromosomal architecture, underestimate the true frequency with which MYC is dysregulated in cancer as aberrant signaling by many mutant growth factor pathways converge on $M Y C$ and promote its over-expression in the absence of structural changes [117-119]. However, as mentioned in the Introduction, it is important to distinguish between MYC's role as a 
primary driver oncogene versus that of a tumor facilitator or enhancer that simply provides metabolic and/or translational support without being necessary for tumor initiation $[66,67,100]$.

Unlike the direct induction of genes mediated by Myc-Max DNA binding mentioned above (Fig. 1), Myc's role in transcriptional suppression is indirect and involves the association of Myc-Max heterodimers with transcription factors such as Miz1 that normally up-regulate genes encoding negative growth regulators such as $P 15 I N K 4 B, P 57 K I P 1$ and P21CIP1 [120-124]. Mechanistically, Myc's bHLH-ZIP domain binds directly to Miz1 and prevents the latter's binding to initiator (Inr) elements at transcription initiation sites of these target genes. Similarly, Sp1's binding to multiple GGGCGG sites located in the P21CIP1 promoter is disrupted via the interaction between its C-terminal zinc-finger and a 200 residue internal region of Myc (amino acids 143-352) [125,126]. This effect is distinct from the suppression mediated by Miz1 since the deletion of P21CIP1's Inr does not interfere with Myc's blocking of SP1-mediated induction [125].

A novel means of Myc-mediated tumor suppression has been suggested by studies showing that ubiquitylation of several lysine residues in Myc's C-terminus by the E3 ubiquitin ligase HectH9 profoundly alters Myc's activation of its target gene repertoire [127]. This modification licenses Myc's interaction with and subsequent stabilization by the histone acetyltransferase (HAT) p300 [128]. HectH9 is over-expressed in many tumors and is inhibited by Miz1 [127]. This suggests that HectH9 is required for Myc to achieve its maximal transcriptional activation potential, presumably by optimizing its recruitment of p300 and other co-activators [129]. HectH9 thus represents a potential therapeutic target that could suppress if not entirely eliminate Myc's impact on tumor growth by dictating its potency as an oncoprotein [127]. The proposed operation of the Myc-Hecth9-Miz1 axis thus suggests that Myc toggles between two states that alternatively activate or repress transcription of the same target genes.

Other post-translational modifications that could contribute to Myc's role in tumor suppression occur via two distinct mechanisms involving the phosphorylation of T358, S373 and T400 by the Ser/Thr kinase Pak2. These alterations lead to a loss of Myc-Max heterodimerization and reduced target gene affinity [130]. In promyelocytic leukemia (PML) cells, this has an additional impact on retinoic acid-induced differentiation mediated by the retinoic acid receptor (RAR $\alpha)$ and its induction of genes that inhibit proliferation and promote differentiation [131,132]. Unphosphorylated Myc contacts RAR $\alpha$ via both its $\mathrm{N}$ - and C-termini and blocks the induction of the former's transcriptional program, thus maintaining both proliferation and the undifferentiated state [133]. Pak2's phosphorylation of Myc abrogates its Cterminal interaction with RAR $\alpha$ while maintaining its $\mathrm{N}$-terminal association. This allows RAR $\alpha$ to induce its target genes in response to retinoic acid thereby circumventing the differentiation and proliferative barriers. Consistent with these findings, unphosphorylated Myc's binding to RAR $\alpha$ decreases the latter's association with co-activators but increases its association with co-repressors whereas the reverse occurs in response to Myc phosphorylation. Among the more prominent of the factors identified under these conditions were the co-repressor HDAC3 histone deacetylase and the co-activator HAT CBP. The relationship between Myc and Pak2 appears to be coordinated in that Pak2 is up-regulated during late stage retinoic acid-induced terminal PML differentiation and coincides with declining Myc levels [134]. Thus, in response to appropriate environmental cues, Myc may function either to block or facilitate PML differentiation and proliferation, thereby either enhancing or suppressing malignant behavior. The mechanism by which Myc blocks PML differentiation, i.e. by directly interacting with and inhibiting another transcription factor, is formally analogous to the previous described inhibition by Myc of Miz1- and Sp1-mediated transcription.

Pak2 phosphorylation of Myc has also been described in many other normal and neoplastic contexts, including primary hematopoietic cells, keratinocytes, fibroblasts and other leukemias [130-132,135-137]. It has been proposed that phosphorylated Myc plays a role in maintaining hematopoietic balance by promoting stem cell adherence and limiting expansion. However, the amplification of PAK2 (as well as PAK2-related genes) is considerably more common in cancer than is inactivation and missense mutations of Pak2 phosphorylation sites in Myc are virtually non-existent $[131,132,138,139]$. Thus any role for Myc as a TS in primary human cancers is likely to be quite limited. 


\section{$\operatorname{Max}$}

Given Max's central role in balancing the transcriptional output of the Myc Network (Fig. 1), it might be perceived as promoting either pro-oncogenic or TS functions in a manner that depends on the relative abundance of Myc-Max heterodimers on the one hand and Mxd-Max heterodimers on the other [10,11,21,140]. Myc-Max association is needed to maintain both normal and tumor cell proliferation and inhibiting this for therapeutic purposes in cancer, whether by pharmacologic or genetic means, has been a long-desired goal [6-8,25,141-146].

The first evidence for Max's potential as a TS was provided by studies showing that, when co-expressed in relative excess to Myc, it suppressed Myc-mediated target gene activation and/or transformation in vitro $[7,8,10,11,147,148]$. Evidence for a natural TS function of Max was first suggested by the observation that the PC12 pheochromocytoma (PC) cell line expressed a mutant Max transcript and no functional protein and that the enforced re-expression of wildtype Max inhibited PC12 growth [149].

Adrenal gland PCs, and their extra-adrenal gland counterparts, paraganglioneuromas (PGLs), are typically benign tumors derived from adrenal chromaffin cells or extra-adrenal sympathetic and para-sympathetic tissues of neural crest origin [150]. Approximately one-third of PCs/PGLs are inherited, particularly those adrenal tumors that are bilateral and non-adrenal tumors that are multi-focal. Collectively, about one-third of PCs/PGLs harbor identifiable germ line mutations. Additionally, about two-thirds of sporadic cases have an underlying genetic cause [106,151]. Mutations in at least 14 genes have been described with the most common being those encoding any one of the four subunits of the succinate dehydrogenase complex of the electron transport chain, otherwise known as Complex II (SDHA, SDHB, SDHC and SDHD) [107-109,112,152]. Max mutations are found in $1-2 \%$ of tumors, particularly those which are inherited, display malignant features, arise in younger individuals and/or are associated with higher levels of metanephrine or normetanephrine secretion $[107,109,150]$.

In the largest single study performed to data involving nearly 1700 inherited and sporadic PCs and PGLs, 20 Max mutations were identified, 18 of which were novel [107]. Nine of these were associated with mutations of the methionine initiation codon, with the remainder causing premature termination, aberrant splicing or in-frame deletion of crucial amino acids. The majority of these failed to express Max protein. The remaining 11 tumors contained missense mutations seven of which were predicted to be deleterious, although all expressed the mutant Max proteins. Loss of heterozygosity (LOH) was observed in 16 of the 18 tumors analyzed.

MAX mutations have subsequently been described in tumors as diverse as multiple myeloma, small cell lung cancer (SCLC), pituitary adenoma and quadruple wild-type gastrointestinal stromal tumor [153-156]. Multiple myeloma, in which the MAX mutation rate is $\sim 3 \%$, was a particularly informative source as the Max mutations provided clues into how they impacted the protein's binding to various epigenetically-modified E-boxes [156]. The fact that methylation at position 5 of the internal cytosine residue $(5 \mathrm{mC})$ of the canonical CACGTG E-box inhibits Max binding has been known since the protein's original discovery [157]. However, the E-box is subject to additional naturally-occurring cytosine modifications mediated by members of the ten-eleven translocation (Tet) family of Fe(II)- and $\alpha$-ketoglutaratedependent dioxygenase family, including 5-hydroxymethylation $(5 \mathrm{hmC})$, 5-formylation $(5 \mathrm{fC})$, and 5-carboxylation $(5 \mathrm{caC})$. All these modifications except $5 \mathrm{caC}$ have been shown to abrogate Max binding, particularly when the modification is present on both strands of the palindromic sequence [156]. A determination of Max's crystal structure in homodimeric association with a 5caC-modified E-Box showed that the R36 residue demonstrated the largest conformational difference when compared to the structure of Max or Myc-Max bound to the unmodified E-box. The importance of this residue was demonstrated by showing that the myeloma-associated Max mutation R36W abolished DNA binding entirely. Moreover, of the 25 unique Max mutations identified among 805 multiple myelomas, 17 
involved missense mutations with five of these directly altering R36 and two altering the adjacent R35 residue. Finally, of the 643 tumor samples for which both mutational status and RNAseq results could be assessed, those harboring Max mutations expressed significantly lower levels of Myc and tended to display more favorable outcomes. The lower level expression of Myc in these samples was likely due to the loss of its Max-mediated stabilization [156,158]. To explain how Myc drives myelomagenesis in the absence of efficient Max association, the authors suggested that Myc interacts with other E-box binding proteins such as WDR5 $[159,160]$.

SCLC in humans is often associated with TP53 and RB1 loss/mutation and amplification of MYC or its paralogs MYCN and MYCL (Fig. 2) [161-163]. A recent CRISPR/Cas9-based screen for suppressors of early-stage SCLC found Max to be among the top hits with no enrichment being observed for other members of the Extended Myc Network [164]. Confirmatory studies showed that Max knockdown in these "preSC" cells led to more robust growth and survival during both anchorage-dependent and independent growth in soft agar. When tested in vivo in an autochthonous Rb1/Trp53-deleted mouse model of SCLC [165] Max knockout was associated with significantly larger numbers of tumors and shortened survival. Max re-expression in a cell line derived from these tumor cells significantly suppressed growth. Interestingly, when preSC cells were engineered to over-express $\mathrm{Myc}, \mathrm{MycN}$ or $\mathrm{MycL}$, the concurrent knockout of Max inhibited growth. These findings suggested that, at least in this model system, Max's role in SCLC development is context dependent and at least partly reliant upon the level of expression of Myc or its paralogs, particularly MYCL. While Max appeared to serve a pro-oncogenic function by facilitating MYC family-mediated transformation, it could also serve as a TS via one or more Myc-independent pathways.

RNAseq was performed in control preSC cells and SCLCs with or without MAX knockout as well as in SCLCs with MAX knockout and restored Max expression. Common deregulated genes shared by these cohorts included 113 that were up-regulated in response to MAX knockout and 56 that were down-regulated. Among the former were genes previously been shown by ChIP to bind Myc-Max and Mxd-Max heterodimers. Collectively, these findings were consistent with the idea that MAX knockout reverses the suppression of genes mediated by the inhibitory arm of the Myc Network (Fig. 1). Further analyses of these 113 genes and several hundred additional ones identified using less stringent criteria showed an enrichment for pathways dedicated to one-carbon metabolism along with the metabolism of nucleotide sugars, serine, alanine, aspartate and glutamate. Many of these genes' promoters were cooccupied by Myc-Max and Mxd-Max heterodimers thus likely representing sites that could bind either heterodimer, depending on the cells' metabolic and/or proliferative. It was speculated that up-regulation of these genes in response to MAX knockout was due to the activity of other transcription factors that are otherwise normally impeded by MaxMxd occupancy of nearby E-boxes. It was further surmised that the over-expression of MYC and its paralogs would displace Max-Mxd heterodimers from these sites, leading to increased Myc-Max binding and even more pronounced target gene induction.

\section{Mxd1}

Mxd1 (previously Mad1) was first identified as a Max partner and subsequently shown to possess the dimerization specificities depicted in Fig. $1[20,21,57,140]$. In the mouse embryo Mxd1 mRNA is selectively expressed in a developmentally-dependent manner in tissues such as liver, epidermis and the brain's mantle layer $[166,167]$. Postnatally, its expression broadens and becomes most prominent in differentiated tissues such as epidermal ketatinocytes and the apical and luminal regions of intestinal crypts [166,167]. These findings, along with the observation that Myc expression is more restricted to highly proliferative cellular compartments, suggested that Myc and Mxd1 were engaged in opposing functions. They thus contributed to the then nascent model that terminal differentiation and proliferative quiescence were driven by the dissolution of Myc-Max heterodimers and the de novo formation of Max-Mxd1 heterodimers. However, the model was complicated by studies showing that Myc-Max heterodimers and Max-Mad heterodimers engaged distinct subsets of E-box-regulated genes, albeit with some overlap [168]. 
Mxd1's function as a TS in vivo was initially tested in a study that knocked out the gene in mice and found there to be no significant increase in spontaneous cancer incidence or other major phenotypes, thereby implying that other members of the Mxd family (Fig. 1) were functionally redundant [23,24]. More careful inspection however, reveled that myeloid cell maturation was impaired due to delayed cell cycle exit during in vitro differentiation in response to GM-CSF or G-CSF. It was postulated that, during the latter stages of bone marrow differentiation, committed colonyforming granulocyte precursors normally expand in a Myc-dependent manner to a degree that is limited by the gradual expression of Mxd1 and diminution of Myc, ultimately giving rise to so-called cluster-forming cells of more limited proliferative capacity [23]. Mxd gene knockout allowed for the accumulation of these cells, which were also more dependent on G/GM-CSF for survival. Notably, no expansion of less mature progenitors was observed, which would have been expected with a more leukemogenic insult. This suggested that Mxd1 was more involved in the advanced stages of terminal differentiation as had been previously surmised from the studies discussed above. This was supported by the observation that $M x d 1$ knockout bone marrow was modestly hypercellular due to an expansion of mature granulocytes [23,166-168]. Consistent with this, recovery from 5-flurouracil-induced bone marrow hypoplasia occurred more rapidly in Mxd1 knockout mice.

Other hints that Mxd1 might be a growth and/or TS under different circumstances came from studies showing that its enforced expression repressed Myc+Ras-mediated transformation of primary rat fibroblasts $[166,167]$ and impaired the in vitro growth of established human cancers in a manner that is consistent with the model depicted in Fig. 1 [169171]. However subsequent studies in human cancers showed that Myc and Mxd1 were often co-expressed and poorly correlated $[169,172,173]$. Sustained proliferation in the face of relatively high levels of Mxd1 might be attributable to its post-translation inactivation. Indeed, the Ser/Thr kinases Akt, RSK and S6K which are frequently over-expressed in cancer can directly phosphorylate Mxd1 at S145 and abrogate transcriptional repression by inhibiting DNA binding without disrupting its association with Max [172,174-178]. Akt-mediated phosphorpylation did not alter Mxd1's already short half-life whereas RSK and S6K did, as evidenced by increased ubiquitination and proteasome-mediated proteolysis [172,178]. Akt-mediated phosphorylation did however, negate DNA binding, thus shifting the gene expression balance to one that was primarily driven by Myc-Max heterodimers and Myc target gene activation. The distinct outcomes mediated by Akt, RSK and S6K on Mxd1 half-life may have been attributable to differences in the cell lines utilized to study these activities, to alternative Mxd1 phosphorylation sites and/or to other proteins that differentially interacted with the kinases to impact Mxd1 stability. Together, the findings indicated that high levels of mitotic signaling mediated by the PI3-kinase/Akt/S6K and MAP kinase/RSK pathways converge on Mxd1 so as to finetune its stability, its association with Max and its DNA binding activity thus allowing for competing Myc-mediated cell cycle-promoting processes to proceed.

An alternative and potentially complementary form of post-translational regulation for Mxd1 and other Myc Network members was investigated by confocal microscopy of cell lines from three different species following transient expression of GFP variant-tagged Myc, Max and Mxd1-3 [179]. When expressed by itself, Max assumed a diffuse and homogeneous intranuclear distribution in contrast to Myc and Mxd1-3, all of which formed multiple discrete foci or "speckles" that co-localized. These speckles were highly dynamic and co-dominant in that, when co-expressed with Max, the observed pattern of each protein assumed the appearance of whichever member of the pair was more abundant. For example, when Max was expressed in excess to Myc, the latter protein assumed a diffuse distribution whereas when Myc was in excess, Max assumed a speckled pattern. Deletion mapping of Mxd1 and Mxd2 indicated that both proteins contained similarly structured domains that were responsible for these expression patterns. In the first case, this included the nuclear localization signal (NLS) centered around residue 91 that was flanked by two regions responsible for nuclear speckling, namely residues 1-42 and 124-141. Similarly, the Mxd2 NLS was mapped to residues 81-131 and was flanked by speckling domains localizing to residues 38-81 and 175-192. The functional importance of these domains was tested with an Mxd2 deletion mutant (1-152) that retained the ability to 
heterodimerize with Max but not the ability to assume a speckled pattern. Despite being expressed at levels identical to wild-type Mxd2, this mutant was significantly impaired in its ability to suppress a Myc-responsive reporter [179].

Myc and Mxd3 nuclear speckles were distinct from those containing the SC-35 splicing factor, which were otherwise similar in size, appearance and abundance $[136,179]$. Indeed, the absence of even random overlap of Myc and Mxd3 speckles with SC-35 speckles strongly suggested that active processes were involved in maintaining the separation between these two speckle compartments. However, when GFP-tagged Myc was co-expressed with non-GFP-tagged Max at near equal ratios that allowed the former protein to retain its speckling pattern, numerous GFP-Myc speckles (presumably in association with Max) now co-localized with about 15\% of SC-35-containing speckles. Higher resolution analysis indicated that the overlap was particularly prominent along the peripheries of SC-35 speckles, which are believed to be the regions most actively engaged in transcription [180-182]. In contrast, GFP-Mxd3+Max speckles did not co-localize with SC-35 speckles. Together, these studies suggested that, prior to dimerization with Max, Myc and Mxd3 (and probably Mxd1, Mxd2, and Mxd4 as well) belong to a common population of subnuclear speckles that exist in a transcriptionally inert state. Following heterodimerization with Max, Myc-Max and Max-Mxd heterodimers are reapportioned into distinct domains with the former residing at sites of active transcription and mRNA processing and the latter occupying regions of relative transcriptional quiescence.

Among the most critical and highly coordinated Myc targets are genes which are regulated by all three RNA polymerases and encode ribosomal structural proteins, rRNAs, tRNAs and the translation initiation, elongation and termination factors needed to ensure maximal protein synthesis and tumor growth $[66,67,100,183,184]$. In addition to localizing to the nucleus as described above, Mxd1 may play a specific role in regulating rRNA synthesis by also localizing to the nucleolus [185]. The nucleolus' fibrillar center (FC) is the site where RNA Pol I and Upstream Binding Factor (UBF) are concentrated [186]. FCs are embedded within the dense fibrillar component (DFC) that sequesters the ribosomal genes and harbors various RNA-binding proteins. Both FCs and DFCs represent sites of active Pol I transcription with subsequent pre-rRNA processing occurring within the DFC to generate mature $18 \mathrm{~S}$ and $28 \mathrm{~S}$ species [187]. The subsequent assembly of these into $40 \mathrm{~S}$ and $60 \mathrm{~S}$ ribosome subunits occurs within the granular component (GC) $[188,189]$. It was shown in several cell lines and primary tissues that nucleolar Mxd1 associates with UBF and becomes particularly prominent following serum starvation [185]. This is in sharp contrast to Myc and Mnt, both of which displayed nuclear segregation. Treatment of cells or whole animals with actinomycin $D$ at low concentrations that selectively inhibited Pol I [190] led to a loss of nucleolar Mxd1 without affecting its nuclear compartmentalization. Chromatin immunoprecipitation studies verified that, as had been previously demonstrated for Myc-Max complexes Mxd1 binding occurred throughout rDNA repeats often, but not always, in association with UBF [184,191].

In addition to the above post-translational varieties of regulation, Mxd1 stability is also regulated at the posttranscriptional level by miR19a/b, which are products of the six-member miR-17-92 cluster that is both over-expressed by and drives numerous cancers, promotes epithelial-mesenchymal transition and is a direct Myc target [192-202]. Individuals with gastric cancers that overexpress miR-19a have significantly shorter survival and a higher incidence of metastatic disease at diagnosis than those with low expression [203]. Two gastric cancer cell lines engineered to overexpress miR-19a or miR-19b and displaying lower levels of Mxd1 as a consequence demonstrated enhanced in vitro migration and invasion whereas these behaviors were impaired when endogenous miR-19a/b were inhibited and normal Mxd1 levels were restored. In gastric cancer xenografts, miR-19a or miR-19b over-expression also increased both the frequency of metastatic deposits and their sizes. Additional experiments identified two direct miR-19a/b binding sites within the Mxd1 mRNA 3'-untranslated region. Finally, in addition to being positively regulated by Myc, the miR-17-92 cluster was also negatively-regulated by Mxd1 over-expression, thus establishing a self-regulatory feedback loop among the MYC, MXD1 and miR-19-92 loci [204].

A putative role for Mxd1 in a more indirect form of tumor suppression may involve its participation in promoting chemotherapeutic drug resistance which, along with increased angiogenesis and a more invasive phenotype, is 
enhanced by hypoxia and its attendant induction of hypoxia-inducible factor- $\alpha$ (HIF-1 $\alpha$ ) [205-210]. In two different osteosarcoma cell lines, hypoxia significantly increased the fraction of cells surviving cis-platinum exposure in a manner that correlated with Mxd1 induction and that paralleled an earlier induction of HIF-1 $\alpha$ [211,212]. siRNAmediated knockdown of HIF-1 $\alpha$ abolished Mxd1 induction and Mxd1 knockdown abolished the survival advantage in response to hypoxia. Because the PTEN TS had been previously identified as conferring doxorubicin resistance in colon cancer cells [205], Zheng et al examined its role in the above models and found Mxd1 binding and transcriptional repression at each of two perfectly conserved E-boxes in PTEN's proximal promoter [211,212]. Moreover, knockdown of PTEN was associated with the phosphorylation-mediated activation of Akt1 and improved survival. Collectively, these findings were compatible with a model in which the hypoxia-mediated induction of HIF-1 $\alpha$ induces Mxd1, which binds to and directly represses PTEN promoter, thereby up-regulating the PI3 kinase/Akt pathway and mediating survival in response to cis-platinum.

\section{Mxd2}

Initially isolated using a yeast two-hybrid screen that employed Max as a "bait", Mxd2 (originally known as Mxi1) is expressed in a variety of tissues and up-regulated in response to the differentiation of U937 monocytic leukemia cells [213]. The human MXD2 gene, located on chromosome 10q25.2 (https://omim.org/entry/600020), resides within a locus that is often subject to recurrent deletion and LOH in several human tumors, most notably over half of prostate cancers and glioblastomas [214-227]. Inactivating point mutations in the retained $M X D 2$ allele were initially identified in a rare subgroup of prostate cancers with cytogenetically detectable 10q24-q25 deletions and subsequently in a larger and more common group of tumors harboring much smaller 10q25.2 deletions detectable only by fluorescence in situ hybridization [224,228]. Regardless of cytogenetic background, MXD2 point mutations in the retained allele, both in prostate and other cancers, are infrequent and their subsequent confirmation has been inconsistent [229-233]. Importantly, the searches for these mutations, which were conducted prior to the employment of whole exome sequencing, typically relied upon insensitive detection methods such as single-strand conformation polymorphism screening that likely would not have detected mutations in small clonal subpopulations of tumor cells and/or in tumors with significant amounts of cytogenetically normal stroma that is a feature of most prostate cancers $[217,230,231,234]$. On the other hand, $M x d 2$ point mutations were relatively common among a diverse group of 24 primary rat cancers and cell lines induced by a variety of known carcinogens [235]. 6 tumors with mis-sense mutations and one with a frame-shift were identified across the protein. The consequences of the missense mutations on Mxd2 function were neither immediately obvious nor tested further. Taken together, the relative infrequency with which biallelic loss/inactivation of MXD2 occurs in human cancers suggests that haplo-insufficiency, an increasingly recognized and wide-spread phenomenon for a number of TSs [236,237], may be more responsible for contributing to tumorigenesis in some of these cancers.

A more convincing role for $M x d 2$ as a TSG was obtained in a longitudinal study of engineered $M x d 2-/-$ mice [238]. These animals showed a propensity to develop splenomegaly in association with a pronounced expansion of splenic white pulp, extramedulary hematopoiesis and the occasional evolution to B cell lymphomas within the first year of life. Mitotic stimulation of $M x d 2-/-$ splenic $T$ cells with anti-CD3/CD28 antibodies led to significantly higher rates of proliferation and expansion relative to wild-type cells that correlated with a more efficient exit from G0/G1 and entry into S-phase. Together with the postulated role for Mxd1 discussed above in supporting the proliferation of myeloid precursors, these findings suggest a broader role for these two negative factors in overseeing hematopoietic cell proliferation. Surprisingly, the authors were unable to demonstrate any proliferative abnormalities in $M x d 2-/-$ B cells in response to lipopolysaccharide-mediated proliferation, despite the fact that the malignancies originating in some of the mice were of $B$ cell origin.

Notable additional abnormalities in aging $M x d 2-/-$ mice involved degenerative changes in the renal cortex that were preceded by the cytoplasmic vacuolization of cells comprising the proximal tubular epithelium and focal atrophic 
degenerative changes in proximal tubules and glomeruli [238]. Some of the changes were reminiscent of autosomal dominant polycystic kidney disease (ADPCKD), which has been linked to Myc over-expression, can be generated by transgenic Myc deregulation and is associated with renal epithelial hyperprolifertation [239]. These results were subsequently confirmed by DNA microarray expression profiling that compared renal epithelia from normal and $M x d 2$ /- polycystic murine kidneys [240]. This study found fewer than 150 gene expression differences, including a ca. twofold up-regulation of Myc and a variety of transcripts that participate in pathways pertaining to inflammation, the immune response and chemokine signaling [240]. The latter included significant up-regulation of the CKL12, CKL14 and CKL19 chemokines. These are related to IL-8, which is known to participate in ADPCKD pathogenesis [241,242]. Indeed, Mxd2-/- human embryonic kidney cells significantly increased IL-8 secretion and activated the p38 MAPK pathway. It was speculated that Mxd2 knockdown either directly or indirectly activated p38 MAPK, which in turn lead to a proinflammatory phenotype that, in addition to increased secretion of IL-8, included Myc up-regulation and the ensuing uncontrolled renal epithelial proliferation.

The basis for ADPCKD was further investigated by establishing 3-D in vitro cultures of murine inner medullary collecting duct (mIMCD-3) cells, which undergo branching tubulogenesis when exposed to epidermal growth factor and hepatocyte growth factor [243,244]. In response to these, tubulogenesis was reduced by nearly 10-fold in Mxd2overexpressing mIMCD-3 cells but was restored when $M x d 2$ was silenced. Genes encoding fibronectin, integrin and Mmp9, which are induced during tubologenesis and play key roles in this process $[245,246]$ failed to be up-regulated in response to $M x d 2$ knockdown. Moreover, the knockdown of $M m p 9$ alone was sufficient to inhibit tubulogenesis in cells that expressed otherwise normal levels of $\mathrm{Mxd} 2$ thus establishing a pathway by which the enforced expression of Mxd2 inhibited tubulogenesis by preventing Mmp9 induction. Taken together, these results suggest that Mxd2 tempers Myc's tendency to drive an over-exuberant proliferation of medullary collecting duct cells and that both genes are needed for normal and properly balanced renal epithelial tubulogenesis.

Because of the previously discussed link between MXD2 loss/mutation and human prostate cancer [224,228] SchreiberAgus et al also examined the prostates of older $M x d 2-/-$ male mice [238]. While not progressing to frank neoplasia, they did develop hypercellular acini and dysplastic cells with higher proliferative indices as determined by Ki-67 immuno-staining. Mxd2-/- MEFs also replicated faster in vitro than their wild-type counterparts and were 3-5-fold more transformable by $M Y C+R A S$ oncogenes. Together, these findings suggested that $M x d 2$ gene silencing was associated with broadly similar outcomes in prostatic epithelium, MEFs and T cells that involved a dysregulation of Myc and dysregulated proliferative signaling. The susceptibility of $M x d-/-M E F s$ to $M Y C+R A S$ transformation was likely due to Myc's failure to be transcriptionally challenged by Mxd2 and thus being better more efficient at suppressing Ras-induced senescence $[247,248]$.

In addition to the modestly higher incidence of spontaneous lymphomas in $M x d 2-/-$ mice mentioned above, a more impressive increase in lymphomas and cutaneous squamous cell carcinoma was observed following DMBA treatment [238]. Finally, Mxd2-/- mice crossed with cancer-susceptible Ink4a-/- mice developed lymphomas and fibrosarcomas at a significantly higher rate and survived for a shorter time than did an Ink4a-/- control group. Together, these findings converge on the idea that $M x d 2$ exerts broad anti-proliferative effects on a variety of cell types and that $M x d 2$ gene loss contributes to the evolution of various cancers, particularly in cases where predisposing conditions already exist. Loss of competition between Myc-Max and Max-Mxd2 heterodimers may, however, only partially explain the cancer susceptibility of these mice since the Myc gene itself is negatively regulated by Mxd2 [249]. Cancer propensities in $M x d 2-/-$ mice may thus reflect both a greater abundance of Myc protein, more efficient Myc binding to its target genes, increases in the expression of target genes that bind Myc with low affinity and a loss of repression of key Mxd2 targets.

Work showing that ectopic Mxd2 expression induced G2/M growth arrest and suppressed the proliferation and/or colony forming capacity of both prostate cancer and glioblastoma cells was broadly compatible with the above model 
$[227,250]$. Interestingly, the growth arrest of U-87 glioblastoma cells coincided with the formation of Max-Mxd2 heterodimers that bound to a consensus E-box in the proximal promoter of the CCNB1 (cyclin B1) gene and suppressed its transcription [251]. This prompted a G2/M arrest due to an inability to accumulate sufficient cyclin B1 to complete mitosis. These findings were compatible with earlier work performed in murine 32D myeloid cells showing that the combination of Myc over-expression and TP53 inhibition promoted the spontaneous accumulation of tetraploidy that was markedly enhanced by sublethal doses of $\gamma$-irradiation and was accompanied by increased cyclin B1 and its associated cdc2 kinase activity [252]. It was shown that the above-mentioned E-box in the CCNB1 promoter was a direct Myc target and that the promoter was also coordinately down-regulated by TP53. Finally, ectopic cyclin B drove tetraploidy if the mitotic spindle checkpoint was blocked or if Myc was concurrently over-expressed [179]. These studies suggested that the loss of $\mathrm{Mxd2}$ and the ensuing dysregulation of Myc predisposes cells to the acquisition of tetraploidy, partcularly if their cell cycle checkpoints were disrupted due to lesions such as INK4A and/or TP53 inactivation [253]. Tetraploidy is likely an early, unstable and transient developmental stage that precedes the more permanent aneuploidy associated with the vast majority of epithelial cancers [254-257].

The above-mentioned negative regulatory loop between Mxd1 and the miR17-92 locus that is amplified in multiple cancers is also influenced by Mxd2 and Mnt [192,193,195-198,200-202]. The first intron of C13orf25, which encodes the primary unprocessed miR17-92 transcript, contains a highly conserved E-box element that binds Myc, Mxd2 and Mnt and is activated or repressed accordingly [204].

\section{Mxd3}

As with Mxd2 [213], Mxd3 and Mxd4 were co-identified in a yeast two-hybrid screen using Max as the bait [27]. Also like Mxd1 and Mxd2, Mxd3 and Mxd4 hetodimerize with Max, bind consensus E-boxes, interact with mSin3, suppress E-box containing Myc reporters and inhibit MYC+RAS-mediated transformation of rat embryo fibroblasts [27].

Despite their functional similarities, $M x d 3$ and $M x d 4$ gene expression patterns in the murine embryo are distinct from one another as well as from those of $M x d 1, M x d 2, M y c$ and $N-M y c$ and are mostly confined to the nervous system and skin [28]. As a general rule, $M y c, M y c n$ and $M x d 2$ gene expression are associated with proliferating compartments, whereas $M x d 3$ and $M x d 4$ are associated with more quiescent ones. However, these individual expression patterns are not absolute and vary in both tissue- and stage-specific ways [27]. For example in the early (ca. d7.5) embryo, Mxd3 expression is low and confined to the posterior regions of the embryonic ectoderm and the peripheral non-reactive decidua where it was co-expressed with Myc [31]. In ca. d11.5 developing limb buds, Mxd3 is co-expressed with Mycn in proliferating mesenchyme adjacent to the epidermis whereas at d17.5, undifferentiated epiphyseal growth plate chondrocytes co-express $M x d 3$ and Myc. These differential expression patterns are maintained in species as diverse as Xenopus and are thus highly conserved throughout evolution [258].

In contrast to $M X D 1$ and $M X D 2$, fewer studies have implicated $M X D 3$ in the direct pathogenesis of cancer and/or tumor suppression. While its structural and functional similarities, coupled with mostly correlative studies, would indicate that it plays roles similar to those of its paralogs, there are some notable differences that might have been anticipated from the above-mentioned embryologic studies. For example, the Sonic Hedgehog (Shh) variant of medulloblastoma expresses high levels of $\mathrm{Mxd} 3$ and Mycn in the cerebellar granule neuron precursors (GNPs) or nestin-expressing progenitors from which tumor cells are thought to originate [259-262]. Indeed, Mxd3 is actually required for Shh-mediated maintenance of GNP proliferation and, in Shh's absence, the over-expression of Mxd3 (but not other Mxd proteins) can drive GNP proliferation. This requires both Max dimerization and the interaction with mSin3 but surprisingly does not require DNA binding by Max-Mxd3 heterodimers. This suggests that Mxd3's role is distinct from that of other Mxd members, that its impact on GNP proliferation might actually complement that of Mycn rather than antagonize it and that the Mxd3's promotion of proliferation might be mediated by interactions outside those of the immediate Myc Network (Fig. 1). For example, Max-Mxd3 heterodimers might interfere with the 
activity of other transcription factors in a manner that does not require direct DNA binding by Max-Mxd3 or they might be recruited to non-E-Box binding sites by such factors. Consistent with this idea are reports indicating that Mxd3 is specifically expressed during S-phase and prior to differentiation in a manner than is determined by an E2F1 binding site in its proximal promoter [27,31,262-265].

Subsequent studies have revealed Mxd3's role to be somewhat more subtle. For example, while its short-term overexpression in DAOY medulloblastoma cells was associated with more rapid proliferation and a higher proportion of cells in S-phase, its longer-term expression actually suppressed proliferation and promoted apoptosis [262,266-269]. Comparative DNA microarray profiling between these two conditions (12 hr vs. $72 \mathrm{hr}$ following Mxd3 induction), showed dysregulation of $>2200$ and $>3300$ genes respectively with considerable overlap between the groups. The uniquely-expressed early transcripts tended to encode proteins involved in immune responses, apoptosis/survival and cell cycle whereas the uniquely-expressed late transcripts encoded proteins involved in protein folding and cell adhesion. Among the many ways to explain this switch from early to late target gene preferences is that the products of the former set of genes are responsible for remodeling the chromatin of the latter in ways that permit them to become targets at later times.

A mechanism has been identified in murine splenic T-cells by which $\mathrm{Mxd} 3$, acting via the Id2 protein, might regulate gene expression in a manner distinct from that of other $\mathrm{Mxd}$ members and potentially contribute to tumorigenesis [265]. In this setting, and in an E-box-dependent manner, the bHLH transcription factor E2A/Tcf3/E47 (E2A) was shown to drive the expression of many genes that are required for B-cell differentiation. Id2 is a HLH protein that lacks a basic domain and thus interferes with B-cell differentiation by heterodimerizing with E2A and inhibiting DNA binding [270]. Mxd3 is expressed at high levels in the most immature and highly proliferative subset of splenic T-cells, binds to at least one of several E-Boxes in the Id 2 gene promoter and up-regulates Id 2 expression in a dose-dependent manner [265]. Mxd3's binding to the Id2 promoter was shown to be associated with the recruitment of p300 histone acetylase in a manner that recalled the interaction between p300 and Myc [128,265,271]. Moreover, the deliberate downregulation of Mxd3 decreased Id2 levels whereas the down-regulation of Mxd4 had the opposite effect. Coupled with a previous finding that $\mathrm{Mxd} 3$ protected against $\gamma$-radiation-induced cell death in primary thymocytes and neural progenitor cells [32], these findings suggested that Mxd3 functions in ways that are both distinct from other Mxd members and potentially pro-oncogenic. First, Mxd3 might maintain the differentiation block that is a well-known consequence of Myc dysregulation and an important general feature of tumors [272,273]. Second, the protection against DNA damage afforded by Mxd3 could dampen the apoptotic response that is triggered by the over-expression of oncogenes such as Myc itself and thereby contribute to their further dysregulation and oncogenic signaling $[105,253]$.

Mxd3 is over-expressed in multiple cancers, including acute lymphocytic leukemia and glioblastoma (Figs. 2 and 3 ) [267]. As with all other Extended Myc Network members, at least 17 different tumor types show survival differences that correlate with MXD3 expression levels (Fig. 3). Supporting the idea that Mxd members are functionally distinct is the finding of considerable variability among Mxd members with regard to their correlations with favorable or unfavorable survival. For example 11 of the 14 tumor types (78.6\%) expressing the highest levels of Mxd4 are associated with more prolonged survival whereas in the case of Mxd3 this is true for only 5 of 17 tumor types (29.4\%).

To better understand these relationships, we examined Myc, Mycn and Mxd1-4 transcripts in primary and recurrent low-grade gliomas (LGGs) cataloged in TCGA. We selected these tumors because of the distinct spatial and temporal expression of Mxd transcripts in the developing brain (see above) [27,31,258,262] and because Mxd3 is the only member of the Myc Network that correlates with unfavorable survival (Fig. 5). Among all tumors, the mean levels of Mxd1-4 transcripts varied by approximately 4-fold, with Mxd3 expression being the lowest (Fig. 5A). Mxd2, Mxd3 and Mxd4 transcripts were expressed at significantly higher levels in recurrent LGGs with those for Mxd3 being the most increased. In contrast, Mxd1 transcript levels were unchanged. Myc transcripts were expressed at higher levels than Mycn transcripts with neither of these being significantly altered in recurrent tumors. However, the levels of both Myc 
and Mycn transcripts, but particularly the latter correlated with Mxd3 expression (Fig. 5B). Actual survival curves were consistent with the summaries depicted in Fig. 3 in showing that LGGs expressing the highest Mxd3 levels were associated with shorter overall survival (Fig. 5C). Collectively, these and the foregoing results indicate that, unlike the case for all other members of the Mxd family and despite frequent and widespread LOH in a variety of cancers (Fig. 2), there is currently little evidence to support a TS role for Mxd3.

\section{Mxd4}

Like other Mxd paralogs, Mxd4 is expressed in distinct spatial and temporal patterns during differentiation $[27,31,263]$. Consistent with a role as a TS and inhibitor of proliferation, Mxd4 is induced within 5-8 hr of initiating murine erythroleukemia (MEL) cell terminal differentiation by dimethlyl sulfoxide [274]. In this model, endogenous Myc, which is abundant in proliferating MEL cells, abruptly declines to nearly undetectable levels within 1-2 hr of induction, returns to pre-induction levels during the ensuing $12-18 \mathrm{hr}$ and then progressively declines again during the terminal differentiation phase that occurs between days 2-5 and is associated with proliferative quiescence, erythroid lineage commitment and the onset of globin synthesis $[275,276]$. Prior to differentiation, an Inr element in the Mxd4 gene proximal promoter binds and is suppressed by Miz1-Myc complexes. Upon differentiation, the decline of Myc allows Miz1 to become transcriptionally active and induce Mxd4 [274].

The above findings were extended to the in vitro differentiation of embryonal stem cells (ESCS) where both similarities and differences were noted $[274,277]$. Within $6 \mathrm{hr}$ of inducing hematopoietic differentiation by the sequential addition of bone morphogenetic protein 4, Activin A, fibroblast growth factor and vascular endothelial growth factor, a transient 80\% decline in Mxd4 transcript levels was noted versus <2-fold changes in those for Myc and other Mxds. Enforcing ectopic Mxd4 expression impaired the emergence of both primitive and committed lineages. This did not affect viability but rather led to G0/G1 cell cycle arrest in association with reductions in the cyclin-dependent kinases (Cdk) 4 and 6 and an increase in the Cdk inhibitor p27 kip1 all of which are Myc targets [141,247,248,278,279]. A model was proposed whereby committed but actively proliferating CD41+ hematopoietic progenitors gradually suppress their expression of Myc while increasing Mxd4, which leads to cell cycle withdrawal during the latter stages of terminal differentiation [277]. The initial down-regulation of Mxd4 was proposed to allow for a transient Myc-driven proliferative burst prior to lineage specification and proliferative arrest.

Somewhat similar findings were made in senescent human fibroblasts or those rendered temporarily quiescent by serum deprivation. Both conditions increased Mxd4 transcripts levels relative to those in proliferating cells although two-fold higher levels were achieved in senescent cells [280]. Quiescent serum-deprived cells also significantly increased Myc transcripts and decreased Mxd4 transcripts as serum-stimulated proliferation resumed whereas little change was seen in serum-treated senescent cells, which was consistent with their irreversible growth-arrested status. However, Miz1 bound the MXD4 promoter and up-regulated Mxd4 expression in both senescent and serum-deprived cells [280]. In quiescent cells, serum treatment increased Myc-Max binding to several Myc target genes while also increasing the abundance of repressive Myc-Miz1 complexes on the Mxd4 promoter. In senescent cells, however, these changes did not occur. Importantly, no other Mxd members appeared to be responsive to serum stimulation in either quiescent or senescent fibroblasts thus implicating Mxd 4 as the major Myc Network factor that is responsible for mediating the permanent proliferative arrest associated with senescence and reversible arrest associated with serum deprivation.

Despite the evidence implicating Mxd4 in the induction and/or maintenance of cell quiescence, there is little published information regarding a similar role in human neoplasia. Yet it is clear from our survey of tumors from TCGA that high Mxd4 expression is associated with favorable survival in 11 cancers and with reduced survival in three (Fig. 2). Mxd4 expression and its relation to long-term survival also do not appear to correlate consistently with the expression of any other members of the Extended Myc Network. 


\section{Mnt}

The same successful yeast two-hybrid screen that identified Mxd3 and Mxd4 as high-affinity Max partners, also isolated Mnt [26], which was soon thereafter identified independently [281]. While also being a bHLH-ZIP protein, Mnt has slightly different sequence-specific DNA binding preferences compared to Myc and Mxd1-4 [26,281]. Like them however, it contains an $\mathrm{mSin} 3 \mathrm{~A} / \mathrm{B}$-interacting SID domain that is necessary for the HDAC-mediated transcriptional repression of E-box-containing target genes and the inhibition MYC+RAS-mediated transformation. Subsequent work demonstrated that Mnt also forms similarly repressive complexes with Mlx [19,20,282]. Embryonic Mnt expression is broader than that of Mxd1-4 and shows tissue patterns that overlap those of Myc members, particularly in regions actively engaged in proliferation. Yet, it is also expressed in more differentiated and replicatively quiescent tissue regions that do not express other Myc Network members [26].

Like Mxd1 and Mxd4, Mnt also heterodimerizes with both Mlx and Max, thereby binding to and regulating its target genes in an E-Box-dependent manner. Homodimeric Mnt also binds E-boxes, albeit relatively weakly [26,283]. It is not entirely clear how transcription is fine-tuned by each of these three different dimeric forms of Mnt. It could be a consequence of non-mutually exclusive differences in DNA binding affinities, stoichiometric variation of mSin3A/B recruitment and the degree of deacetylation of the local chromatin environment. Mnt homodimers might be more potent transcriptional repressors by virtue of being able to recruit two mSin3 molecules versus only one each for MaxMnt and Mlx-Mnt. For target genes whose regulation relies upon more than one E-box or on ChoREs, differential transcriptional effects might depend on the identities of the dimers bound at these sites, the proximity of these sites to one another and the factors they recruit. Any or all of these activities could be further refined by Mnt phosphorylation, which is more pronounced during quiescence and is needed for the formation of mSin 3 complexes and the transcriptional repression of cell cycle entry-critical genes such as cyclin D2 [284].

Mnt participates in a negative feedback loop with its own promoter, which contains two evolutionarily conserved but non-identical E-boxes residing within $800 \mathrm{bp}$ of the transcriptional start site $[185,283]$. Both sites bind Max but only the more 5' and less canonical E-box does so in association with Mnt. However, Max is not necessary for Mnt-mediated repression as it still occurs in Max-negative cells, albeit more weakly [283]. A genome-wide ChIP-seq analysis in Maxnegative cells has shown that Mnt binds a large number of additional genes and generally down-regulates their expression. These findings are in keeping with the observations mentioned above that Mnt dimers can be of several types. It remains unclear, however, how much Mnt-mediate transcriptional repression, both of itself and other targets in Max-negative cells, is mediated by Mnt homodimers versus Mnt-Mlx heterodimers given that both interactions were documented. Interestingly, rather than suppressing proliferation like Mxd1-4, or as it does in fibroblasts [26], Mnt was shown to support proliferation in certain Max-negative cells even when Max expression was restored $[185,283]$. Max contributed to Mnt's role as a regulator of gene expression since RNAseq of Mnt over-expressing Maxnegative versus Max-replete isologous cells showed nearly twice as many gene expression changes in the latter. This difference in gene target numbers may have been due in part to the fact that Mnt localizes exclusively to the nucleus in cells that express Max whereas, in Max-negative cells, about half of Mnt is cytoplasmic.

Several observations have supported the idea that Mnt functions as a TS under some circumstances. First, in contrast to Mnt's function in Max-negative pheochromocytoma cells mentioned above [283] Mnt-/- MEFs, grow more rapidly than their WT counterparts, are less contacted inhibited, prematurely enter S-phase, show delayed onset of senescence with continued passage, are more efficiently transformed by MYC+RAS and can be transformed by RAS alone $[26,285]$. These phenotypes are reminiscent of those seen in response to varying levels of Myc over-expression [286-288] and suggested that Mnt loss, like that of other Mxds, might rebalance the Myc Network in ways that favor Myc-driven and transformation-prone phenotypes. Indeed, Mnt-/- MEFs over-express and/or deregulate several Myc 
target genes associated with cell cycle progression including cyclin E and cdk4 and possess more robust cyclinE-cdk2 activity [26].

Despite their transformation-prone tendencies, low passage Mnt-/- MEFs actually express less Myc than their WT counterparts even though Myc induction in response to mitogenic stimuli remains strong [26]. One possible reason for this is that there is less competition for E-box binding by Myc-Max heterodimers, leading to a more efficient induction of Myc target genes and thus a readjustment of otherwise unnecessarily high Myc levels. Nevertheless the abnormalities in Mnt-/- MEFs still indicate that, regardless of this presumed Myc re-balancing, the precision of its signaling remains reliant on the more nuanced regulation that can only be achieved by actual competition between Mnt-Max and Myc-Max heterodimers as well as by the regulation of genes that are Mnt targets but not Myc targets.

Conditional T-cell-specific knockout of Mnt prior to the divergence of CD4+ and CD8+ populations is oncogenic while concurrently leading to marked immune dysregulation [289]. Juvenile Mnt-/- mice were found to have smaller thymuses with atrophy of the thymic medulla that is normally enriched for T cells. They also showed a differentiation block at the point of transition between the CD25+ CD44- and CD25- CD44- states (i.e. DN stages III and IV), had peripheral lymphopenia and reduced populations of CD4+CD8+, CD4+ and CD8+ thymocytes associated with higher levels of apoptosis. In keeping with the general theme described for Mnt-/- MEFs [26], Mnt-/- thymocytes up-regulated cell cycle-related Myc target genes, including those encoding cdk4, cyclin D2 and cyclin B1 $[179,289]$. These mice also developed hepatosplenomegaly and lymphadenopahthy at an early age. Initially, this was associated with the uncontrolled infiltration of non-transformed B-cells and macrophages driven by the secretion of cytokines such as IFN$\gamma$, TNF- $\alpha$ and IL-2 elaborated by Mnt-/- Th1 cells. By 12-22 months of age, however, most of these mice succumbed to T-cell lymphomas, although their onset was slower relative to the lymphomas seen in Myc transgenic animals that arose as early as 2 months of age [290]. This indicated that Mnt loss and Myc over-expression were not interchangeable, probably because the levels of Myc in the transgenic setting were much higher. As a result, they bound and regulated different sets of target genes, particularly those with low-affinity E-boxes in the case of Myc transgenics. The aggressive immune dysregulation and expansion of B-cells and macrophages seen in $\mathrm{Mnt}-/-\mathrm{T}$ cells have also not been previously reported in association with Myc-driven lymphomas.

A different role for Mnt was seen when it was conditionally inactivated in T-cells that also constitutively overexpressed a stabilized and particularly oncogenic form of Myc $\left(\mathrm{Myc}^{\top 58 A}\right)$ [291]. These Mnt-/- mice showed a 1.6-fold longer mean survival than was seen in $\mathrm{Myc}^{\top 58 \mathrm{~A}} \mathrm{Mnt+} /+$ mice. Thus, rather than serving as a TS, Mnt functioned as a pro-oncogenic tumor facilitator in cooperation with Myc. Mnt-/- T-cells were also more susceptible to apoptosis. This suggested that cells with Myc deregulation walk a fine line between transformation and apoptosis with the highest levels of Myc expression favoring the latter fate. By blocking apoptosis, Mnt could cooperate with Myc to allow more cells to be directed down the transformation pathway.

Some support for these notions come from studies in mice that develop distinct types of hematopoietic malignancies due to the over-expression of different levels of Myc driven by the vav-promoter [292]. Those with two copies of the vav-Myc transgene ("Mychi") developed pure T-cell lymphomas whereas those with only a single copy of the transgene ("Myclo") developed a mix of lymphoid and myeloid neoplasms [292,293]. Hypothesizing that Mnt would function as a TS, it was predicted that Mnt+/- Myclo mice would have enhanced Myc function, generate a higher proportion of the lymphoid neoplasms otherwise associated with Mychi mice and would succumb earlier [292]. Instead, virtually all tumors generated in Mnt+/- Myclo mice were myeloid and associated with longer rather than shorter survival. Similar studies performed in Mnt+/- Mychi mice also showed a higher than expected fraction of myeloid neoplasms and extended survival. Thus, under these conditions, Mnt facilitated Myc-driven tumorigenesis. An extension of these studies to $\mathrm{E} \mu-\mathrm{Myc}$ transgenic mice revealed that Mnt haploinsufficiency was not associated with any change in B-cell lymphoma phenotypes but did extend survival by 1.7-fold. Additionally, no differences were observed in the apoptotic susceptibility of the pre-leukemic B-cell populations of $\mathrm{E} \mu-M y c / M n t+/+$ and $\mathrm{E} \mu-M y c / M n t+/-$ 
mice to IL7 deprivation nor did tumors show any differences in the fractions of cells undergoing S-phase transition, apoptosis or senescence. Finally Mnt heterogeneity prolonged rather than reduced survival due to spontaneous tumorigenesis in $T p 53+/-$ mice.

In contrast to the above observations in hematopoietic tissues, female mice bearing a mammary epithelium-specific knockout of Mnt were prone to the development of breast adenocarcinoma [29,294]. Moreover, and unlike the more delayed appearance of lymphomas that arise in Mnt-/- mice described above [292], the breast cancers developing in Mnt-/- and Myc over-expressing mice showed similar latency periods [29,294,295]. Like Mnt-/- MEFs, Mnt-/- breast epithelium expressed higher levels of cyclin E and cdk4 that increased further following transformation. Together, these findings implicated shared biochemical features of Mnt-/- cells that correlate with deregulated growth and transformation. This is further in keeping with the idea that, because Myc-Max and Mnt-Max complexes seem to comprise the most common heterodimeric species in most cells, loss of Mnt might wield a disproportionate impact on growth.

MNT's function as a TSG in humans may be quite common given the frequency of MNT LOH in human cancers although the impact on survival is variable (Figs 2 and 3). For example, a significant fraction of breast cancers harbor MNT gene deletion within the chromosome 17p13.3 locus that do not include the nearby TP53 gene located on $17 p 13.1[296,297]$. Where it has been examined, most such MNT deletions are not associated with mutation of the retained allele, which again raises questions about alternate means of $M N T$ gene inactivation or the role of MNT haplo-insufficiency such as that discussed above in mouse models [292,298]. One means by which the former could be achieved is via the up-regulation of miR-210, which occurs under hypoxic conditions and is over-expressed in numerous cancers, particularly those associated with metastases or unfavorable survival [299]. Mnt mRNA contains multiple miR-210 binding sites in its 3'-untranslated region and knockdown of the transcript phenocopies miR-210 over-expression [299]. Such alternative means of inactivating other Mxd members, including epigenetic ones, have not been systemically investigated in human cancers.

Sezary syndrome is a rare but aggressive cutaneous T-cell lymphoma of CD4+ memory cells that is molecularly heterogeneous [300-304]. In a study of 20 patient that employed high-resolution comparative genomic hybridization, MYC copy number gains were detected in 75\% of leukemic cell samples, MXD2 loss in 60\% and MNT loss in 55\% [304]. These commonly occurred together, with MYC amplification and MXD2 loss being seen in seven samples, MYC amplification and MNT loss being seen in nine samples and MYC amplification and loss of both MXD2 and MNT loss being documented in six samples. Interestingly, the solitary loss of MXD2 or MNT was found only once. A subsequent European and multi-institutional study of Sezary syndrome samples utilized a targeted, quantitative PCR-based approach that examined gains and losses in a prescribed set of genes [305]. The study found a $40 \%$ incidence of MYC gain and a $66 \%$ incidence of MNT LOH in 58 samples. Although Mnt expression was not quantified, none of the 58 samples showed evidence of Myc over-expression, regardless of gene copy number. Taken together, these findings further contribute to the idea that the rebalancing of the Myc Network can involve contributions from more than one member (Fig. 2).

A high-resolution single nucleotide polymorphism array analyses of more than 350 previously untreated chronic lymphocytic leukemias (CLLs) identified a mean of 1.8 CNVs per sample, with deletions being nearly four times more frequent [306]. 8\% of cases involved focal MNT LOH at 17.13.3 although the vast majority of losses were considerably larger, encompassing as much as the entire chromosomal arm. An additional $4 \%$ of cases showed LOH of the MGA gene locus on 15q15.1. Finally, 5\% of cases showed MYC amplification although, reportedly, none showed actual evidence of Myc over-expression despite this often being associated with shorter survivals in a variety of B-cell neoplasms, including CLL (Fig. 3) [64,307-310]. This study again hinted at the possibility that MNT and MGA haploinsufficiency might be sufficient to contribute to and alter clinical courses in their role as actual TSGs. 
Recent evidence has pointed to a role for Mnt, and perhaps other members of the Extended Myc Network, in the TGF$\beta$-induced epithelial-to-mesenchymal transition (EMT) of normal murine and human breast epithelium. Mnt was highly induced during this process and its knockdown increased cellular proliferation and blocked EMT [311]. Mnt was also expressed at higher levels in human triple negative breast cancer (TNBC) cell lines, which typically show more marked EMT and a predisposition to invasive and metastatic behaviors [312-314]. The above study also used the expression of a group of established EMT markers to classify breast cancers from TCGA into those with "EMT high" or "EMT low" features [311]. As had been seen previously in TNBC cell lines, EMT high tumors also expressed the highest levels of Mnt whereas the reverse was true for EMT low tumors. Although no evidence was presented to show whether Mnt expression correlated with survival, our analyses of the same TCGA data set indicates that it does not (Fig. 3) [311]. Collectively, these studies suggest that the higher expression of Mnt associated with EMT in breast cancer actually serves to temper proliferation and thus serves more as a TS. Moreover, the simple model that MNT amplification might be pro-oncogenic is belied by the finding that gene copy number loss rather than gain is much more frequent in breast and many other cancers (Fig. 2).

A recent comparison of RNAseq results from control and Mnt-knockdown normal mammary cells undergoing TGF- $\beta$ induced EMT showed that Mnt negatively regulated 1180 genes and positively regulated 678 genes [311]. The former set was enriched for transcripts encoding epithelial markers whereas the latter was enriched for transcripts encoding mesenchymal markers. ChIP seq confirmed the interaction of Mnt with numerous genes that were negatively regulated by Mnt and co-IP experiments showed that Mnt interacted with mSin3A and HDAC1, while promoting the deacetylation of histone H3K27.

The above experimental studies suggest that Mnt's dual roles as either a TS or tumor facilitator are fluid and dependent-in at least some cases-upon the degree of Myc over-expression, the tissue-specific target gene repertoire and the sensitivity of the target tissue to genes that promote apoptosis and transformation. On the one hand, Mnt may impede oncogenic growth by competing for and suppressing critical Myc target genes. Alternatively, as Myc levels rise and pro-apoptotic genes are summoned, Mnt may facilitate tumorigenesis by blocking apoptotic pathways or altering the balance of competing factors leading to EMT [29,105,285-287,291,311,315,316]. The ensuing higher levels of Myc expression may have secondary consequences beyond its direct ones on gene expression, including the induction of ROS and chromosomal instability that can further contribute to tumor pathogenesis and/or evolution as well as tumor cell apoptosis or senescence $[252,253,317]$. In some circumstances, Mnt's suppression of apoptosis may facilitate Myc-mediated tumorigenesis as happens in collaboration with the over-expression of $\mathrm{Bcl}-\mathrm{XL}$ or $\mathrm{Bcl}-2$ or the knockout of TP53 [318].

\section{Mga}

Mga is yet another Max partner that was identified by yeast two-hybrid screening [26-30]. It is an extremely large protein (3065 amino acids) that, in addition to containing a canonical C-terminal bHLH-Zip domain most closely related to that of Myc, also contains an N-terminal 185 residue ' $T$ domain' that is conserved among the evolutionarily related T-Box transcription factors that include Brachyury and the Tbx family members [319]. Between these two regions is a 300 residue 'DUF4801' domain that until recently has been largely uncharacterized [320]. Like the bHLH-ZIP domain, the T domain, which most resembles that of Tbx6, functions in both dimerization and DNA binding [28,321-323]. Thus, Mga's architecture immediately suggested that it might possess unusually versatile DNA binding and transcriptional functions by participating in the regulation of both E-box- and T-Box containing genes.

E-box binding by Mga requires Max and is dependent on its basic domain and probably on Mga's basic domain as well although this has not been tested directly (Fig. 5A) [28]. T-box-mediated activation also requires both Mga and Max but not Max's basic domain (Fig. 5B). This suggests that Max's role in T-box-containing gene activation is to facilitate the recruitment of other T-box-specific transcription-critical factors in a manner analogous to that of Myc [129]. The 
up-regulation of a reporter gene containing both E-boxes and T-Boxes has been shown to be additive when Mga and Max are co-expressed but only if Max's basic domain is present to allow E-box binding (Fig. 5C). Finally, in Max's absence, Mga actually repressed transcription from a T-box-containing reporter (Fig. 5D) [28]. These studies indicate that Mga's function is complex. Firstly, it may behave like Myc with regard to its interaction with Max and its transactivation potential. Secondly, as the only member of the Brachyury/Tbx family with a bHLH-ZIP domain, Mga can bind to and regulate two distinct classes of genes [324]. Finally, whether Mga serves as a transcriptional activator or repressor appears to depend strongly on Max levels.

Despite its Myc-like function as a transcriptional activator, Mga profoundly suppressed $M Y C+R A S$-mediated fibroblast transformation [28]. This required an intact bHLH-ZIP domain and could be reversed by sufficient amounts of Max. This suggested that Mga functionally blocks Myc by competing for Max as well as for E-box and/or ChoRE occupancy. In keeping with the fact that no other member of the Brachyury/Tbx family contains bHLH-ZIP domains [324], Brachyury exerted no influence on MYC+RAS-mediated transformation [28].

Tbx proteins are intimately involved in multiple stages of embryonic differentiation and, like the Myc Network, regulate their target genes in distinct but overlapping stage- and tissue-specific ways [323]. The murine embryonal expression pattern of Mga closely mimics that of Brachyury and Tbx's 2-5 thereby suggesting that it might cooperate with these proteins in the control of mesoderm induction, while being particularly well-positioned to integrate and coordinate these processes with the Myc Network [28]. Investigations of Mga's role during murine embryogenesis have shown Mga to be required for survival of the epiblast of the pre-implantation embryo. Mga hypomorphs survive longer but still died early in gestation with reduced development of pluripotent cells in embryonic regions [325,326].

CNVs of the MGA locus (15q15.1) occur in many human cancers, with virtually all cases involving single copy loss (Fig. 2). For example, the previously cited SNP array survey of CLL samples found a $4 \%$ incidence of $15 q .15 .1$ heterozygous deletion with only a single sample showing inactivation of the retained allele [306]. Moreover, as seen recurrently for other members of the Extended Myc Network, the correlation between Mga expression and survival, when it does occur, is highly tumor-specific and may correlate with either favorable or unfavorable survival (Fig. 3).

Another study of CLL that addressed the potential role of MGA hemizygosity involved 55 previously treated individuals with high-risk disease and 33 with Richter's syndrome (a particularly aggressive form of CLL associated with rapid conversion into DLBCL [327]. Somatically-acquired inactivating MGA mutations were identified in $5.4 \%$ of cases and copy number loss was identified in an additional $4 \%$, with none of these being correlated with survival. A larger study in $288 \mathrm{CLL}$ patient, $65 \%$ of whom had developed relapsed or refractory disease, found a $4 \%$ incidence of somaticallyacquired MGA mutations, with a small but significant tendency among this group to have a worse overall response to treatment [328].

In two studies involving 105 and 71 patients with untreated, EBV-associated NK-cell lymphoma, an aggressive neoplasm involving CD56+ cytoCD3+ lymphocytes, MGA mutations were identified at frequencies of $8.8 \%$ and $4 \%$, respectively $[143,329,330]$. However, neither study determined the consequences of these mutations or whether they correlated with survival.

In addition to the above and other reports in CLL, MGA inactivation, mostly involving terminating mutations or gene deletion (and nearly always hemizygous), have been described in as many as $10-20 \%$ of a variety of cancers including retinoblastomas, sporadic colo-rectal cancers, gastroenteropancreatic neuroendocrine tumors, gastrointestinal stromal cell tumors, lung squamous cell and adenocarcinomas, head and neck cancers and acute myelogenous leukemias (AML) [93,104,327,331-342]. Silencing Mga in an AML cell line increased both its in vitro colony formation and its growth rate [340]. Supporting the idea that Mga-Max heterodimers may compete with Myc-Max heterodimers for E-box occupancy [28], knockdown of Mga increased the expression of a Myc reporter vector [340]. This work also 
confirmed that AML blasts expressing higher levels of Mga are associated with favorable survival (Fig. 3) [340]. A reasonable expectation of this result is that patients with AML whose leukemic blasts express lower levels of Myc would also have more favorable survival but this was not observed using data from TCGA (Fig. 3). In contrast, a more recent study of 265 previously untreated AML patients did show a near doubling of survival for those whose blasts expressed the lowest levels of Myc [343]. These differences may have been attributable to different patient populations and/or to the fact that the latter group measured actual Myc protein levels rather than transcript levels, which as discussed above, do not always correlate. Features of the 'low Myc' cohort that were proposed as contributing to longer survival included lower numbers of both peripheral and bone marrow blasts and lower percentages of Flt3-internal tandem duplications [343,344].

An interesting racial disparity has been observed in a large comparative study of recurrent mutations associated with DLBCL in African versus Caucasian individuals. This revealed deleterious MGA mutations at a 3.7 times higher incidence in the former cohort $(19.7 \%$ vs. $5.33 \%, \mathrm{P}<0.001)$ [345]. $M g a$ also registered as one of the top hits in a genome-wide CRISPR screen for TSGs in DLBCL [346].

Despite Mgs's function as a dual-specificity transcriptional activator [28], the above studies clearly imply that it functions in vivo and in numerous clinical settings as a TS, albeit with tumor-specific differences on survival (Figs. 2 and 3). This has been investigated in studies that attempted to ascertain the mechanism underlying this behavior. To this end, the composition of endogenous Mga protein complexes from human HEK293T and lung adenocarcinoma cells have recently been analyzed by immuno-precipitation and mass spectrometry. In addition to Mga itself and Max, over 80 additional associated proteins were identified [335]. Many of these play roles in transcriptional repression including the dimeric pair of E2F6 and TFDP1; components of the Polycomb Repressive Complex 1 (PRC1) complex such as RNF2, RING, L3MBTL2 and PCGF6; the histone deacetylases HDAC1 and HDAC2; and the heterochromatin-associated chromobox protein CBX3, which recognizes the H3K27me3 epigenetic markers left by PRC2 [347-351]. ChIP-seq studies performed in lung adenocarcinoma cells and surveys of the ENCODE data base also showed the binding sites for Mga to be enriched for Max and virtually identical to Myc binding sites. Other Mga binding sites were enriched for E2F6. An interesting finding was that ChIP with anti-Mga antibodies was not reported to have identified binding to T-box elements, thus indicating that transcriptional regulation by Mga, at least in the cell lines examined, was primarily centered around Myc targets. These results indicated that, in several normal and neoplastic cell types, DNA-binding complexes comprised of Mga, Max and E2F6 interact with members of the PRC1 complex, compete with Myc-Max complexes for binding to Myc-activated targets and represses their expression.

The above study also examined the gene expression profiles of Mga over-expressing A549 lung adenocarcinoma cells and identified 625 repressed genes and 658 activated genes [335]. Gene set enrichment analysis of the former indicated that they tended to contain direct Myc whereas Mga-activated genes tended to be comprised of a distinct group that was five-fold less likely to contain Myc targets. Nevertheless, both gene groups tended to be associated with the same types of Myc-like cellular activities such as cell cycle control and glycolysis. Finally, Mga over-expression and siRNA-mediated Myc knockdown had indistinguishable effects with regard to their ability to inhibit cell proliferation, thus further attesting to the idea that the TS-like consequences of Mga over-expression are equivalent to those obtained following Myc depletion [335]. The fact that Mga-Max binding to direct Myc targets could be more readily identified in A549 cells when Mga was over-expressed suggested that these targets contained low-affinity MgaMax sites although this was not tested directly.

A more recent study of Mga function in cancer that expanded upon the above results indicated that CRISPR-mediated Mga inactivation accelerated tumor growth and shortened survival in both the KrasLSL-G12D and KrasLSL-G12D+Tp53/- models of lung cancer [335,337]. While this indicated that Mga loss facilitated the growth of tumors in highly susceptible hosts, it was not determined whether Mga inactivation in otherwise normal mice impacted spontaneous tumor growth as happens with more traditional TSs such as TP53 or Mlx [63,352-354]. 
Whole transcriptomic comparison of KrasLSL-G12D tumors with intact or inactivated Mga indicated that the latter upregulated many genes previously identified as Mga-PRC1.6-repressed targets in ES and germline cells [355] cells, including numerous Myc target genes. Mga-inactivated tumors also down-regulated genes involved in the anti-tumor response such as those encoding NK cell markers and interferon signaling pathway components. Similar analyses performed on cell lines established from KrasLSL-G12D+Tp53-/- tumors supported the previous findings with regard to Myc target genes and Mga-PRC1.6-repressed genes while also showing a substantial up-regulation of genes related to TGF- $\beta$ signaling and EMT. These latter findings implicated Mga in repressing invasion and maintaining epithelial identity while also demonstrating that the identities of Mga-regulated genes can be altered by the tumor's TP53 status.

Mga-interacting proteins identified by mass spectrometry of immuno-precipitates from 293FT cells included some of those previously described [335], including the ncPRC1.6 complex-associated proteins L3MBTL2 and RING2 as well as HDACS1 and 2 and components of the chromatin-modifying MLL-WRDA complex such as WDR5, RBBP5, ASH2L, and DPY30. Cells lacking Mga also expressed lower levels of Max, E2F6 and L3MBTL2, which have been previously identified as being stabilized by the ncPRC1.6 complex $[348,349,356]$. The functionally uncharacterized DUF4801 domain of Mga was also shown to serve as a scaffold for the ncPRC1.6 complex as well as to suppress tumor cell growth.

A recently performed ChIPseq survey identify the genomic sites occupied for Myc, Max, Mga, L3MBTL2, E2F6 and phosphorylated RNA pol II in Mga-replete and Mga-knockout KrasLSL-G12D+Tp53-/- tumor cells [337]. Components of the Mga-PRC1.6 complex (i.e. Mga, Max, L3MBTL2 and E2F6) bound several thousand promoters in Mga-replate cells with the vast majority of Max-, E2F6- and L3MBTL2- binding sites also being bound by Mga. In cells lacking Mga, MycMax binding increased for a subset of binding sites but otherwise remained largely unaltered. This stability of the Myc binding landscape could have been due to sites no longer occupied by Mga now being replaced by Mxd-Max or MntMax rather than Myc-Max, to the newly exposed sites being unfavorable to Myc-Max binding in general and/or to factors that directly blocked Myc binding. Further consistent with the relative lack of influence of Mga depletion on Myc binding was the finding that, rather than increasing, the association of RNA pol II with previous Myc-bound genes actually decreased somewhat. The depletion of Myc from either Mga-replete or Mga-inactivated KrasLSL-G12D+Tp53/- or A549 lung adenocarcinoma cells equally suppressed proliferation whereas the depletion of Mga, L3mbtl2 or Pcgf6 had no impact.

The above findings were extended to normal colonic epithelium and colo-rectal cancer, in which MGA is frequently mutated or deleted (Fig. 2) [337]. In the former case, CRISPR-mediated MGA inactivation in colon organoids was associated with reduced levels of $\mathrm{L} 3 \mathrm{mbt} / 2$ and an increased rate of 3D growth in vitro. In addition to the up-regulation of several EMT-associated genes, and an array of E2F-regulated genes involved in cell cycle regulation and DNA replication, four of the five genes that were up-regulated in response to MGA inactivation in lung cancer (STAG3, PODXL2, NHLRC1, and ZCWPW1) were also up-regulated in MGA-knockout colonic organoids. Also in keeping with the findings in KrasLSL-G12D tumors, down-regulated gene sets included those involved in interferon signaling and inflammation.

The above findings raise several questions regarding the role(s) played by Mga-Max and Myc-Max in regulating Myc targets and Myc-driven functions. For example, to what degree do different tissues and transformation impact the target gene repertoires of these heterodimers? How do the identities of Myc targets recognized by Mga and the extent of their suppression differ from what is achieved by Mxd1-4 or Mnt? How is the regulation of Myc targets with multiple E-boxes impacted by the binding of only a single type of heterodimer versus the binding of other heterodimers? What determines whether Mga-Max heterodimers will activate or repress target genes, despite binding to E-boxes in both? Is it a consequence of subtle differences in the E-box sequences, the presence of other factors bound nearby or at more distant sites or tissue-specific factors that can dictate the identities and 
stoichiometries of the numerous proteins that associate Mga-Max heterodimers? Finally, depending upon the circumstances, the T-box of Mga seems capable of either strongly activating transcription or not activating transcription at all $[28,335]$. Other than the presence of T-boxes, what determines the relative strength and dominance of these effects and how does cross-talk with other Myc Network members bound at nearby sites fine tune them?

\section{ChREBP}

ChREBP was originally identified in rat liver by its ability to bind directly to and up-regulate the liver-type pyruvate kinase gene (Pklr) [36]. This occurred via ChREBP's binding to a ChoRE in the gene's promoter (Fig. 1) and was facilitated by glucose and/or glycolytic intermediates such as glucose-6-phosphate [36,41]. Under these conditions, transcriptional activation relied upon the insulin-independent binding of glucose to cytoplasmically resident ChREBP which was then dephosphorylated by protein phosphatase $2 \mathrm{~A}$ and translocated to the nucleus where it bound to and activated its target gene repertoire [357]. ChREBP was proposed to be important for optimizing glucose uptake and glycolysis, for converting carbohydrates into fats and for long-term energy storage. A number of other ChREBPresponsive ChoRE-containing genes have been identified such as acetyl CoA carboxylase, fatty acid synthase and other lipogenic genes [60,73,358-361]. Just as Myc's transcriptionally active state involves its heterodimeric association with Max, ChREBP requires a similar association with Mlx [58,60,61]. In contrast to Myc, however, the target gene repertoire for ChREBP-Mlx heterodimers is more restricted, which is likely although probably not entirely related to the more complex nature of the ChoRE (Fig. 1). Rather than the originally proposed consensus sequence (CACGTG) $\mathrm{N}_{5}(\mathrm{CACGTG}$ ), a more ambiguous one (CAYGNGN ${ }_{5}$ CNCRTG) has been proposed more recently [58]. Moreover, ChREBP can also bind to single E-boxes and can do so in a glucose-independent manner [59-61]. The fact that Myc can also bind the double Eboxes of the ChoRE suggests that shared gene targets may allow for transcriptional promiscuity and additional levels of cross-talk among members of the Extended Myc Network[63].

Several studies have identified domains within ChREBP's N-terminal "glucose-sensing module" (GSM) that are responsible for glucose-binding and transactivation. The GSM contains five so-called Mondo Conserved Regions (MCRs) that are required for the protein's binding of and response to glucose [362]. When glucose concentrations are low, MCRs I-IV, and MCR IV in particular, interact with and suppress the MCR V-containing transactivation domain (also known as the GRACE domain). Glucose relieves this inhibition in a manner that appears to be more reliant on MCRs 13. The glucose responsiveness of ChREBP however also requires the interaction between MCR3 and members of the 14-3-3 protein family that include its $\beta, \gamma, \zeta$ and $\theta$ isoforms $[363,364]$. 14-3-3 proteins are an important class of signaling proteins that bind many important proteins such as TP53, various phosphatases and Raf and MAP kinases with roles in critical functions such as growth, proliferation and survival [365,366]. 14-3-3 proteins appear to be involved in reversing or preventing the suppression of MCR IV on the GRACE domain. However, the interaction between MCR IV and 14-3-3 requires neither glucose nor the recognition of phosphoryated Ser and Thr substrates to which 14-3-3 proteins typically bind in other targets. It has been suggested that 14-3-3 plays a permissive role, possibly by allowing ChREBP to assume the conformation needed to relive its transcriptional repression of the GRACE domain in response to glucose [362]. This raises the possibility that concurrent 14-3-3 recognition of phospho-Ser/Thr sites on active signaling pathway intermediates might coordinate the glycolytic and fatty acid synthetic responses mediated through ChREBP.

The interdependence of Myc, ChREBP and the Mlx Network in general for both normal and cancer cell proliferation has been demonstrated in studies that employed the previously-discussed mouse model of hereditary tyrosinemia $[63,66,67,367]$. Unlike Myc-/- hepatocytes, Chrebp-/- hepatocytes were defective in repopulating the liver. However, the combined knockout of both $M y c$ and ChreBP was additive and the knockout of both Myc and Mlx, which functionally inactivated both pathways (Fig. 1), was the most defective of all $[63,66,67]$. The importance of these deficits on neoplastic growth was further demonstrated in MycKO, ChrebpKO and MycKOxChrebpKO livers in which HBs were generated by mutant forms of $\beta$-catenin and YAP $[66,67,156,201,235]$. Transcriptional profiling of KO livers 
and tumors from these groups showed that the proliferative defects correlated with the suppression of numerous genes related to protein translation and metabolism. In the first case, these included virtually all of the 80 ribosomal subunit genes, many genes controlling translational initiation, elongation and termination and additional genes whose products are involved in tRNA and rRNA biosynthesis and processing $[63,66,67]$. Genes involved in metabolism included those regulating mitochondrial structure and function along with mitochondrial ribosomal proteins and components of the TCA cycle and electron transport chain. These findings indicated that maximizing normal and neoplastic hepatocyte growth was variably dependent on cross-talk between the Myc and Mlx Networks. Importantly, while neither of these was necessary for tumor initiation, each one was important for maximizing the expression of the above gene sets in order to achieve the levels of expression commensurate with proliferative demands. This likely reflected the fact that protein translation and proliferation are among the most energy-dependent processes of normal and neoplastic cells and must be coordinated accordingly $[80,368]$. A similar role for ChREBP has been described in pancreatic $\beta$-cells where ChREBP is required for their proliferative expansion in response to insulin signaling [369].

While there is little published information as to whether ChREBP expression impacts the behavior of human cancers as it does in the case of murine HBs [67], our survey points to clear associations in at least 18 different tumor types (Figs. 2 and 3). For example, elevated ChREBP expression is associated with favorable survival in epithelial tumors as diverse as bladder, liver and pancreatic cancer whereas the reverse is true for low-grade gliomas, AML and clear cell renal cancer. One interesting finding, although of currently unknown significance, is that DLBCL is the only cancer for which the expression of only one member of the Extended Myc Network is predictive of survival. These findings again emphasize that, as is true for the Myc Network, different cancers show distinct patterns of Mlx Network member expression and survival correlations that likely reflect their differential co-dependencies.

\section{MondoA}

Originally identified by yeast two-hybrid screening as a bHLH-ZIP binding partner for Mlx, MondoA was quickly determined to be a paralog of ChREBP, albeit with a wider tissue distribution pattern including particularly high expression in skeletal muscle, where it is required for normal development $[33,34,77,78,370]$. Like ChREBP, MondoA is regulated by glucose and G6P in a manner that utilizes a similar $\mathrm{N}$-terminal GSM module that is also dependent upon 14-3-3 protein interactions [41,371]. MondoA associates with the outer mitochondrial membrane, suggesting that it is well-positioned to respond to both glycolytic and TCA cycle substrates and their fluxes [47-49]. Its rapid nuclear translocation in response to glucose or G6P requires prior heterodimerization with Mlx followed by glucosedependent target gene promoter binding of the heterodimers and their recruitment of a histone $\mathrm{H} 3$ acetyltransferase that restructures chromatin in preparation for gene activation $[44,48,49]$. MondoA-Mlx binding then directly induces the transcription of at least three glycolytic genes, namely, those for hexokinase II, 6-phosphofructo-2kinase/fructose-2,6-bisphosphatase and lactate dehydrogenase A, although in a manner that recognizes consensus Eboxes rather than ChoREs [47]. Given that the PKLR gene is also a target for ChREBP and Myc, and likely for MondoA as well $[55,63,64,104,299,310,342]$, these findings suggest that significant control over glycolysis is supervised by both arms of the Extended Myc Network in ways that match proliferation with appropriate levels of glucose oxidation, ATP production, mitochondrial function and anabolic substrate supply.

In addition to the above glycolytic targets, two paralogous genes, namely thioredoxin-interacting protein (TXNIP) and arrestin domain-containing protein 4 (ARRDC4) are among the most highly MondoA-responsive in HA1E renal epithelial cells [48,49]. TXNIP induction is direct and due to the binding of MondoA-Mlx heterodimers to two consensus ChoREs in the gene's promoter [48,49,372]. As a thiol-oxidoreductase, TXNIP protein regulates redox balance, primarily by reducing oxidized cysteine and cleaving disulfide bonds [373]. However, it also counters the pro-glycolytic effects of MondoA-Mlx by down-regulating glucose uptake in skeletal muscle and other cell types [48]. Thus, the induction of glycolytic genes by MondoA in response to intracellular glucose and G6P is balanced by MondoA's indirect inhibition of 
glucose uptake mediated by TXNIP and presumably ARRDC4 as well. A potential connection between TXNIP's role as glycolytic regulator and that of an oxido-reductase has been demonstrated by studies showing TXNIP to be inducible by adenosine-containing molecules, including adenosine itself, ATP and NADH in ways that cooperate with glucose [40,54]. A more extensive role for TXNIP (and indirectly for MondoA and ChREBP) as a TS in several cancer types has recently emerged although it appears to involve more than simply its negative regulation of glucose uptake [55,374]. For example, TXNIP stabilizes the cyclin-dependent kinase inhibitor p27 $7^{\text {KIP1 }}$ [375]. While a similar TS role for ARRDC4 is lacking, recent work indicates that its paralogs ARRDC1 and ARRDC3 may fulfill a similar function $[211,212,376,377]$.

In our TCGA survey, MondoA expression correlated with extended survival in three different cancer types and with shortened survival in nine (Fig. 3). However, there was little consistency with regard to gene CNV across a broad range of tumors (Fig. 2). In contrast, ChREBP expression correlated with favorable survival in nine cancer types and with unfavorable survival in an additional nine, with copy number gains rather than losses tending to be considerably more common. These findings further underscore the notion that MondoA and ChREBP, while perhaps being redundant, are not interachangeable. Rather they perform distinct functions at specific times during development and in tissuespecific ways that are likely influenced by various glycolytic and other metabolites, the level and the source of ATP (glycolysis versus oxidative phosphorylation [Oxphos]) and the redox environment $[20,21,43]$.

In a small, microarray-based study of 25 primary pediatric acute pre-B cell leukemias (ALL), extremely high levels of MondoA expression were found in leukemic blasts relative to fetal pre-B cells and numerous normal tissues, including peripheral blood and bone marrow $\left(P=1.6 \times 10^{-21}\right)$ [85]. Also noted was a strong correlation between MondoA and $\mathrm{Mlx}$ expression. MondoA over-expression was highly specific for pre-B ALL and was not observed in more than 200 cases of AML. Profiling of Nalm6 ALL cells line after stable genetic knockdown of MondoA showed the dysregulation of nearly 200 genes with selective roles in metabolism, differentiation and survival. A number of the down-regulated genes corresponded to those previously identified in primary ALL blasts as being associated with better therapeutic outcomes and survival [378]. Even more strikingly, cells with a genetic knockdown of MondoA demonstrated reduced clonogenicity; lower glucose utilization; a 5- and 19-fold up-regulation of the B-cell differentiation markers CD22 and CD24, respectively and a higher levels of spontaneous apoptosis. These studies supported the idea that MondoA maintains a differentiation block in ALL blasts. Consistent with this finding, a subsequent study showed leukemic blasts with the highest levels of MondoA were associated with shorter survival [84].

In contrast to the foregoing study that ascribed a pro-oncogenic function to MondoA, evidence for TS-like activity was provided by studies which examined glycolytic rates of melanomas bearing oncogenic B-Raf ${ }^{\mathrm{V} 600 \mathrm{E}}$ mutations prior to and following treatment with the B-Raf inhibitors vemurafinib and dabrafenib [379]. This study observed that melanomas have high glycolytic rates, which is consistent with their reported avid uptake of ${ }^{18} \mathrm{~F}$-deoxyglucose [380-382]. Treatment with venurafinib potently suppressed glucose uptake in a manner that correlated with inhibition of the BRaf $\rightarrow$ MEK $\rightarrow$ ERK pathway. Transcriptional profiling revealed that vemurafinib inhibited the induction of the glucose transporter genes GLUT1 (SLC2A1) and GLUT3 (SLC2A3) and hexokinase 2 (HK2), whose encoded enzyme catalyzes the first step of glycolysis. Significant down-regulation of these three genes was observed in multiple primary B-Raf ${ }^{\mathrm{V} 600 \mathrm{E}}$ melanomas from patients treated with B-Raf inhibitors and normalization of their expression in drug-resistant tumors. B-Raf inhibition also induced MONDOA, TXNIP and ARRDC4. These studies indicated that B-Raf ${ }^{V 600 E}$ normally suppresses MONDOA expression, which would be expected to benefit the tumor given that TXNIP inhibits glucose uptake $[48,49,83]$.

The circumstances under which MondoA facilitates or suppresses cell growth may be determined by the fine balance between glycolysis, Oxphos and the rapidity of cell growth, which may be fleeting in nature and spatially and temporally different, even within the same tumor [383]. In turn the glycolytic rate may be modulated by competition between glucose uptake and oxidation, which are regulated in opposite ways by MondoA and ChREBP as discussed above. High glycolytic rates are needed to supply anabolic precursors such as amino acids and ribose sugars while 
generating energy and maintaining the proper redox state to maintain these reactions [384,385]. Oxphos must also be maintained (although typically at a reduced rate) to furnish ATP more efficiently than is possible by glycolysis and to supply other anabolic intermediates. One way to achieve this is via glutaminolysis which anplerotically provides $\alpha$ ketoglutarate $(\alpha-K G)$ [386-388]. This TCA cycle substrate can be used to generate energy and anabolic substrates such as amino acids or for fatty acid synthesis via reverse carboxylation. A mechanism has been identified by which TXNIP is differentially regulated in response to glucose or glutamine [83]. This involves the recruitment of MondoA-Mlx heterodimers to the TXNIP promoter where they associate with one or more histone acetyltransferases, which activate the gene, inhibit glucose uptake and temper the Warburg effect. Both glucose and glutamine alter this interaction such that MondoA-MIx heterodimers interact with histone deacetylases thereby mitigating TXNIP induction and allowing higher levels of glucose uptake. While this model is appealing, it is plausible that other Oxphos intermediates also regulate TXNIP expression as evidenced by the fact that inhibiting Oxphos actually inhibits TXNIP expression rather than induces it [53]. Other factors that activate TXNIP and/or ARRDC4 include lactate and nonglucose hexoses whereas serum stimulation of quiescent diploid fibroblasts inhibits TXNIP [37,48,81,374].

In many tumors, Myc up-regulates not only the Warburg effect but mitochondrial biogenesis, Oxphos and glutaminolysis $[66,67,384,389,390]$. In doing so, Myc dysregulation has been shown to indirectly impact the activity of MondoA and its activation in several distinct ways. First, by strongly stimulating the uptake of glucose and glycolysis, Myc provides the key metabolites needed to promote MondoA's nuclear translocation and transcriptional activation. Second, the additional transcriptional induction of glycolytic genes provided by MondoA reinforces those which are already Myc-responsive such as PLKR [63,64,310]. Third, Myc-mediated promotion of glutaminolysis activates the pathway by which MondoA suppresses TXNIP and ARRDC4, thereby contributing to glycolysis by relieving the block to glucose uptake. Finally, the well-known induction of $L D H A$ by Myc [391] provides the lactate needed to further induce transcription of both TXNIP and ARRC4 genes Together these observations reinforce one of the central themes of this review, namely that any given member of the Extended Myc Network does not function alone but rather is dependent on the well-integrated and cooperative activities of its other members.

\section{Mlx}

Originally identified in yeast two-hybrid screens that used Mxd1 or Mnt as baits, Mlx's bHLH-ZIP domain bears significant structural and functional homology to that of Max [61,281,392], hence the designation Max-like protein $X$ $(\mathrm{Mlx})$. Moreover, the expression pattern of $\mathrm{Mlx}$, both in adult and embryonic tissues, is quite broad and also resembles that of Max [20]. The Mlx protein is stable, forms avid E-box-binding heterodimers in association with Mxd1 and, also like Max, binds DNA as a homodimer albeit with lower affinity than its heterodimeric forms [281,392]. Mlx also heterodimerizes with Mxd4, Mnt, ChREBP and MondoA [20,61,281,392] (Fig. 1).

Mlx's collaboration with ChREBP and MondoA may not be the only means by which it reprograms metabolism and cell behavior, particularly with regard to the maintenance of the undifferentiated state that typifies most cancers [393]. For example, MondoA expression is particularly prominent in skeletal muscle, where high levels of glucose are necessary for myogenesis and where glycolytic demand and activity are high [370,394]. In a study focused primarily on the murine C2C12 myogenic cell line, Mlx over-expression induced the expression of several soluble myokines such as insulin-like growth factor 2 that promote skeletal muscle differentiation $[395,396]$. This induction was direct as indicated by the documentation of Mlx being localized to ChoREs in the proximal promoters of some of these genes and an associated increase in histone $\mathrm{H} 4$ acetylation at nearby sites. Surprisingly, despite Mlx also directly activating Txnip and Arrdc4 in these cells in a glucose-dependent manner, it did not induce any of the usual glycolytic gene repertoire. This indicated that the function of Mlx in skeletal muscle (in collaboration with MondoA) was quite different from its function in liver where its major heterodimeric partner is ChREBP. Interestingly the ChoREs within the Txnip promoter, which were initially occupied by Myc, were displaced by over-expressed Mlx. Given that the ectopic expression of Myc can block myogenic differentiation [397], these findings suggested an attractive model by 
which myogenesis was regulated by the balance between the Myc and Mlx Networks. In agreement with this, C2C12 myoblasts with enforced expression of Mlx underwent fusion-associated differentiation more rapidly than control cells whereas myoblasts with a knockdown of Mlx showed evidence of a differentiation block. It is tempting to consider that the loss of $M l x$ expression whether by mutation, gene deletion or promoter silencing could contribute to the maintenance of the undifferentiated state and thus serve as a TS.

A role for Mlx in overseeing normal hepatocyte proliferation has recently been described in a study that again employed the the Fah-/- mouse model of hereditary tyrosinemia [63,66,67,367]. Donor hepatocytes expressed an albumin gene promoter-driven Cre-estrogen receptor (CreER) fusion protein that allowed for the tamoxifen-deriven excisional inactivation of the 'floxed' endogenous Mlx locus 3-4 months after birth. Anticipating from prior work that these MIxKO hepatocytes would be at a proliferative disadvantage $[66,67]$, they were administered intrasplenically to recipient Fah-/- mice together with WT hepatocytes at a 6:1 ratio. 24-28 wks later, the donor population was assessed in the reconstituted liver and was found to be $>95 \%$ WT. Thus despite their initially large numerical advantage, $M / x-/$ - hepatocytes were nevertheless heavily outcompeted.

The above findings were extended by performing similar competitive repopulation studies using a double knockout (DKO) population of Myc-/- x Mlx-/- hepatocytes that were delivered to Fah-/- recipients together with WT cells at a $\sim 10: 1$ ratio [63]. An end-of-study reassessment showed that WT hepatocytes now comprised $>97 \%$ of the donor population. Suspecting that these cells were even more deficient than the previously studied Mlx-/- hepatocytes, a third round of competitive repopulation was performed with a 1:1 ratio of $M / x-/-$ and DKO hepatocytes. Despite their profound proliferative disadvantage relative to WT cells noted above, Mlx-/- cells still possessed a clear growth advantage over DKO cells, with the former population comprising nearly $95 \%$ of the retrieved donor pool. Taken together, these studies as well as those reported previously and discussed above, indicated that the regenerative potential of normal hepatocytes declines as the Extended Myc Network is progressively dismantled (WT=Myc-/$>$ Chrebp-/- >Myc-/-x Chrebp-/- >Myc-/-x Mlx-/-) [63,66,67].

Gene expression profiling in Mlx-/- and DKO livers documented dysregulation of many of the same pathways previously described as being altered in Myc-/-, Chrebp-/- and Myc-/- x Chrebp-/- livers[63]. Most notably, these included gene sets with roles in ribosomal structure and function, mRNA processing and translational, energy metabolism and mitochondrial structure and function, including transcripts encoding most mitochondrial ribosomal subunits. All these gene sets were down-regulated in their respective knockout livers, with particularly robust suppression being seen in DKO livers. This correlated quite well with the above-described competitive repopulation studies and indicated that the most severe proliferative defects were associated with the greatest degree of suppression of target genes that were involved in the processes (translation and energy production) most needed to sustain growth and proliferation. As previously described in comparing Myc-/- and Chrebp-/- livers [67], significant overlap in gene expression changes was observed, providing support for cross-regulation of one another's transcriptional targets by each arm of the Extended Myc Network. A carefully-performed analysis of ChIPseq results from a HepG2 hepatocellular carcinoma (HCC) cell line indicated that many direct Myc and Mlx target genes bound to common E-Boxes and ChoREs.

Despite the inherent proliferative defects of their hepatocytes, over one-third of $M / x-/-$ and DKO mice developed multiple small liver tumors by 14-16 mos. of age compared to none in similarly-aged WT, Myc-/-, Chrebp-/- and Myc-/$x$ Chrebp-/- mice [63]. Histologically, these tumors were well-differentiated and/or myxoid-type adenomas containing many Ki67-positive cells and rare foci of hepatocellular carcinoma. Their lack of expression of the deleted gene(s) indicated that they did not originate from a minority population of cells that had failed to excise the target and therefore maintained a replicative advantage. Whole transcriptome profiling of these tumors confirmed their lack of expression of Myc and/or Mlx while showing that they were readily distinguishable from normal liver and previously characterized HBs $[66,67,104,342]$. The fact that similar tumors had not been previously observed in Chrebp-/- mice 
strongly suggested that MondoA serves a redundant function in protecting against neoplastic conversion and that the functional inactivation of both Chrebp and MondoA were needed for this feature to be revealed. Because these studies were terminated when mice reached the age of 14-16 mo. and because gene knockouts were confined to hepatocytes, the actual penetrance of the tumor phenotype over the entire lifespan of the animals remains to be determined as does the question of whether $M / x$ is a more general TSG in other tissues and, if so, what types of tumors appear. Nonetheless, these studies showed $M / x$ to be a potent TSG in the context of an otherwise normal genetic background and in the absence of any predisposing factors.

Histologically, the adenomas originating in Mlx-/- and DKO livers closely resemble their human counterparts [398,399]. However, they differed in several respects that included their multi-focality and high-level expression of Ki67 ( 20-30\% of cells), both of which are rare features of human hepatic adenomas [400]. M/x-/- and DKO adenomas also dysregulated 15 transcripts that had been previously shown to be associated with inferior survival in $\mathrm{HBs}$ and over a dozen adult cancers [201]. These characteristics, the occasional tendency of these adenomas to evolve in HCCs and their unique transcriptional profiles [201] suggests that they occupy a transitional state between benign and malignant neoplasms and may take on more of the latters' features as mice age.

It is also important to consider the possibility that the observed hepatic neoplasms were related to the pronounced non-alcoholic fatty liver disease (NAFLD) that is associated with the loss of individual Extended Myc Network members and appears earlier in DKO animals $[63,66,67]$. NAFLD is a known risk factor for the development of both adenomas and HCC [400-402]. However, while potentially contributing to the evolution of adenomas, it seems unlikely that NAFLD per se was directly causative given that adenomas have not been observed in the livers of Myc-/-, Chrebp-/- or Myc-/$x$ Chrebp-/- mice [63] which also developed NAFLD[63].

\section{Conclusions}

This review, along with other studies, has emphasized both the complexity and flexibility of the Extended Myc Network in promoting normal and neoplastic cell growth largely by regulating ribosomal biogenesis and translation, metabolic and energy-generating pathways, cell cycle progression and other key pathways $[25,33,45,50,57,63,66,67,75,77,368,386-390,403]$. Yet the unavoidable conclusion is that most members of this highly interconnected network function more as TSs than as oncoproteins. Indeed, the only ones with indisputable oncogenic functions [404] are MYC and its paralogs while the tumor facilitators CHREBP and MONDOA facilitate growth and proliferation without being directly oncogenic $[63,66,67]$.

Additional layers of complexity among members of the Extended Myc network have recently been identified with machine learning-based dimensionality reduction techniques such as t-SNE or UMAP that simultaneously compared the relationships among all Extended Myc Network member transcripts $[405,406]$. These studies showed most cancers to be comprised of 2-5 distinct clusters of Extended Myc Network transcripts that had prognostic value beyond that afforded by standard whole transcriptome profiling or the examination of single transcripts such as those depicted in Fig. 3. Even favorable and unfavorable prognostic groups, initially identified by whole transcriptome profiling, could be further subdivided based on the clustering patterns of Extended Myc Network transcripts and vice versa thus showing the two methods to be complementary. This approach proved useful in 10 different cancer types, comprising over one-third of cancers in TCGA. Moreover, such clustering was not confined to Extended Myc Network transcripts. Indeed, it had been previously demonstrated with human ribosomal protein transcripts whose patterns also correlated with molecular and pathological features and long-term survival in some cancers[100,407]. Eventually, the approach was applied to a collection of 212 transcripts representing eleven additional cancer-related pathways such as those involved in Wnt and Notch signaling, purine and pyrimidine biosynthesis and the TCA cycle. Clustering was predictive of survival in 30 of the 34 cancers, or $91.4 \%$ of all tumors in TCGA [405]. 
This review has raised a number of questions that will be important to address in future work. Among these are the degree to which direct Myc Network and Mlx Network target genes are co-regulated and the extent to which their binding sites are shared[63]. What are the gene expression consequences when targets are bound by different heterodimeric combinations of factors versus only a single type and to what extent is such differential binding even possible? It is already known that Myc-Max targets overlap Mxd-Max targets but how are these sites selected, what determines site selection and how and why does it change under different circumstances? The simplicity of E-boxes and the degeneracy of ChoREs implies many more potential than actual binding sites. What determines binding in the first place and why do particular E-boxes specifically bind Myc, Mxds or Mlx? How is the binding to these sites altered in different tissues or when a tissue undergoes transformation due, for example to Myc over-expression or the loss of Max or Mlx? What is the role of epigenetic modification in altering binding site affinities [156]? It seems likely that many E-boxes and ChoREs represent 'latent' elements with low binding affinities and little functional relevance until Myc is over-expressed or dysregulated during tumorigenesis. Finally, given the fact that Myc and Mlx binding sites can be shared, is it possible that the ChREBP/MondoA metabolite responsiveness of at least some genes can be "acquired" in a manner that reflects the abundance of these factors, their intrinsic affinity for their binding sites, the competition of Myc Network members for the site and the intracellular concentration of enabling metabolites? The contribution of genes associated with these sites is likely to provide significant insights into the pathogenesis of many tumor types that are initiated and/or maintained by high Myc levels. Finally what is the role in tumor suppression for genes bound exclusively by Mxd members versus those in which these factors can be displaced by Myc, ChREBP and MondoA? Having filled in the basic components and workings of the Extended Myc Network, we are now positioned to begin to address these more subtle questions and thus to reveal fundamental aspects of their oncogenic and TS functions. Exciting times lie ahead! 


\section{Figures}

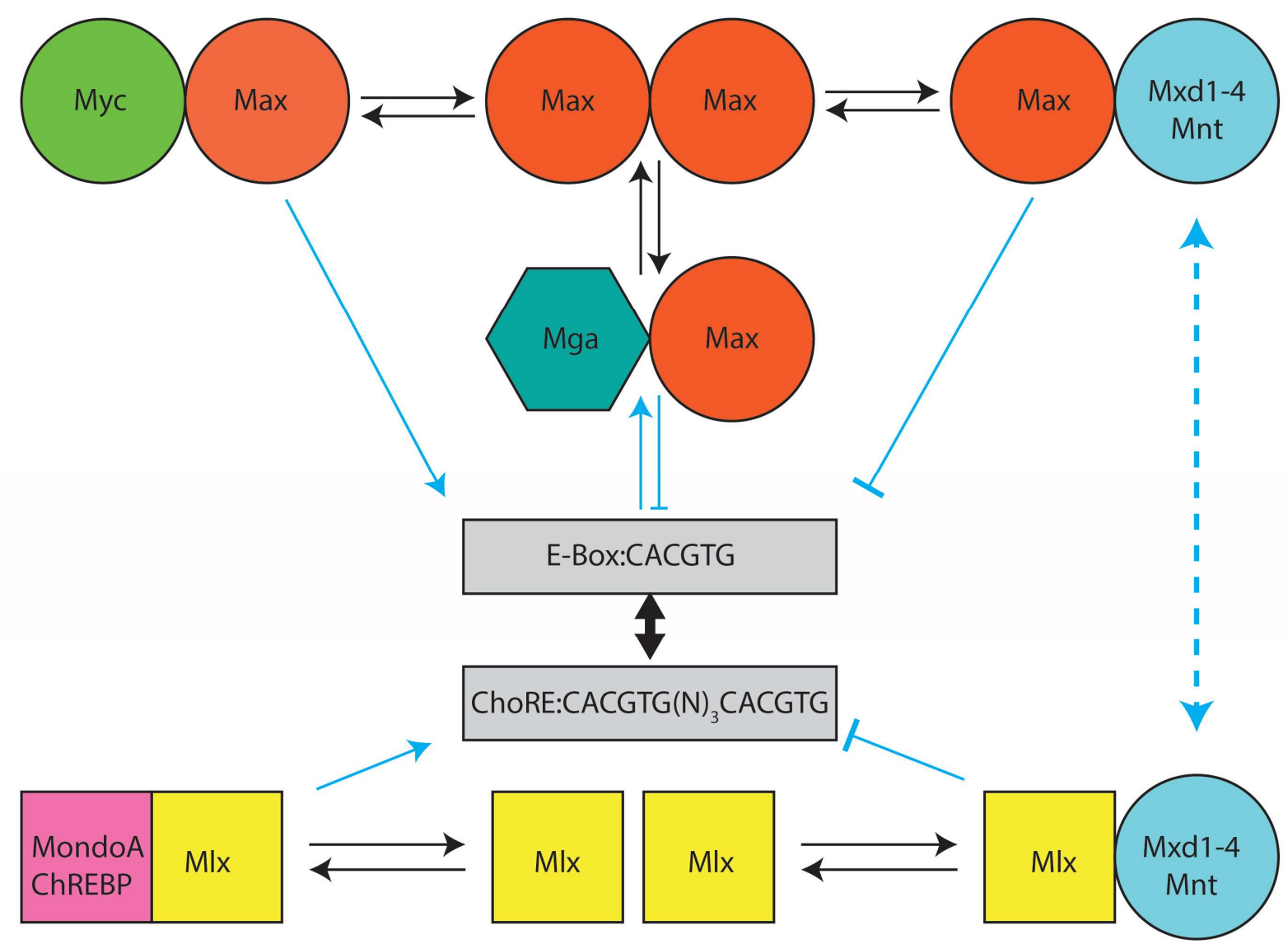

Fig. 1. The Extended Myc Network. Top: The Myc Network. Myc-Max heterodimers bind to cognate E-boxes in target genes. They then recruit chromatin-modifying enzymes such as histone acetyl transferases and transcription co-factors which mediate the histone acetylation and demethylation that permits subsequent increases in RNA polymerase II (Pol II) binding, the relief of Pol II pausing and read-through transcription [17,129,408-410]. DNA binding by Max homodimers is prevented by inhibitory N-terminal phosphorylation $[14,15]$. Max also lacks a TAD that is needed for chromatin re-modeling and transcriptional activation [13,129,372]. Transcriptional repression of Myc-activated genes is mediated by six factors "Mxd proteins" (Mxd1-4, Mnt and Mga) whose expression is tissue-, development-, age- and cell cycle-specific [27,31,284,387,388,411]. These compete with Myc-Max heterodimers for E-boxes, recruit mSin3, histone deacetylases, methyltransferases and complexes that mediate more direct transcriptional repression $[18,335,337]$. Bottom: The Mlx Network. The Myc-like factors MondoA and ChREBP heterodimerize with Mlx (which, unlike Max, can homodimerize, albeit weakly), bind certain metabolites such as glucose, glucose-6-phosphate, lactate and adenosine, and translocate from the cytoplasm to the nucleus where they bind to target genes containing both ChoREs and E-boxes although the size of this repertoire is smaller than that of Myc targets [33,37-39,41,43$45,47,50,65,67]$. The negative regulatory arm of the Mlx Network employs some of the same repressive strategies utilized by the Myc network with some distinct exceptions in the case of Mga (see below). 


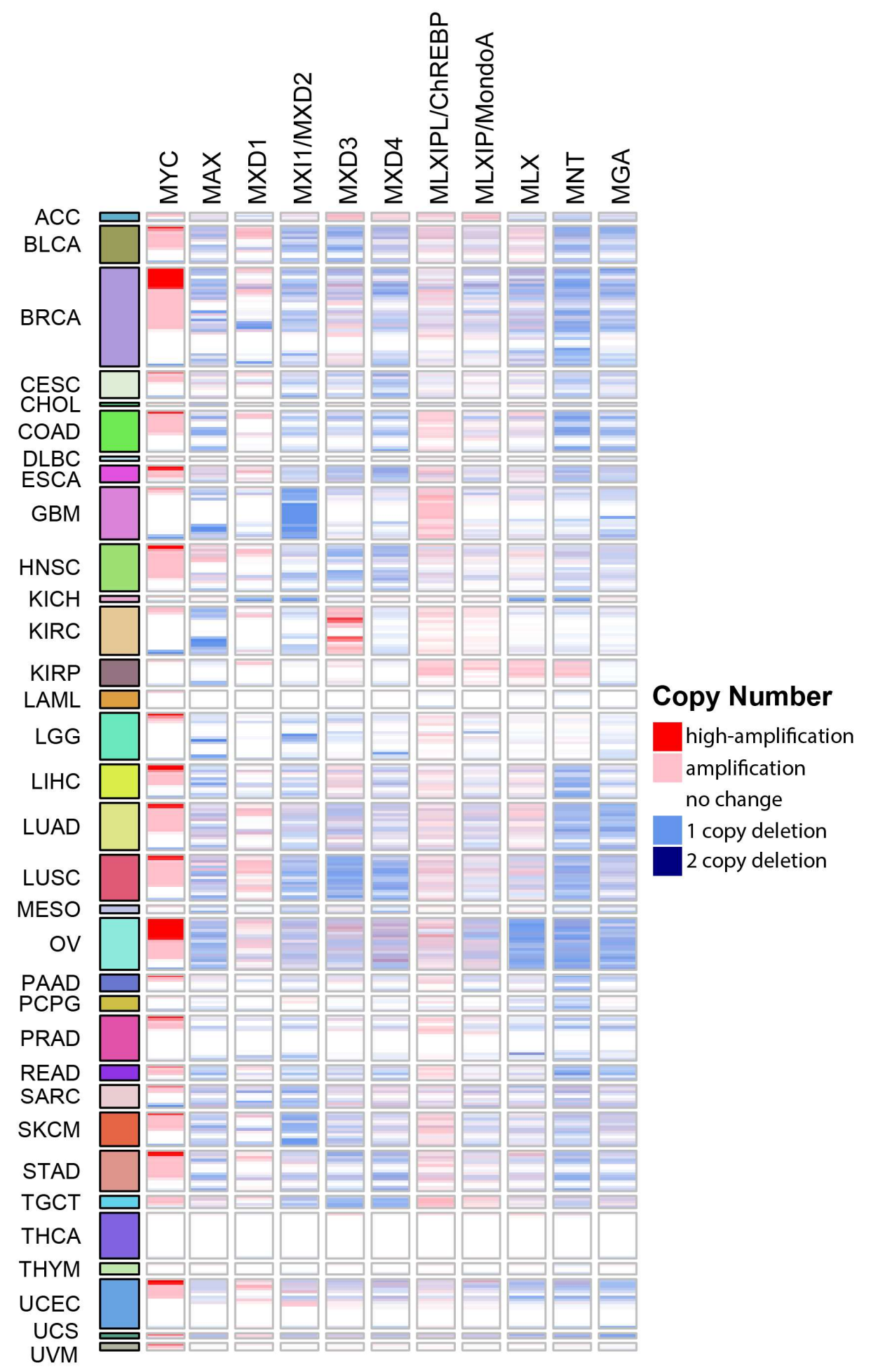

Fig. 2. CNVs among individual members of the Extended Myc Network. Gene-level copy number (gistic2_thresholded) [412] data were downloaded from the TCGA Pan-Cancer (PANCAN) database (https://xenabrowser.net/datapages/?cohort=TCGA\%20Pan-Cancer\%20(PANCAN)) Heatmaps were drawn using ComplexHeatmap R package[413]. 


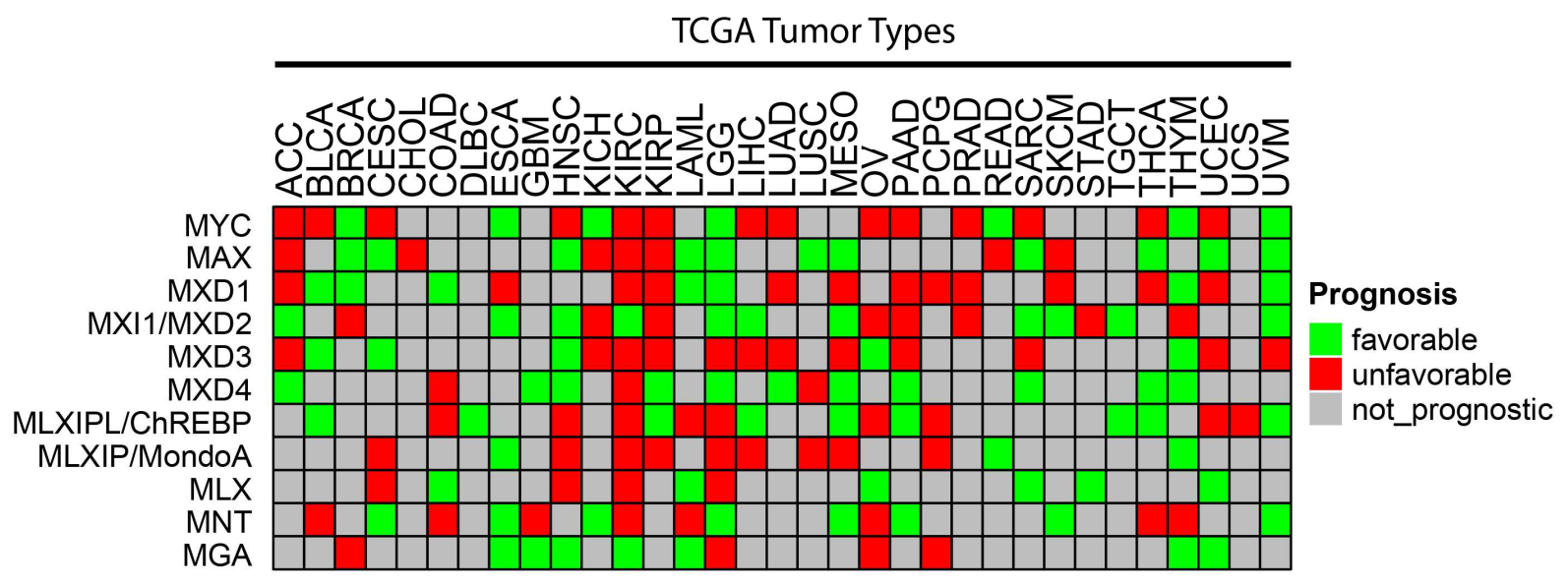

Fig. 3. Correlations between survival and expression of members of the Extended Myc Network. Based on RNAseq results from TCGA, the expression of each Extended Myc Network member was examined in the indicated tumors from the same data base. Tumors were divided into subsets with overall favorable or unfavorable survival. The numbers in each of these subsets were based on the levels of transcript expression that provided the most significant survival differences. The "survival" and "survminer" R packages were used for survival analysis. FPKM value ranks were used to classify individuals into two groups by 50 series cutoffs ranging from $10 \%-90 \%$. Survivorship was examined by Kaplan-Meier survival estimators, and the survival outcomes of the two groups were compared by logrank tests. Curves were based on the FPKM cutoffs that yielded maximal survival difference between the two groups with the lowest log-rank P-value. 

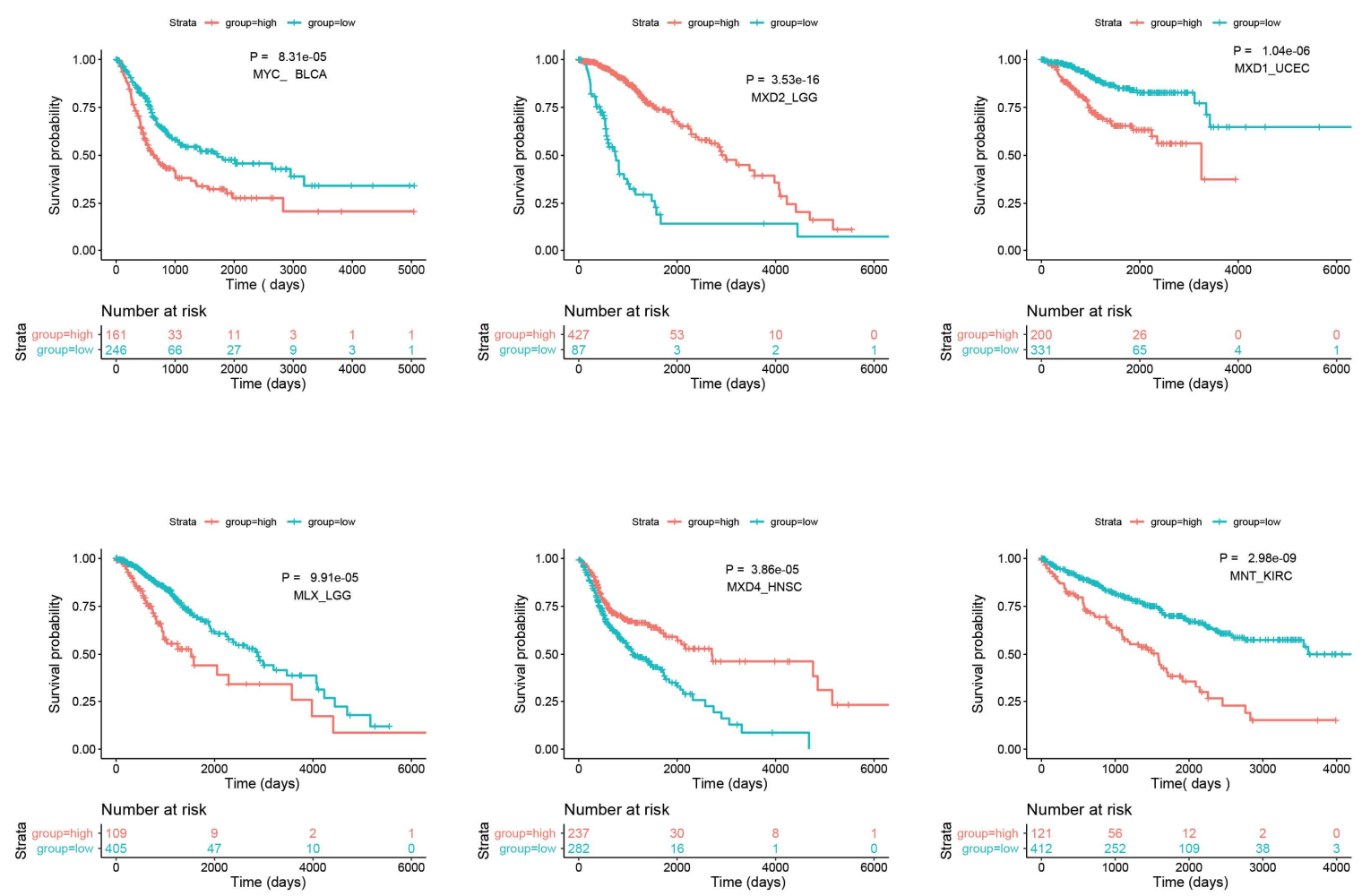

Fig. 4. Correlations between survival and expression of select members of the Extended Myc Network. Tumors were chosen from those in TCGA and further subdivided as described in Fig. 3. All curves were generated using the "survival" and "survminer" R packages. The number of individuals in the favorable and unfavorable survival groups which provided the greatest significance in survival is depicted in the " 0 time point" beneath each survival curve. 


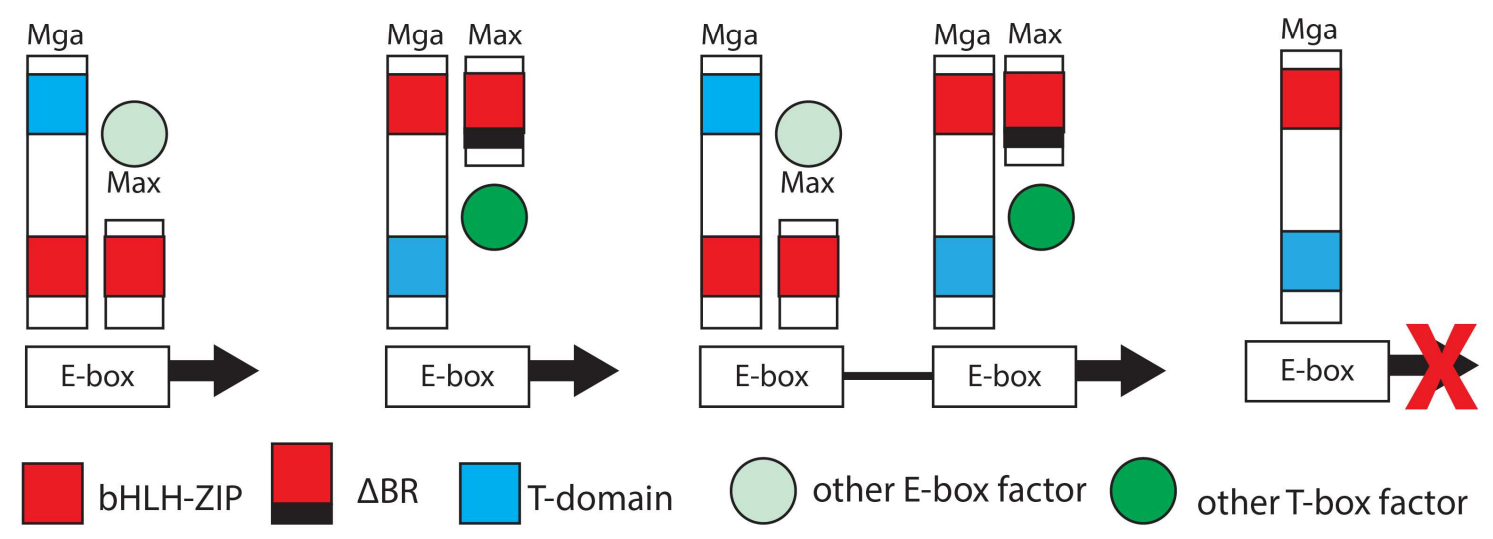

Fig. 5. DNA binding specificity and transcriptional activation by Mga. (A). E-Box binding. DNA binding is mediated by the cooperative interaction between the bHLH-ZIP domains of Mga and Max. This requires an intact basic domain of Max, and presumably Mga as well. Transcriptional activation is indicated by the block arrow (B). T-box binding. This is mediated via the $\mathrm{T}$ domain of Mga. Transcriptional activation requires dimerization with Max but does not require Max's basic domain since a Max $\Delta B R$ mutant lacking this domain functions in the same way as intact Max. Max's role is unclear but may be involved, either directly or indirectly in the recruitment of other factors that are needed for chromatin modification and/or the formation of an active transcriptional activation complex. The factors are different from those recruited by Myc-Max heterodimers and are referred to here as 'T-box factors'. (C). Cooperative dual E-box and T-box binding. Mga binds both sites in the same manner and with the same requirements as binding to individual sites. (D). In the absence of Max and other necessary co-factors, Mga still binds its T-Box sites but acts as a transcriptional repressor.

\section{Reference}

1. Alitalo, K.; Bishop, J.M.; Smith, D.H.; Chen, E.Y.; Colby, W.W.; Levinson, A.D. Nucleotide sequence to the v-myc oncogene of avian retrovirus MC29. Proc Natl Acad Sci U S A 1983, 80, 100-104, doi:10.1073/pnas.80.1.100.

2. Blackwood, E.M.; Eisenman, R.N. Max: a helix-loop-helix zipper protein that forms a sequence-specific DNA-binding complex with Myc. Science 1991, 251, 1211-1217, doi:10.1126/science.2006410.

3. Reddy, E.P.; Reynolds, R.K.; Watson, D.K.; Schultz, R.A.; Lautenberger, J.; Papas, T.S. Nucleotide sequence analysis of the proviral genome of avian myelocytomatosis virus (MC29). Proc Natl Acad Sci U S A 1983, 80, 2500-2504, doi:10.1073/pnas.80.9.2500.

4. Vennstrom, B.; Sheiness, D.; Zabielski, J.; Bishop, J.M. Isolation and characterization of c-myc, a cellular homolog of the oncogene (v-myc) of avian myelocytomatosis virus strain 29. J Virol 1982, 42, 773-779, doi:10.1128/JVI.42.3.773-779.1982.

5. Watson, D.K.; Reddy, E.P.; Duesberg, P.H.; Papas, T.S. Nucleotide sequence analysis of the chicken c-myc gene reveals homologous and unique coding regions by comparison with the transforming gene of avian myelocytomatosis virus MC29, delta gag-myc. Proc Natl Acad Sci U S A 1983, 80, 2146-2150, doi:10.1073/pnas.80.8.2146.

6. Amati, B.; Dalton, S.; Brooks, M.W.; Littlewood, T.D.; Evan, G.I.; Land, H. Transcriptional activation by the human c-Myc oncoprotein in yeast requires interaction with Max. Nature 1992, 359, 423-426, doi:10.1038/359423a0. 
7. Amati, B.; Brooks, M.W.; Levy, N.; Littlewood, T.D.; Evan, G.I.; Land, H. Oncogenic activity of the c-Myc protein requires dimerization with Max. Cell 1993, 72, 233-245, doi:10.1016/0092-8674(93)90663-b.

8. Amati, B.; Littlewood, T.D.; Evan, G.I.; Land, H. The C-Myc Protein Induces Cell-Cycle Progression and Apoptosis through Dimerization with Max. Embo Journal 1993, 12, 5083-5087, doi:DOI 10.1002/j.14602075.1993.tb06202.x.

9. Gu, W.; Cechova, K.; Tassi, V.; Dalla-Favera, R. Opposite regulation of gene transcription and cell proliferation by c-Myc and Max. Proc Natl Acad Sci U S A 1993, 90, 2935-2939, doi:10.1073/pnas.90.7.2935.

10. Kretzner, L.; Blackwood, E.M.; Eisenman, R.N. Myc and Max proteins possess distinct transcriptional activities. Nature 1992, 359, 426-429, doi:10.1038/359426a0.

11. Kretzner, L.; Blackwood, E.M.; Eisenman, R.N. Transcriptional activities of the Myc and Max proteins in mammalian cells. Curr Top Microbiol Immunol 1992, 182, 435-443, doi:10.1007/978-3-642-77633-5_55.

12. Min, S.; Taparowsky, E.J. v-Myc, but not Max, possesses domains that function in both transcription activation and cellular transformation. Oncogene 1992, 7, 1531-1540.

13. Kato, G.J.; Barrett, J.; Villa-Garcia, M.; Dang, C.V. An amino-terminal c-myc domain required for neoplastic transformation activates transcription. Mol Cell Biol 1990, 10, 5914-5920, doi:10.1128/mcb.10.11.5914-5920.1990.

14. Berberich, S.J.; Cole, M.D. Casein kinase II inhibits the DNA-binding activity of Max homodimers but not Myc/Max heterodimers. Genes Dev 1992, 6, 166-176, doi:10.1101/gad.6.2.166.

15. Prochownik, E.V.; VanAntwerp, M.E. Differential patterns of DNA binding by myc and max proteins. Proc Natl Acad Sci U S A 1993, 90, 960-964, doi:10.1073/pnas.90.3.960.

16. Yin, X.; Grove, L.; Prochownik, E.V. Lack of transcriptional repression by max homodimers. Oncogene 1998, 16, 2629-2637, doi:10.1038/sj.onc.1201777.

17. Amente, S.; Bertoni, A.; Morano, A.; Lania, L.; Avvedimento, E.V.; Majello, B. LSD1-mediated demethylation of histone H3 lysine 4 triggers Myc-induced transcription. Oncogene 2010, 29, 3691-3702, doi:10.1038/onc.2010.120.

18. Ayer, D.E.; Lawrence, Q.A.; Eisenman, R.N. Mad-Max Transcriptional Repression Is Mediated by Ternary Complex-Formation with Mammalian Homologs of Yeast Repressor Sin3. Cell 1995, 80, 767-776, doi:Doi 10.1016/0092-8674(95)90355-0.

19. Carroll, P.A.; Diolaiti, D. A novel role for the extended MYC network in cancer cell survival. Mol Cell Oncol 2016, 3, e1026528, doi:10.1080/23723556.2015.1026528.

20. Diolaiti, D.; McFerrin, L.; Carroll, P.A.; Eisenman, R.N. Functional interactions among members of the MAX and MLX transcriptional network during oncogenesis. Biochim Biophys Acta 2015, 1849, 484-500, doi:10.1016/j.bbagrm.2014.05.016.

21. Carroll, P.A.; Freie, B.W.; Mathsyaraja, H.; Eisenman, R.N. The MYC transcription factor network: balancing metabolism, proliferation and oncogenesis. Front Med 2018, 12, 412-425, doi:10.1007/s11684-018-0650-z.

22. Poole, C.J.; van Riggelen, J. MYC-Master Regulator of the Cancer Epigenome and Transcriptome. Genes (Basel) 2017, 8, 142, doi:10.3390/genes8050142.

23. Foley, K.P.; McArthur, G.A.; Queva, C.; Hurlin, P.J.; Soriano, P.; Eisenman, R.N. Targeted disruption of the MYC antagonist MAD1 inhibits cell cycle exit during granulocyte differentiation. EMBO J 1998, 17, 774785, doi:10.1093/emboj/17.3.774.

24. Foley, K.P.; Eisenman, R.N. Two MAD tails: what the recent knockouts of Mad1 and Mxi1 tell us about the MYC/MAX/MAD network. Biochimica et Biophysica Acta (BBA) - Reviews on Cancer 1999, 1423, M37-M47, doi:10.1016/s0304-419x(99)00012-8.

25. Grandori, C.; Cowley, S.M.; James, L.P.; Eisenman, R.N. The Myc/Max/Mad network and the transcriptional control of cell behavior. Annu Rev Cell Dev Biol 2000, 16, 653-699, doi:10.1146/annurev.cellbio.16.1.653.

26. Hurlin, P.J.; Queva, C.; Eisenman, R.N. Mnt, a novel Max-interacting protein is coexpressed with Myc in proliferating cells and mediates repression at Myc binding sites. Genes Dev 1997, 11, 44-58, doi:10.1101/gad.11.1.44.

27. Hurlin, P.J.; Queva, C.; Koskinen, P.J.; Steingrimsson, E.; Ayer, D.E.; Copeland, N.G.; Jenkins, N.A.; Eisenman, R.N. Mad3 and Mad4 - Novel Max-Interacting Transcriptional Repressors That Suppress C- 
Myc Dependent Transformation and Are Expressed during Neural and Epidermal Differentiation. Embo Journal 1995, 14, 5646-5659, doi:DOI 10.1002/j.1460-2075.1995.tb00252.x.

28. Hurlin, P.J.; Steingrimsson, E.; Copeland, N.G.; Jenkins, N.A.; Eisenman, R.N. Mga, a dual-specificity transcription factor that interacts with Max and contains a T-domain DNA-binding motif (vol 18, pg 7019, 1999). Embo Journal 2000, 19, 3841-3841, doi:DOI 10.1093/emboj/19.14.3841.

29. Hurlin, P.J.; Zhou, Z.Q.; Toyo-oka, K.; Ota, S.; Walker, W.L.; Hirotsune, S.; Wynshaw-Boris, A. Deletion of Mnt leads to disrupted cell cycle control and tumorigenesis. EMBO J 2003, 22, 4584-4596, doi:10.1093/emboj/cdg442.

30. Hurlin, P.J.; Zhou, Z.Q.; Toyo-Oka, K.; Ota, S.; Walker, W.L.; Hirotsune, S.; Wynshaw-Boris, A. Evidence of mnt-myc antagonism revealed by mnt gene deletion. Cell Cycle 2004, 3, 97-99, doi:10.4161/cc.3.2.638.

31. Queva, C.; Hurlin, P.J.; Foley, K.P.; Eisenman, R.N. Sequential expression of the MAD family of transcriptional repressors during differentiation and development. Oncogene 1998, 16, 967-977, doi:10.1038/sj.onc.1201611.

32. Queva, C.; McArthur, G.A.; Iritani, B.M.; Eisenman, R.N. Targeted deletion of the S-phase-specific Myc antagonist Mad3 sensitizes neuronal and lymphoid cells to radiation-induced apoptosis. Mol Cell Biol 2001, 21, 703-712, doi:10.1128/MCB.21.3.703-712.2001.

33. Billin, A.N.; Ayer, D.E. The Mlx network: evidence for a parallel Max-like transcriptional network that regulates energy metabolism. Curr Top Microbiol Immunol 2006, 302, 255-278, doi:10.1007/3-54032952-8_10.

34. Billin, A.N.; Eilers, A.L.; Coulter, K.L.; Logan, J.S.; Ayer, D.E. MondoA, a novel basic helix-loop-helix-leucine zipper transcriptional activator that constitutes a positive branch of a max-like network. Mol Cell Biol 2000, 20, 8845-8854, doi:10.1128/MCB.20.23.8845-8854.2000.

35. Billin, A.N.; Eilers, A.L.; Queva, C.; Ayer, D.E. Mlx, a novel Max-like BHLHZip protein that interacts with the Max network of transcription factors. J Biol Chem 1999, 274, 36344-36350, doi:10.1074/jbc.274.51.36344.

36. Yamashita, H.; Takenoshita, M.; Sakurai, M.; Bruick, R.K.; Henzel, W.J.; Shillinglaw, W.; Arnot, D.; Uyeda, K. A glucose-responsive transcription factor that regulates carbohydrate metabolism in the liver. Proc Natl Acad Sci U S A 2001, 98, 9116-9121, doi:10.1073/pnas.161284298.

37. Chen, J.L.; Merl, D.; Peterson, C.W.; Wu, J.; Liu, P.Y.; Yin, H.; Muoio, D.M.; Ayer, D.E.; West, M.; Chi, J.T. Lactic acidosis triggers starvation response with paradoxical induction of TXNIP through MondoA. PLOS Genet 2010, 6, e1001093, doi:10.1371/journal.pgen.1001093.

38. Davies, M.N.; O'Callaghan, B.L.; Towle, H.C. Glucose activates ChREBP by increasing its rate of nuclear entry and relieving repression of its transcriptional activity. I Biol Chem 2008, 283, 24029-24038, doi:10.1074/jbc.M801539200.

39. Davies, M.N.; O'Callaghan, B.L.; Towle, H.C. Activation and repression of glucose-stimulated ChREBP requires the concerted action of multiple domains within the MondoA conserved region. Am J Physiol Endocrinol Metab 2010, 299, E665-674, doi:10.1152/ajpendo.00349.2010.

40. Han, K.S.; Ayer, D.E. MondoA senses adenine nucleotides: transcriptional induction of thioredoxininteracting protein. Biochem $J$ 2013, 453, 209-218, doi:10.1042/BJ20121126.

41. Li, M.V.; Chang, B.; Imamura, M.; Poungvarin, N.; Chan, L. Glucose-dependent transcriptional regulation by an evolutionarily conserved glucose-sensing module. Diabetes 2006, 55, 1179-1189, doi:10.2337/db05-0822.

42. Li, M.V.; Chen, W.; Harmancey, R.N.; Nuotio-Antar, A.M.; Imamura, M.; Saha, P.; Taegtmeyer, H.; Chan, L. Glucose-6-phosphate mediates activation of the carbohydrate responsive binding protein (ChREBP). Biochem Biophys Res Commun 2010, 395, 395-400, doi:10.1016/j.bbrc.2010.04.028.

43. O'Shea, J.M.; Ayer, D.E. Coordination of nutrient availability and utilization by MAX- and MLX-centered transcription networks. Cold Spring Harb Perspect Med 2013, 3, a014258, doi:10.1101/cshperspect.a014258.

44. Peterson, C.W.; Stoltzman, C.A.; Sighinolfi, M.P.; Han, K.S.; Ayer, D.E. Glucose controls nuclear accumulation, promoter binding, and transcriptional activity of the MondoA-Mlx heterodimer. Mol Cell Biol 2010, 30, 2887-2895, doi:10.1128/MCB.01613-09.

45. Peterson, C.W.; Ayer, D.E. An extended Myc network contributes to glucose homeostasis in cancer and diabetes. Front Biosci (Landmark Ed) 2011, 16, 2206-2223, doi:10.2741/3848. 
46. Petrie, J.L.; Al-Oanzi, Z.H.; Arden, C.; Tudhope, S.J.; Mann, J.; Kieswich, J.; Yaqoob, M.M.; Towle, H.C.; Agius, L. Glucose induces protein targeting to glycogen in hepatocytes by fructose 2,6-bisphosphatemediated recruitment of MondoA to the promoter. Mol Cell Biol 2013, 33, 725-738, doi:10.1128/MCB.01576-12.

47. Sans, C.L.; Satterwhite, D.J.; Stoltzman, C.A.; Breen, K.T.; Ayer, D.E. MondoA-Mlx heterodimers are candidate sensors of cellular energy status: mitochondrial localization and direct regulation of glycolysis. Mol Cell Biol 2006, 26, 4863-4871, doi:10.1128/MCB.00657-05.

48. Stoltzman, C.A.; Kaadige, M.R.; Peterson, C.W.; Ayer, D.E. MondoA senses non-glucose sugars: regulation of thioredoxin-interacting protein (TXNIP) and the hexose transport curb. J Biol Chem 2011, 286, 38027-38034, doi:10.1074/jbc.M111.275503.

49. Stoltzman, C.A.; Peterson, C.W.; Breen, K.T.; Muoio, D.M.; Billin, A.N.; Ayer, D.E. Glucose sensing by MondoA:Mlx complexes: a role for hexokinases and direct regulation of thioredoxin-interacting protein expression. Proc Natl Acad Sci U S A 2008, 105, 6912-6917, doi:10.1073/pnas.0712199105.

50. Wilde, B.R.; Ayer, D.E. Interactions between Myc and MondoA transcription factors in metabolism and tumourigenesis. Br J Cancer 2015, 113, 1529-1533, doi:10.1038/bjc.2015.360.

51. Wilde, B.R.; Kaadige, M.R.; Guillen, K.P.; Butterfield, A.; Welm, B.E.; Ayer, D.E. Protein synthesis inhibitors stimulate MondoA transcriptional activity by driving an accumulation of glucose 6-phosphate. Cancer Metab 2020, 8, 27, doi:10.1186/s40170-020-00233-6.

52. Wilde, B.R.; Ye, Z.; Lim, T.Y.; Ayer, D.E. Cellular acidosis triggers human MondoA transcriptional activity by driving mitochondrial ATP production. Elife 2019, 8, e40199, doi:10.7554/eLife.40199.

53. Yu, F.X.; Chai, T.F.; He, H.; Hagen, T.; Luo, Y. Thioredoxin-interacting protein (Txnip) gene expression: sensing oxidative phosphorylation status and glycolytic rate. J Biol Chem 2010, 285, 25822-25830, doi:10.1074/jbc.M110.108290.

54. Yu, F.X.; Goh, S.R.; Dai, R.P.; Luo, Y. Adenosine-containing molecules amplify glucose signaling and enhance txnip expression. Mol Endocrinol 2009, 23, 932-942, doi:10.1210/me.2008-0383.

55. Zhang, X.; Fu, T.; He, Q.; Gao, X.; Luo, Y. Glucose-6-Phosphate Upregulates Txnip Expression by Interacting With MondoA. Front Mol Biosci 2020, 6, 147, doi:10.3389/fmolb.2019.00147.

56. Mejhert, N.; Kuruvilla, L.; Gabriel, K.R.; Elliott, S.D.; Guie, M.A.; Wang, H.; Lai, Z.W.; Lane, E.A.; Christiano, R.; Danial, N.N., et al. Partitioning of MLX-Family Transcription Factors to Lipid Droplets Regulates Metabolic Gene Expression. Mol Cell 2020, 77, 1251-1264 e1259, doi:10.1016/j.molcel.2020.01.014.

57. Carroll, P.A.; Diolaiti, D.; McFerrin, L.; Gu, H.; Djukovic, D.; Du, J.; Cheng, P.F.; Anderson, S.; Ulrich, M.; Hurley, J.B., et al. Deregulated Myc requires MondoA/Mlx for metabolic reprogramming and tumorigenesis. Cancer Cell 2015, 27, 271-285, doi:10.1016/j.ccell.2014.11.024.

58. Ma, L.; Robinson, L.N.; Towle, H.C. ChREBP*Mlx is the principal mediator of glucose-induced gene expression in the liver. J Biol Chem 2006, 281, 28721-28730, doi:10.1074/jbc.M601576200.

59. Ma, L.; Sham, Y.Y.; Walters, K.J.; Towle, H.C. A critical role for the loop region of the basic helix-loophelix/leucine zipper protein Mlx in DNA binding and glucose-regulated transcription. Nucleic Acids Res 2007, 35, 35-44, doi:10.1093/nar/gkl987.

60. Ma, L.; Tsatsos, N.G.; Towle, H.C. Direct role of ChREBP.Mlx in regulating hepatic glucose-responsive genes. J Biol Chem 2005, 280, 12019-12027, doi:10.1074/jbc.M413063200.

61. Stoeckman, A.K.; Ma, L.; Towle, H.C. Mlx is the functional heteromeric partner of the carbohydrate response element-binding protein in glucose regulation of lipogenic enzyme genes. J Biol Chem 2004, 279, 15662-15669, doi:10.1074/jbc.M311301200.

62. Wutthisathapornchai, A.; Vongpipatana, T.; Muangsawat, S.; Boonsaen, T.; MacDonald, M.J.; Jitrapakdee, S. Multiple E-boxes in the distal promoter of the rat pyruvate carboxylase gene function as a glucoseresponsive element. PLoS One 2014, 9, e102730, doi:10.1371/journal.pone.0102730.

63. Wang, H.; Lu, J.; Alencastro, F.; Roberts, A.; Fiedor, J.; Carroll, P.; Eisenman, R.N.; Ranganathan, S.; Torbenson, M.; Duncan, A.W., et al. Coordinated Cross-Talk Between the Myc and Mlx Networks in Liver Regeneration and Neoplasia. bioRxiv 2021, 10.1101/2021.08.05.455215, 2021.2008.2005.455215, doi:10.1101/2021.08.05.455215.

64. Zhang, P.; Metukuri, M.R.; Bindom, S.M.; Prochownik, E.V.; O'Doherty, R.M.; Scott, D.K. c-Myc is required for the CHREBP-dependent activation of glucose-responsive genes. Mol Endocrinol 2010, 24, 1274-1286, doi:10.1210/me.2009-0437. 
65. Poungvarin, N.; Chang, B.; Imamura, M.; Chen, J.; Moolsuwan, K.; Sae-Lee, C.; Li, W.; Chan, L. GenomeWide Analysis of ChREBP Binding Sites on Male Mouse Liver and White Adipose Chromatin. Endocrinology 2015, 156, 1982-1994, doi:10.1210/en.2014-1666.

66. Wang, H.; Lu, J.; Edmunds, L.R.; Kulkarni, S.; Dolezal, J.; Tao, J.; Ranganathan, S.; Jackson, L.; Fromherz, M.; Beer-Stolz, D., et al. Coordinated Activities of Multiple Myc-dependent and Myc-independent Biosynthetic Pathways in Hepatoblastoma. J Biol Chem 2016, 291, 26241-26251, doi:10.1074/jbc.M116.754218.

67. Wang, H.; Dolezal, J.M.; Kulkarni, S.; Lu, J.; Mandel, J.; Jackson, L.E.; Alencastro, F.; Duncan, A.W.; Prochownik, E.V. Myc and ChREBP transcription factors cooperatively regulate normal and neoplastic hepatocyte proliferation in mice. J Biol Chem 2018, 293, 14740-14757, doi:10.1074/jbc.RA118.004099.

68. Denechaud, P.D.; Bossard, P.; Lobaccaro, J.M.; Millatt, L.; Staels, B.; Girard, J.; Postic, C. ChREBP, but not LXRs, is required for the induction of glucose-regulated genes in mouse liver. J Clin Invest 2008, 118, 956964, doi:10.1172/JCI34314.

69. Denechaud, P.D.; Dentin, R.; Girard, J.; Postic, C. Role of ChREBP in hepatic steatosis and insulin resistance. FEBS Lett 2008, 582, 68-73, doi:10.1016/j.febslet.2007.07.084.

70. Havula, E.; Hietakangas, V. Glucose sensing by ChREBP/MondoA-Mlx transcription factors. Semin Cell Dev Biol 2012, 23, 640-647, doi:10.1016/j.semcdb.2012.02.007.

71. Havula, E.; Hietakangas, V. Sugar sensing by ChREBP/Mondo-Mlx-new insight into downstream regulatory networks and integration of nutrient-derived signals. Curr Opin Cell Biol 2018, 51, 89-96, doi:10.1016/j.ceb.2017.12.007.

72. Havula, E.; Teesalu, M.; Hyotylainen, T.; Seppala, H.; Hasygar, K.; Auvinen, P.; Oresic, M.; Sandmann, T.; Hietakangas, V. Mondo/ChREBP-Mlx-regulated transcriptional network is essential for dietary sugar tolerance in Drosophila. PLoS Genet 2013, 9, e1003438, doi:10.1371/journal.pgen.1003438.

73. lizuka, K.; Bruick, R.K.; Liang, G.; Horton, J.D.; Uyeda, K. Deficiency of carbohydrate response elementbinding protein (ChREBP) reduces lipogenesis as well as glycolysis. Proc Natl Acad Sci U S A 2004, 101, 7281-7286, doi:10.1073/pnas.0401516101.

74. Jeong, Y.S.; Kim, D.; Lee, Y.S.; Kim, H.J.; Han, J.Y.; Im, S.S.; Chong, H.K.; Kwon, J.K.; Cho, Y.H.; Kim, W.K., et al. Integrated expression profiling and genome-wide analysis of ChREBP targets reveals the dual role for ChREBP in glucose-regulated gene expression. PLoS One 2011, 6, e22544, doi:10.1371/journal.pone.0022544.

75. Ke, H.; Luan, Y.; Wu, S.; Zhu, Y.; Tong, X. The Role of Mondo Family Transcription Factors in NutrientSensing and Obesity. Front Endocrinol (Lausanne) 2021, 12, 653972, doi:10.3389/fendo.2021.653972.

76. Lane, E.A.; Choi, D.W.; Garcia-Haro, L.; Levine, Z.G.; Tedoldi, M.; Walker, S.; Danial, N.N. HCF-1 Regulates De Novo Lipogenesis through a Nutrient-Sensitive Complex with ChREBP. Mol Cell 2019, 75, 357-371 e357, doi:10.1016/j.molcel.2019.05.019.

77. Richards, P.; Ourabah, S.; Montagne, J.; Burnol, A.F.; Postic, C.; Guilmeau, S. MondoA/ChREBP: The usual suspects of transcriptional glucose sensing; Implication in pathophysiology. Metabolism 2017, 70, 133151, doi:10.1016/j.metabol.2017.01.033.

78. Richards, P.; Rachdi, L.; Oshima, M.; Marchetti, P.; Bugliani, M.; Armanet, M.; Postic, C.; Guilmeau, S.; Scharfmann, R. MondoA Is an Essential Glucose-Responsive Transcription Factor in Human Pancreatic beta-Cells. Diabetes 2018, 67, 461-472, doi:10.2337/db17-0595.

79. Airley, R.E.; McHugh, P.; Evans, A.R.; Harris, B.; Winchester, L.; Buffa, F.M.; Al-Tameemi, W.; Leek, R.; Harris, A.L. Role of carbohydrate response element-binding protein (ChREBP) in generating an aerobic metabolic phenotype and in breast cancer progression. $B r J$ Cancer 2014, 110, 715-723, doi:10.1038/bjc.2013.765.

80. Buttgereit, F.; Brand, M.D. A hierarchy of ATP-consuming processes in mammalian cells. Biochem J 1995, 312 ( Pt 1), 163-167, doi:10.1042/bj3120163.

81. Elgort, M.G.; O'Shea, J.M.; Jiang, Y.; Ayer, D.E. Transcriptional and Translational Downregulation of Thioredoxin Interacting Protein Is Required for Metabolic Reprogramming during G(1). Genes Cancer 2010, 1, 893-907, doi:10.1177/1947601910389604.

82. Kaadige, M.R.; Looper, R.E.; Kamalanaadhan, S.; Ayer, D.E. Glutamine-dependent anapleurosis dictates glucose uptake and cell growth by regulating MondoA transcriptional activity. Proc Natl Acad Sci U S A 2009, 106, 14878-14883, doi:10.1073/pnas.0901221106. 
83. Kaadige, M.R.; Yang, J.; Wilde, B.R.; Ayer, D.E. MondoA-Mlx transcriptional activity is limited by mTORMondoA interaction. Mol Cell Biol 2015, 35, 101-110, doi:10.1128/MCB.00636-14.

84. Sipol, A.; Hameister, E.; Xue, B.; Hofstetter, J.; Barenboim, M.; Ollinger, R.; Jain, G.; Prexler, C.; Rubio, R.A.; Baldauf, M.C., et al. MondoA Drives B-ALL Malignancy through Enhanced Adaptation to Metabolic Stress. Blood 2021, 10.1182/blood.2020007932, doi:10.1182/blood.2020007932.

85. Wernicke, C.M.; Richter, G.H.; Beinvogl, B.C.; Plehm, S.; Schlitter, A.M.; Bandapalli, O.R.; Prazeres da Costa, O.; Hattenhorst, U.E.; Volkmer, I.; Staege, M.S., et al. MondoA is highly overexpressed in acute lymphoblastic leukemia cells and modulates their metabolism, differentiation and survival. Leuk Res 2012, 36, 1185-1192, doi:10.1016/j.leukres.2012.05.009.

86. Afshar, A.R.; Pekmezci, M.; Bloomer, M.M.; Cadenas, N.J.; Stevers, M.; Banerjee, A.; Roy, R.; Olshen, A.B.; Van Ziffle, J.; Onodera, C., et al. Next-Generation Sequencing of Retinoblastoma Identifies Pathogenic Alterations beyond RB1 Inactivation That Correlate with Aggressive Histopathologic Features. Ophthalmology 2020, 127, 804-813, doi:10.1016/j.ophtha.2019.12.005.

87. Berry, J.L.; Polski, A.; Cavenee, W.K.; Dryja, T.P.; Murphree, A.L.; Gallie, B.L. The RB1 Story: Characterization and Cloning of the First Tumor Suppressor Gene. Genes (Basel) 2019, 10, 879, doi:10.3390/genes10110879.

88. Garber, J.E.; Offit, K. Hereditary cancer predisposition syndromes. J Clin Oncol 2005, 23, 276-292, doi:10.1200/JCO.2005.10.042.

89. Gargallo, P.; Yanez, Y.; Segura, V.; Juan, A.; Torres, B.; Balaguer, J.; Oltra, S.; Castel, V.; Canete, A. LiFraumeni syndrome heterogeneity. Clin Transl Oncol 2020, 22, 978-988, doi:10.1007/s12094-019-022362.

90. Guha, T.; Malkin, D. Inherited TP53 Mutations and the Li-Fraumeni Syndrome. Cold Spring Harb Perspect Med 2017, 7, a026187, doi:10.1101/cshperspect.a026187.

91. Marmolejo, D.H.; Wong, M.Y.Z.; Bajalica-Lagercrantz, S.; Tischkowitz, M.; Balmana, J.; extended, E.R.N.G.T.G. Overview of hereditary breast and ovarian cancer (HBOC) guidelines across Europe. Eur J Med Genet 2021, 64, 104350, doi:10.1016/j.ejmg.2021.104350.

92. Beroukhim, R.; Mermel, C.H.; Porter, D.; Wei, G.; Raychaudhuri, S.; Donovan, J.; Barretina, J.; Boehm, J.S.; Dobson, J.; Urashima, M., et al. The landscape of somatic copy-number alteration across human cancers. Nature 2010, 463, 899-905, doi:10.1038/nature08822.

93. Schaub, F.X.; Dhankani, V.; Berger, A.C.; Trivedi, M.; Richardson, A.B.; Shaw, R.; Zhao, W.; Zhang, X.; Ventura, A.; Liu, Y., et al. Pan-cancer Alterations of the MYC Oncogene and Its Proximal Network across the Cancer Genome Atlas. Cell Syst 2018, 6, 282-300 e282, doi:10.1016/j.cels.2018.03.003.

94. Zack, T.I.; Schumacher, S.E.; Carter, S.L.; Cherniack, A.D.; Saksena, G.; Tabak, B.; Lawrence, M.S.; Zhsng, C.Z.; Wala, J.; Mermel, C.H., et al. Pan-cancer patterns of somatic copy number alteration. Nat Genet 2013, 45, 1134-1140, doi:10.1038/ng.2760.

95. Fallah, Y.; Brundage, J.; Allegakoen, P.; Shajahan-Haq, A.N. MYC-Driven Pathways in Breast Cancer Subtypes. Biomolecules 2017, 7, 53, doi:10.3390/biom7030053.

96. Kawate, S.; Fukusato, T.; Ohwada, S.; Watanuki, A.; Morishita, Y. Amplification of c-myc in hepatocellular carcinoma: correlation with clinicopathologic features, proliferative activity and p53 overexpression. Oncology 1999, 57, 157-163, doi:10.1159/000012024.

97. Li, C.; Bonazzoli, E.; Bellone, S.; Choi, J.; Dong, W.; Menderes, G.; Altwerger, G.; Han, C.; Manzano, A.; Bianchi, A., et al. Mutational landscape of primary, metastatic, and recurrent ovarian cancer reveals cMYC gains as potential target for BET inhibitors. Proc Natl Acad Sci U S A 2019, 116, 619-624, doi:10.1073/pnas.1814027116.

98. Cancer Genome Atlas Research, N. Comprehensive molecular profiling of lung adenocarcinoma. Nature 2014, 511, 543-550, doi:10.1038/nature13385.

99. Singh, A.; Ham, J.; Po, J.W.; Niles, N.; Roberts, T.; Lee, C.S. The Genomic Landscape of Thyroid Cancer Tumourigenesis and Implications for Immunotherapy. Cells 2021, 10, 1082, doi:10.3390/cells10051082.

100. Dolezal, J.M.; Wang, H.; Kulkarni, S.; Jackson, L.; Lu, J.; Ranganathan, S.; Goetzman, E.S.; Bharathi, S.S.; Beezhold, K.; Byersdorfer, C.A., et al. Sequential adaptive changes in a c-Myc-driven model of hepatocellular carcinoma. J Biol Chem 2017, 292, 10068-10086, doi:10.1074/jbc.M117.782052. 
101. Leder, A.; Pattengale, P.K.; Kuo, A.; Stewart, T.A.; Leder, P. Consequences of widespread deregulation of the c-myc gene in transgenic mice: multiple neoplasms and normal development. Cell 1986, 45, 485-495, doi:10.1016/0092-8674(86)90280-1.

102. Shachaf, C.M.; Kopelman, A.M.; Arvanitis, C.; Karlsson, A.; Beer, S.; Mandl, S.; Bachmann, M.H.; Borowsky, A.D.; Ruebner, B.; Cardiff, R.D., et al. MYC inactivation uncovers pluripotent differentiation and tumour dormancy in hepatocellular cancer. Nature 2004, 431, 1112-1117, doi:10.1038/nature03043.

103. Tao, J.; Calvisi, D.F.; Ranganathan, S.; Cigliano, A.; Zhou, L.; Singh, S.; Jiang, L.; Fan, B.; Terracciano, L.; Armeanu-Ebinger, S., et al. Activation of beta-catenin and Yap1 in human hepatoblastoma and induction of hepatocarcinogenesis in mice. Gastroenterology 2014, 147, 690-701, doi:10.1053/j.gastro.2014.05.004.

104. Zhang, W.; Meyfeldt, J.; Wang, H.; Kulkarni, S.; Lu, J.; Mandel, J.A.; Marburger, B.; Liu, Y.; Gorka, J.E.; Ranganathan, S., et al. beta-Catenin mutations as determinants of hepatoblastoma phenotypes in mice. J Biol Chem 2019, 294, 17524-17542, doi:10.1074/jbc.RA119.009979.

105. Soucek, L.; Evan, G.I. The ups and downs of Myc biology. Curr Opin Genet Dev 2010, 20, 91-95, doi:10.1016/j.gde.2009.11.001.

106. Brito, J.P.; Asi, N.; Bancos, I.; Gionfriddo, M.R.; Zeballos-Palacios, C.L.; Leppin, A.L.; Undavalli, C.; Wang, Z.; Domecq, J.P.; Prustsky, G., et al. Testing for germline mutations in sporadic pheochromocytoma/paraganglioma: a systematic review. Clin Endocrinol (Oxf) 2015, 82, 338-345, doi:10.1111/cen.12530.

107. Burnichon, N.; Cascon, A.; Schiavi, F.; Morales, N.P.; Comino-Mendez, I.; Abermil, N.; Inglada-Perez, L.; de Cubas, A.A.; Amar, L.; Barontini, M., et al. MAX mutations cause hereditary and sporadic pheochromocytoma and paraganglioma. Clin Cancer Res 2012, 18, 2828-2837, doi:10.1158/10780432.CCR-12-0160.

108. Comino-Mendez, I.; Gracia-Aznarez, F.J.; Schiavi, F.; Landa, I.; Leandro-Garcia, L.J.; Leton, R.; Honrado, E.; Ramos-Medina, R.; Caronia, D.; Pita, G., et al. Exome sequencing identifies MAX mutations as a cause of hereditary pheochromocytoma. Nat Genet 2011, 43, 663-667, doi:10.1038/ng.861.

109. Galan, S.R.; Kann, P.H. Genetics and molecular pathogenesis of pheochromocytoma and paraganglioma. Clin Endocrinol (Oxf) 2013, 78, 165-175, doi:10.1111/cen.12071.

110. Korpershoek, E.; Koffy, D.; Eussen, B.H.; Oudijk, L.; Papathomas, T.G.; van Nederveen, F.H.; Belt, E.J.; Franssen, G.J.; Restuccia, D.F.; Krol, N.M., et al. Complex MAX Rearrangement in a Family With Malignant Pheochromocytoma, Renal Oncocytoma, and Erythrocytosis. J Clin Endocrinol Metab 2016, 101, 453-460, doi:10.1210/jc.2015-2592.

111. Roszko, K.L.; Blouch, E.; Blake, M.; Powers, J.F.; Tischler, A.S.; Hodin, R.; Sadow, P.; Lawson, E.A. Case Report of a Prolactinoma in a Patient With a Novel MAX Mutation and Bilateral Pheochromocytomas. J Endocr Soc 2017, 1, 1401-1407, doi:10.1210/js.2017-00135.

112. Welander, J.; Andreasson, A.; Juhlin, C.C.; Wiseman, R.W.; Backdahl, M.; Hoog, A.; Larsson, C.; Gimm, O.; Soderkvist, P. Rare germline mutations identified by targeted next-generation sequencing of susceptibility genes in pheochromocytoma and paraganglioma. J Clin Endocrinol Metab 2014, 99, E13521360, doi:10.1210/jc.2013-4375.

113. Boxer, L.M.; Dang, C.V. Translocations involving c-myc and c-myc function. Oncogene 2001, 20, 55955610, doi:10.1038/sj.onc.1204595.

114. Jovanovic, K.K.; Roche-Lestienne, C.; Ghobrial, I.M.; Facon, T.; Quesnel, B.; Manier, S. Targeting MYC in multiple myeloma. Leukemia 2018, 32, 1295-1306, doi:10.1038/s41375-018-0036-x.

115. Liu, Y.; Barta, S.K. Diffuse large B-cell lymphoma: 2019 update on diagnosis, risk stratification, and treatment. Am J Hematol 2019, 94, 604-616, doi:10.1002/ajh.25460.

116. Schmitz, R.; Ceribelli, M.; Pittaluga, S.; Wright, G.; Staudt, L.M. Oncogenic mechanisms in Burkitt lymphoma. Cold Spring Harb Perspect Med 2014, 4, a014282, doi:10.1101/cshperspect.a014282.

117. Herranz, D.; Ambesi-Impiombato, A.; Palomero, T.; Schnell, S.A.; Belver, L.; Wendorff, A.A.; Xu, L.; Castillo-Martin, M.; Llobet-Navas, D.; Cordon-Cardo, C., et al. A NOTCH1-driven MYC enhancer promotes T cell development, transformation and acute lymphoblastic leukemia. Nat Med 2014, 20, 1130-1137, doi:10.1038/nm.3665. 
118. Kaur, M.; Cole, M.D. MYC acts via the PTEN tumor suppressor to elicit autoregulation and genome-wide gene repression by activation of the Ezh2 methyltransferase. Cancer Res 2013, 73, 695-705, doi:10.1158/0008-5472.CAN-12-2522.

119. Wilkins, J.A.; Sansom, O.J. C-Myc is a critical mediator of the phenotypes of Apc loss in the intestine. Cancer Res 2008, 68, 4963-4966, doi:10.1158/0008-5472.CAN-07-5558.

120. Gebhardt, A.; Frye, M.; Herold, S.; Benitah, S.A.; Braun, K.; Samans, B.; Watt, F.M.; Elsasser, H.P.; Eilers, M. Myc regulates keratinocyte adhesion and differentiation via complex formation with Miz1. J Cell Biol 2006, 172, 139-149, doi:10.1083/jcb.200506057.

121. Seoane, J.; Pouponnot, C.; Staller, P.; Schader, M.; Eilers, M.; Massague, J. TGFbeta influences Myc, Miz1 and Smad to control the CDK inhibitor p15INK4b. Nat Cell Biol 2001, 3, 400-408, doi:10.1038/35070086.

122. Si, J.; Yu, X.; Zhang, Y.; DeWille, J.W. Myc interacts with Max and Miz1 to repress C/EBPdelta promoter activity and gene expression. Mol Cancer 2010, 9, 92, doi:10.1186/1476-4598-9-92.

123. Staller, P.; Peukert, K.; Kiermaier, A.; Seoane, J.; Lukas, J.; Karsunky, H.; Moroy, T.; Bartek, J.; Massague, J.; Hanel, F., et al. Repression of p15INK4b expression by Myc through association with Miz-1. Nat Cell Biol 2001, 3, 392-399, doi:10.1038/35070076.

124. van Riggelen, J.; Muller, J.; Otto, T.; Beuger, V.; Yetil, A.; Choi, P.S.; Kosan, C.; Moroy, T.; Felsher, D.W.; Eilers, M. The interaction between Myc and Miz1 is required to antagonize TGFbeta-dependent autocrine signaling during lymphoma formation and maintenance. Genes Dev 2010, 24, 1281-1294, doi:10.1101/gad.585710.

125. Gartel, A.L.; Shchors, K. Mechanisms of c-myc-mediated transcriptional repression of growth arrest genes. Exp Cell Res 2003, 283, 17-21, doi:10.1016/s0014-4827(02)00020-4.

126. Gartel, A.L.; Ye, X.; Goufman, E.; Shianov, P.; Hay, N.; Najmabadi, F.; Tyner, A.L. Myc represses the p21(WAF1/CIP1) promoter and interacts with Sp1/Sp3. Proc Natl Acad Sci U S A 2001, 98, 4510-4515, doi:10.1073/pnas.081074898.

127. Adhikary, S.; Marinoni, F.; Hock, A.; Hulleman, E.; Popov, N.; Beier, R.; Bernard, S.; Quarto, M.; Capra, M.; Goettig, S., et al. The ubiquitin ligase HectH9 regulates transcriptional activation by Myc and is essential for tumor cell proliferation. Cell 2005, 123, 409-421, doi:10.1016/j.cell.2005.08.016.

128. Faiola, F.; Liu, X.; Lo, S.; Pan, S.; Zhang, K.; Lymar, E.; Farina, A.; Martinez, E. Dual regulation of c-Myc by p300 via acetylation-dependent control of Myc protein turnover and coactivation of Myc-induced transcription. Mol Cell Biol 2005, 25, 10220-10234, doi:10.1128/MCB.25.23.10220-10234.2005.

129. Lourenco, C.; Resetca, D.; Redel, C.; Lin, P.; MacDonald, A.S.; Ciaccio, R.; Kenney, T.M.G.; Wei, Y.; Andrews, D.W.; Sunnerhagen, M., et al. MYC protein interactors in gene transcription and cancer. Nat Rev Cancer 2021, 21, 579-591, doi:10.1038/s41568-021-00367-9.

130. Huang, Z.; Traugh, J.A.; Bishop, J.M. Negative control of the Myc protein by the stress-responsive kinase Pak2. Mol Cell Biol 2004, 24, 1582-1594, doi:10.1128/MCB.24.4.1582-1594.2004.

131. Uribesalgo, I.; Benitah, S.A.; Di Croce, L. From oncogene to tumor suppressor: the dual role of Myc in leukemia. Cell Cycle 2012, 11, 1757-1764, doi:10.4161/cc.19883.

132. Uribesalgo, I.; Buschbeck, M.; Gutierrez, A.; Teichmann, S.; Demajo, S.; Kuebler, B.; Nomdedeu, J.F.; Martin-Caballero, J.; Roma, G.; Benitah, S.A., et al. E-box-independent regulation of transcription and differentiation by MYC. Nat Cell Biol 2011, 13, 1443-1449, doi:10.1038/ncb2355.

133. Horlein, A.J.; Naar, A.M.; Heinzel, T.; Torchia, J.; Gloss, B.; Kurokawa, R.; Ryan, A.; Kamei, Y.; Soderstrom, M.; Glass, C.K., et al. Ligand-independent repression by the thyroid hormone receptor mediated by a nuclear receptor co-repressor. Nature 1995, 377, 397-404, doi:10.1038/377397a0.

134. Nisimoto, Y.; Ogawa, H. Interaction between p21-activated protein kinase and Rac during differentiation of HL-60 human promyelocytic leukemia cell induced by all-trans-retinoic acid. Eur J Biochem 2002, 269, 2622-2629, doi:10.1046/j.1432-1033.2002.02939.x.

135. Benitah, S.A.; Frye, M.; Glogauer, M.; Watt, F.M. Stem cell depletion through epidermal deletion of Rac1. Science 2005, 309, 933-935, doi:10.1126/science.1113579.

136. Huang, S.; Spector, D.L. Nascent pre-mRNA transcripts are associated with nuclear regions enriched in splicing factors. Genes Dev 1991, 5, 2288-2302, doi:10.1101/gad.5.12a.2288.

137. Watt, F.M.; Frye, M.; Benitah, S.A. MYC in mammalian epidermis: how can an oncogene stimulate differentiation? Nat Rev Cancer 2008, 8, 234-242, doi:10.1038/nrc2328. 
138. Cerami, E.; Gao, J.; Dogrusoz, U.; Gross, B.E.; Sumer, S.O.; Aksoy, B.A.; Jacobsen, A.; Byrne, C.J.; Heuer, M.L.; Larsson, E., et al. The cBio cancer genomics portal: an open platform for exploring multidimensional cancer genomics data. Cancer Discov 2012, 2, 401-404, doi:10.1158/2159-8290.CD-120095.

139. Chakraborty, A.A.; Scuoppo, C.; Dey, S.; Thomas, L.R.; Lorey, S.L.; Lowe, S.W.; Tansey, W.P. A common functional consequence of tumor-derived mutations within c-MYC. Oncogene 2015, 34, 2406-2409, doi:10.1038/onc.2014.186.

140. Ayer, D.E.; Kretzner, L.; Eisenman, R.N. Mad - a Heterodimeric Partner for Max That Antagonizes Myc Transcriptional Activity. Cell 1993, 72, 211-222, doi:Doi 10.1016/0092-8674(93)90661-9.

141. Amati, B.; Alevizopoulos, K.; Vlach, J. Myc and the cell cycle. Front Biosci 1998, 3, d250-268, doi:10.2741/a239.

142. Fletcher, S.; Prochownik, E.V. Small-molecule inhibitors of the Myc oncoprotein. Biochim Biophys Acta 2015, 1849, 525-543, doi:10.1016/j.bbagrm.2014.03.005.

143. Jiang, H.; Bower, K.E.; Beuscher, A.E.t.; Zhou, B.; Bobkov, A.A.; Olson, A.J.; Vogt, P.K. Stabilizers of the Max homodimer identified in virtual ligand screening inhibit Myc function. Mol Pharmacol 2009, 76, 491-502, doi:10.1124/mol.109.054858.

144. Jung, K.Y.; Wang, H.; Teriete, P.; Yap, J.L.; Chen, L.; Lanning, M.E.; Hu, A.; Lambert, L.J.; Holien, T.; Sundan, A., et al. Perturbation of the c-Myc-Max protein-protein interaction via synthetic alpha-helix mimetics. $J$ Med Chem 2015, 58, 3002-3024, doi:10.1021/jm501440q.

145. Prochownik, E.V.; Vogt, P.K. Therapeutic Targeting of Myc. Genes Cancer 2010, 1, 650-659, doi:10.1177/1947601910377494.

146. Whitfield, J.R.; Beaulieu, M.E.; Soucek, L. Strategies to Inhibit Myc and Their Clinical Applicability. Front Cell Dev Biol 2017, 5, 10, doi:10.3389/fcell.2017.00010.

147. Mukherjee, B.; Morgenbesser, S.D.; DePinho, R.A. Myc family oncoproteins function through a common pathway to transform normal cells in culture: cross-interference by Max and trans-acting dominant mutants. Genes Dev 1992, 6, 1480-1492, doi:10.1101/gad.6.8.1480.

148. Prendergast, G.C.; Hopewell, R.; Gorham, B.J.; Ziff, E.B. Biphasic effect of Max on Myc cotransformation activity and dependence on amino- and carboxy-terminal Max functions. Genes Dev 1992, 6, 2429-2439, doi:10.1101/gad.6.12a.2429.

149. Hopewell, R.; Ziff, E.B. The nerve growth factor-responsive PC12 cell line does not express the Myc dimerization partner Max. Mol Cell Biol 1995, 15, 3470-3478, doi:10.1128/MCB.15.7.3470.

150. Jafri, M.; Maher, E.R. The genetics of phaeochromocytoma: using clinical features to guide genetic testing. Eur J Endocrinol 2012, 166, 151-158, doi:10.1530/EJE-11-0497.

151. Flynn, A.; Benn, D.; Clifton-Bligh, R.; Robinson, B.; Trainer, A.H.; James, P.; Hogg, A.; Waldeck, K.; George, J.; Li, J., et al. The genomic landscape of phaeochromocytoma. J Pathol 2015, 236, 78-89, doi:10.1002/path.4503.

152. Maniam, P.; Zhou, K.; Lonergan, M.; Berg, J.N.; Goudie, D.R.; Newey, P.J. Pathogenicity and Penetrance of Germline SDHA Variants in Pheochromocytoma and Paraganglioma (PPGL). J Endocr Soc 2018, 2, 806816, doi:10.1210/js.2018-00120.

153. Daly, A.F.; Castermans, E.; Oudijk, L.; Guitelman, M.A.; Beckers, P.; Potorac, I.; Neggers, S.; Sacre, N.; van der Lely, A.J.; Bours, V., et al. Pheochromocytomas and pituitary adenomas in three patients with MAX exon deletions. Endocr Relat Cancer 2018, 25, L37-L42, doi:10.1530/ERC-18-0065.

154. Pantaleo, M.A.; Urbini, M.; Indio, V.; Ravegnini, G.; Nannini, M.; De Luca, M.; Tarantino, G.; Angelini, S.; Gronchi, A.; Vincenzi, B., et al. Genome-Wide Analysis Identifies MEN1 and MAX Mutations and a Neuroendocrine-Like Molecular Heterogeneity in Quadruple WT GIST. Mol Cancer Res 2017, 15, 553-562, doi:10.1158/1541-7786.MCR-16-0376.

155. Romero, O.A.; Torres-Diz, M.; Pros, E.; Savola, S.; Gomez, A.; Moran, S.; Saez, C.; Iwakawa, R.; Villanueva, A.; Montuenga, L.M., et al. MAX inactivation in small cell lung cancer disrupts MYC-SWI/SNF programs and is synthetic lethal with BRG1. Cancer Discov 2014, 4, 292-303, doi:10.1158/2159-8290.CD-13-0799.

156. Wang, D.; Hashimoto, H.; Zhang, X.; Barwick, B.G.; Lonial, S.; Boise, L.H.; Vertino, P.M.; Cheng, X. MAX is an epigenetic sensor of 5-carboxylcytosine and is altered in multiple myeloma. Nucleic Acids Res 2017, 45, 2396-2407, doi:10.1093/nar/gkw1184. 
157. Prendergast, G.C.; Lawe, D.; Ziff, E.B. Association of Myn, the murine homolog of max, with c-Myc stimulates methylation-sensitive DNA binding and ras cotransformation. Cell 1991, 65, 395-407, doi:10.1016/0092-8674(91)90457-a.

158. Mathsyaraja, H.; Freie, B.; Cheng, P.F.; Babaeva, E.; Catchpole, J.T.; Janssens, D.; Henikoff, S.; Eisenman, R.N. Max deletion destabilizes MYC protein and abrogates Emicro-Myc lymphomagenesis. Genes Dev 2019, 33, 1252-1264, doi:10.1101/gad.325878.119.

159. Thomas, L.R.; Wang, Q.; Grieb, B.C.; Phan, J.; Foshage, A.M.; Sun, Q.; Olejniczak, E.T.; Clark, T.; Dey, S.; Lorey, S., et al. Interaction with WDR5 promotes target gene recognition and tumorigenesis by MYC. Mol Cell 2015, 58, 440-452, doi:10.1016/j.molcel.2015.02.028.

160. Thomas, L.R.; Adams, C.M.; Wang, J.; Weissmiller, A.M.; Creighton, J.; Lorey, S.L.; Liu, Q.; Fesik, S.W.; Eischen, C.M.; Tansey, W.P. Interaction of the oncoprotein transcription factor MYC with its chromatin cofactor WDR5 is essential for tumor maintenance. Proc Natl Acad Sci U S A 2019, 116, 25260-25268, doi:10.1073/pnas.1910391116.

161. Dammert, M.A.; Bragelmann, J.; Olsen, R.R.; Bohm, S.; Monhasery, N.; Whitney, C.P.; Chalishazar, M.D.; Tumbrink, H.L.; Guthrie, M.R.; Klein, S., et al. MYC paralog-dependent apoptotic priming orchestrates a spectrum of vulnerabilities in small cell lung cancer. Nat Commun 2019, 10, 3485, doi:10.1038/s41467019-11371-x.

162. McFadden, D.G.; Papagiannakopoulos, T.; Taylor-Weiner, A.; Stewart, C.; Carter, S.L.; Cibulskis, K.; Bhutkar, A.; McKenna, A.; Dooley, A.; Vernon, A., et al. Genetic and clonal dissection of murine small cell lung carcinoma progression by genome sequencing. Cell 2014, 156, 1298-1311, doi:10.1016/j.cell.2014.02.031.

163. Mollaoglu, G.; Guthrie, M.R.; Bohm, S.; Bragelmann, J.; Can, I.; Ballieu, P.M.; Marx, A.; George, J.; Heinen, C.; Chalishazar, M.D., et al. MYC Drives Progression of Small Cell Lung Cancer to a Variant Neuroendocrine Subtype with Vulnerability to Aurora Kinase Inhibition. Cancer Cell 2017, 31, 270-285, doi:10.1016/j.ccell.2016.12.005.

164. Augert, A.; Mathsyaraja, H.; Ibrahim, A.H.; Freie, B.; Geuenich, M.J.; Cheng, P.F.; Alibeckoff, S.P.; Wu, N.; Hiatt, J.B.; Basom, R., et al. MAX Functions as a Tumor Suppressor and Rewires Metabolism in Small Cell Lung Cancer. Cancer Cell 2020, 38, 97-114 e117, doi:10.1016/j.ccell.2020.04.016.

165. Meuwissen, R.; Linn, S.C.; Linnoila, R.I.; Zevenhoven, J.; Mooi, W.J.; Berns, A. Induction of small cell lung cancer by somatic inactivation of both Trp53 and Rb1 in a conditional mouse model. Cancer Cell 2003, 4, 181-189, doi:Doi 10.1016/S1535-6108(03)00220-4.

166. Chin, L.; Schreiber-Agus, N.; Pellicer, I.; Chen, K.; Lee, H.W.; Dudast, M.; Cordon-Cardo, C.; DePinho, R.A. Contrasting roles for Myc and Mad proteins in cellular growth and differentiation. Proc Natl Acad Sci U S A 1995, 92, 8488-8492, doi:10.1073/pnas.92.18.8488.

167. Vastrik, I.; Kaipainen, A.; Penttila, T.L.; Lymboussakis, A.; Alitalo, R.; Parvinen, M.; Alitalo, K. Expression of the mad gene during cell differentiation in vivo and its inhibition of cell growth in vitro. J Cell Biol 1995, 128, 1197-1208, doi:10.1083/jcb.128.6.1197.

168. O'Hagan, R.C.; Schreiber-Agus, N.; Chen, K.; David, G.; Engelman, J.A.; Schwab, R.; Alland, L.; Thomson, C.; Ronning, D.R.; Sacchettini, J.C., et al. Gene-target recognition among members of the myc superfamily and implications for oncogenesis. Nat Genet 2000, 24, 113-119, doi:10.1038/72761.

169. Han, S.; Park, K.; Kim, H.Y.; Lee, M.S.; Kim, H.J.; Kim, Y.D. Expression of Mad1 protein inhibits proliferation of cancer cells and inversely correlated with Myc protein expression in primary gastric cancer. Oncol Rep 1999, 6, 569-574, doi:10.3892/or.6.3.569.

170. Han, S.; Park, K.; Kim, H.Y.; Lee, M.S.; Kim, H.J.; Kim, Y.D.; Yuh, Y.J.; Kim, S.R.; Suh, H.S. Clinical implication of altered expression of Mad1 protein in human breast carcinoma. Cancer 2000, 88, 1623-1632, doi:10.1002/(sici)1097-0142(20000401)88:7<1623::aid-cncr17>3.0.co;2-w.

171. Zou, L.; Zhang, P.; Luo, C.; Tu, Z. Mad1 suppresses bladder cancer cell proliferation by inhibiting human telomerase reverse transcriptase transcription and telomerase activity. Urology 2006, 67, 1335-1340, doi:10.1016/j.urology.2005.12.029.

172. Chou, C.K.; Lee, D.F.; Sun, H.L.; Li, L.Y.; Lin, C.Y.; Huang, W.C.; Hsu, J.M.; Kuo, H.P.; Yamaguchi, H.; Wang, Y.N., et al. The suppression of MAD1 by AKT-mediated phosphorylation activates MAD1 target genes transcription. Mol Carcinog 2009, 48, 1048-1058, doi:10.1002/mc.20557. 
173. Guo, X.L.; Pan, L.; Zhang, X.J.; Suo, X.H.; Niu, Z.Y.; Zhang, J.Y.; Wang, F.; Dong, Z.R.; Da, W.; Ohno, R. Expression and mutation analysis of genes that encode the Myc antagonists Mad1, Mxi1 and Rox in acute leukaemia. Leuk Lymphoma 2007, 48, 1200-1207, doi:10.1080/10428190701342018.

174. Brunet, A.; Bonni, A.; Zigmond, M.J.; Lin, M.Z.; Juo, P.; Hu, L.S.; Anderson, M.J.; Arden, K.C.; Blenis, J.; Greenberg, M.E. Akt promotes cell survival by phosphorylating and inhibiting a Forkhead transcription factor. Cell 1999, 96, 857-868, doi:10.1016/s0092-8674(00)80595-4.

175. Poomakkoth, N.; Issa, A.; Abdulrahman, N.; Abdelaziz, S.G.; Mraiche, F. p90 ribosomal S6 kinase: a potential therapeutic target in lung cancer. J Transl Med 2016, 14, 14, doi:10.1186/s12967-016-0768-1.

176. Sahin, F.; Kannangai, R.; Adegbola, O.; Wang, J.; Su, G.; Torbenson, M. mTOR and P70 S6 kinase expression in primary liver neoplasms. Clin Cancer Res 2004, 10, 8421-8425, doi:10.1158/10780432.CCR-04-0941.

177. Sulzmaier, F.J.; Ramos, J.W. RSK isoforms in cancer cell invasion and metastasis. Cancer Res 2013, 73, 6099-6105, doi:10.1158/0008-5472.CAN-13-1087.

178. Zhu, J.; Blenis, J.; Yuan, J. Activation of PI3K/Akt and MAPK pathways regulates Myc-mediated transcription by phosphorylating and promoting the degradation of Mad1. Proc Natl Acad Sci U S A 2008, 105, 6584-6589, doi:10.1073/pnas.0802785105.

179. Yin, X.; Landay, M.F.; Han, W.; Levitan, E.S.; Watkins, S.C.; Levenson, R.M.; Farkas, D.L.; Prochownik, E.V. Dynamic in vivo interactions among Myc network members. Oncogene 2001, 20, 4650-4664, doi:10.1038/sj.onc.1204606.

180. Xing, Y.; Johnson, C.V.; Dobner, P.R.; Lawrence, J.B. Higher level organization of individual gene transcription and RNA splicing. Science 1993, 259, 1326-1330, doi:10.1126/science.8446901.

181. Xing, Y.; Johnson, C.V.; Moen, P.T., Jr.; McNeil, J.A.; Lawrence, J. Nonrandom gene organization: structural arrangements of specific pre-mRNA transcription and splicing with SC-35 domains. J Cell Biol 1995, 131, 1635-1647, doi:10.1083/jcb.131.6.1635.

182. Smith, K.P.; Moen, P.T.; Wydner, K.L.; Coleman, J.R.; Lawrence, J.B. Processing of endogenous premRNAs in association with SC-35 domains is gene specific. J Cell Biol 1999, 144, 617-629, doi:10.1083/jcb.144.4.617.

183. Gomez-Roman, N.; Felton-Edkins, Z.A.; Kenneth, N.S.; Goodfellow, S.J.; Athineos, D.; Zhang, J.; Ramsbottom, B.A.; Innes, F.; Kantidakis, T.; Kerr, E.R., et al. Activation by c-Myc of transcription by RNA polymerases I, II and III. Biochem Soc Symp 2006, 73, 141-154, doi:10.1042/bss0730141.

184. Grandori, C.; Gomez-Roman, N.; Felton-Edkins, Z.A.; Ngouenet, C.; Galloway, D.A.; Eisenman, R.N.; White, R.J. c-Myc binds to human ribosomal DNA and stimulates transcription of rRNA genes by RNA polymerase I. Nat Cell Biol 2005, 7, 311-318, doi:10.1038/ncb1224.

185. Lafita-Navarro, M.C.; Blanco, R.; Mata-Garrido, J.; Liano-Pons, J.; Tapia, O.; Garcia-Gutierrez, L.; GarciaAlegria, E.; Berciano, M.T.; Lafarga, M.; Leon, J. MXD1 localizes in the nucleolus, binds UBF and impairs rRNA synthesis. Oncotarget 2016, 7, 69536-69548, doi:10.18632/oncotarget.11766.

186. McStay, B.; Grummt, I. The epigenetics of rRNA genes: from molecular to chromosome biology. Annu Rev Cell Dev Biol 2008, 24, 131-157, doi:10.1146/annurev.cellbio.24.110707.175259.

187. Koberna, K.; Malinsky, J.; Pliss, A.; Masata, M.; Vecerova, J.; Fialova, M.; Bednar, J.; Raska, I. Ribosomal genes in focus: new transcripts label the dense fibrillar components and form clusters indicative of "Christmas trees" in situ. J Cell Biol 2002, 157, 743-748, doi:10.1083/jcb.200202007.

188. Boisvert, F.M.; van Koningsbruggen, S.; Navascues, J.; Lamond, A.I. The multifunctional nucleolus. Nat Rev Mol Cell Biol 2007, 8, 574-585, doi:10.1038/nrm2184.

189. Moss, T.; Langlois, F.; Gagnon-Kugler, T.; Stefanovsky, V. A housekeeper with power of attorney: the rRNA genes in ribosome biogenesis. Cell Mol Life Sci 2007, 64, 29-49, doi:10.1007/s00018-006-6278-1.

190. Perry, R.P.; Kelley, D.E. Inhibition of RNA synthesis by actinomycin D: characteristic dose-response of different RNA species. J Cell Physiol 1970, 76, 127-139, doi:10.1002/jcp.1040760202.

191. Shiue, C.N.; Nematollahi-Mahani, A.; Wright, A.P. Myc-induced anchorage of the rDNA IGS region to nucleolar matrix modulates growth-stimulated changes in higher-order rDNA architecture. Nucleic Acids Res 2014, 42, 5505-5517, doi:10.1093/nar/gku183.

192. Castellano, L.; Giamas, G.; Jacob, J.; Coombes, R.C.; Lucchesi, W.; Thiruchelvam, P.; Barton, G.; Jiao, L.R.; Wait, R.; Waxman, J., et al. The estrogen receptor-alpha-induced microRNA signature regulates itself and 
its transcriptional response. Proc Natl Acad Sci $U$ S A 2009, 106, 15732-15737, doi:10.1073/pnas.0906947106.

193. Hayashita, Y.; Osada, H.; Tatematsu, Y.; Yamada, H.; Yanagisawa, K.; Tomida, S.; Yatabe, Y.; Kawahara, K.; Sekido, Y.; Takahashi, T. A polycistronic microRNA cluster, miR-17-92, is overexpressed in human lung cancers and enhances cell proliferation. Cancer Res 2005, 65, 9628-9632, doi:10.1158/0008-5472.CAN05-2352.

194. Hu, W.; Jin, P.; Ding, C.; Liu, W. miR-19a/b modulates lung cancer cells metastasis through suppression of MXD1 expression. Oncol Lett 2016, 12, 1901-1905, doi:10.3892/ol.2016.4881.

195. Lanza, G.; Ferracin, M.; Gafa, R.; Veronese, A.; Spizzo, R.; Pichiorri, F.; Liu, C.G.; Calin, G.A.; Croce, C.M.; Negrini, M. mRNA/microRNA gene expression profile in microsatellite unstable colorectal cancer. Mol Cancer 2007, 6, 54, doi:10.1186/1476-4598-6-54.

196. Mestdagh, P.; Fredlund, E.; Pattyn, F.; Schulte, J.H.; Muth, D.; Vermeulen, J.; Kumps, C.; Schlierf, S.; De Preter, K.; Van Roy, N., et al. MYCN/c-MYC-induced microRNAs repress coding gene networks associated with poor outcome in MYCN/c-MYC-activated tumors. Oncogene 2010, 29, 1394-1404, doi:10.1038/onc.2009.429.

197. O'Donnell, K.A.; Wentzel, E.A.; Zeller, K.I.; Dang, C.V.; Mendell, J.T. c-Myc-regulated microRNAs modulate E2F1 expression. Nature 2005, 435, 839-843, doi:10.1038/nature03677.

198. Plum, P.S.; Warnecke-Eberz, U.; Drebber, U.; Chon, S.H.; Alakus, H.; Holscher, A.H.; Quaas, A.; Bruns, C.J.; Gockel, I.; Lorenz, D., et al. Upregulation of miR-17-92 cluster is associated with progression and lymph node metastasis in oesophageal adenocarcinoma. Sci Rep 2019, 9, 12113, doi:10.1038/s41598-01948624-0.

199. Rinaldi, A.; Poretti, G.; Kwee, I.; Zucca, E.; Catapano, C.V.; Tibiletti, M.G.; Bertoni, F. Concomitant MYC and microRNA cluster miR-17-92 (C13orf25) amplification in human mantle cell lymphoma. Leuk Lymphoma 2007, 48, 410-412, doi:10.1080/10428190601059738.

200. Sandhu, S.K.; Fassan, M.; Volinia, S.; Lovat, F.; Balatti, V.; Pekarsky, Y.; Croce, C.M. B-cell malignancies in microRNA Emu-miR-17 92 transgenic mice. Proc Natl Acad Sci U S A 2013, 110, 18208-18213, doi:10.1073/pnas.1315365110.

201. Wang, H.; Lu, J.; Mandel, J.A.; Zhang, W.; Schwalbe, M.; Gorka, J.; Liu, Y.; Marburger, B.; Wang, J.; Ranganathan, S., et al. Patient-Derived Mutant Forms of NFE2L2/NRF2 Drive Aggressive Murine Hepatoblastomas. Cell Mol Gastroenterol Hepatol 2021, 12, 199-228, doi:10.1016/j.jcmgh.2021.02.004.

202. Yan, S.; Jia, C.; Quan, L.; Zhao, L.; Tian, Y.; Liu, A. Significance of the microRNA1792 gene cluster expressed in Bcell nonHodgkin's lymphoma. Mol Med Rep 2019, 20, 2459-2467, doi:10.3892/mmr.2019.10448.

203. Wu, Q.; Yang, Z.; An, Y.; Hu, H.; Yin, J.; Zhang, P.; Nie, Y.; Wu, K.; Shi, Y.; Fan, D. MiR-19a/b modulate the metastasis of gastric cancer cells by targeting the tumour suppressor MXD1. Cell Death Dis 2014, 5, e1144, doi:10.1038/cddis.2014.110.

204. Ji, M.; Rao, E.; Ramachandrareddy, H.; Shen, Y.; Jiang, C.; Chen, J.; Hu, Y.; Rizzino, A.; Chan, W.C.; Fu, K., et al. The miR-17-92 microRNA cluster is regulated by multiple mechanisms in B-cell malignancies. Am J Pathol 2011, 179, 1645-1656, doi:10.1016/j.ajpath.2011.06.008.

205. Cho, K.; Shin, H.W.; Kim, Y.I.; Cho, C.H.; Chun, Y.S.; Kim, T.Y.; Park, J.W. Mad1 mediates hypoxia-induced doxorubicin resistance in colon cancer cells by inhibiting mitochondrial function. Free Radic Biol Med 2013, 60, 201-210, doi:10.1016/j.freeradbiomed.2013.02.022.

206. Muz, B.; de la Puente, P.; Azab, F.; Azab, A.K. The role of hypoxia in cancer progression, angiogenesis, metastasis, and resistance to therapy. Hypoxia (Auckl) 2015, 3, 83-92, doi:10.2147/HP.S93413.

207. Pradhan, S.; Mahajan, D.; Kaur, P.; Pandey, N.; Sharma, C.; Srivastava, T. Scriptaid overcomes hypoxiainduced cisplatin resistance in both wild-type and mutant p53 lung cancer cells. Oncotarget 2016, 7, 71841-71855, doi:10.18632/oncotarget.12378.

208. Shin, D.H.; Choi, Y.J.; Park, J.W. SIRT1 and AMPK mediate hypoxia-induced resistance of non-small cell lung cancers to cisplatin and doxorubicin. Cancer Res 2014, 74, 298-308, doi:10.1158/0008-5472.CAN13-2620.

209. Zhao, W.; Xia, S.Q.; Zhuang, J.P.; Zhang, Z.P.; You, C.C.; Yan, J.L.; Xu, G.P. Hypoxia-induced resistance to cisplatin-mediated apoptosis in osteosarcoma cells is reversed by gambogic acid independently of HIF1alpha. Mol Cell Biochem 2016, 420, 1-8, doi:10.1007/s11010-016-2759-1. 
210. Zhu, P.; Ning, Y.; Yao, L.; Chen, M.; Xu, C. The proliferation, apoptosis, invasion of endothelial-like epithelial ovarian cancer cells induced by hypoxia. J Exp Clin Cancer Res 2010, 29, 124, doi:10.1186/1756-9966-29-124.

211. Zheng, D.; Wu, W.; Dong, N.; Jiang, X.; Xu, J.; Zhan, X.; Zhang, Z.; Hu, Z. Mxd1 mediates hypoxia-induced cisplatin resistance in osteosarcoma cells by repression of the PTEN tumor suppressor gene. Mol Carcinog 2017, 56, 2234-2244, doi:10.1002/mc.22676.

212. Zheng, Y.; Lin, Z.Y.; Xie, J.J.; Jiang, F.N.; Chen, C.J.; Li, J.X.; Zhou, X.; Zhong, W.D. ARRDC3 Inhibits the Progression of Human Prostate Cancer Through ARRDC3-ITGbeta4 Pathway. Curr Mol Med 2017, 17, 221-229, doi:10.2174/1566524017666170807144711.

213. Zervos, A.S.; Gyuris, J.; Brent, R. Mxi1, a Protein That Specifically Interacts with Max to Bind Myc-Max Recognition Sites. Cell 1993, 72, 223-232, doi:Doi 10.1016/0092-8674(93)90662-A.

214. Albarosa, R.; DiDonato, S.; Finocchiaro, G. Redefinition of the coding sequence of the MXI1 gene and identification of a polymorphic repeat in the 3 ' non-coding region that allows the detection of loss of heterozygosity of chromosome 10q25 in glioblastomas. Hum Genet 1995, 95, 709-711, doi:10.1007/BF00209493.

215. Ariyanayagam-Baksh, S.M.; Baksh, F.K.; Swalsky, P.A.; Finkelstein, S.D. Loss of heterozygosity in the MXI1 gene is a frequent occurrence in melanoma. Mod Pathol 2003, 16, 992-995, doi:10.1097/01.MP.0000087421.44975.1C.

216. Edelhoff, S.; Sweetser, D.A.; Disteche, C.M. Mapping of the NEP receptor tyrosine kinase gene to human chromosome 6p21.3 and mouse chromosome 17C. Genomics 1995, 25, 309-311, doi:10.1016/08887543(95)80144-b.

217. Gray, I.C.; Stewart, L.M.; Phillips, S.M.; Hamilton, J.A.; Gray, N.E.; Watson, G.J.; Spurr, N.K.; Snary, D. Mutation and expression analysis of the putative prostate tumour-suppressor gene PTEN. Br J Cancer 1998, 78, 1296-1300, doi:10.1038/bjc.1998.674.

218. Kim, S.K.; Ro, J.Y.; Kemp, B.L.; Lee, J.S.; Kwon, T.J.; Hong, W.K.; Mao, L. Identification of two distinct tumor-suppressor loci on the long arm of chromosome 10 in small cell lung cancer. Oncogene 1998, 17, 1749-1753, doi:10.1038/sj.onc.1202073.

219. Lacombe, L.; Orlow, I.; Reuter, V.E.; Fair, W.R.; Dalbagni, G.; Zhang, Z.F.; Cordon-Cardo, C. Microsatellite instability and deletion analysis of chromosome 10 in human prostate cancer. Int J Cancer 1996, 69, 110113, doi:10.1002/(SICI)1097-0215(19960422)69:2<110::AID-IJC7>3.0.CO;2-3.

220. Lazcoz, P.; Munoz, J.; Nistal, M.; Pestana, A.; Encio, I.J.; Castresana, J.S. Loss of heterozygosity and microsatellite instability on chromosome arm 10q in neuroblastoma. Cancer Genet Cytogenet 2007, 174, 1-8, doi:10.1016/j.cancergencyto.2006.08.014.

221. Matsuyama, H.; Pan, Y.; Yoshihiro, S.; Kudren, D.; Naito, K.; Bergerheim, U.S.; Ekman, P. Clinical significance of chromosome 8p, 10q, and 16q deletions in prostate cancer. Prostate 2003, 54, 103-111, doi:10.1002/pros.10173.

222. Morita, R.; Saito, S.; Ishikawa, J.; Ogawa, O.; Yoshida, O.; Yamakawa, K.; Nakamura, Y. Common regions of deletion on chromosomes 5q, 6q, and 10q in renal cell carcinoma. Cancer Res 1991, 51, 5817-5820.

223. Scott, D.K.; Straughton, D.; Cole, M.; Bailey, S.; Ellison, D.W.; Clifford, S.C. Identification and analysis of tumor suppressor loci at chromosome 10q23.3-10q25.3 in medulloblastoma. Cell Cycle 2006, 5, 23812389, doi:10.4161/cc.5.20.3360.

224. Prochownik, E.V.; Grove, L.E.; Deubler, D.; Zhu, X.L.; Stephenson, R.A.; Rohr, L.R.; Yin, X.; Brothman, A.R. Commonly occurring loss and mutation of theMXI1 gene in prostate cancer. Genes, Chromosomes and Cancer 1998, 22, 295-304, doi:10.1002/(sici)1098-2264(199808)22:4<295::Aid-gcc5>3.0.Co;2-q.

225. Shapiro, D.N.; Valentine, V.; Eagle, L.; Yin, X.; Morris, S.W.; Prochownik, E.V. Assignment of the human MAD and MXI1 genes to chromosomes 2p12-p13 and 10q24-q25. Genomics 1994, 23, 282-285, doi:10.1006/geno.1994.1496.

226. Simon, M.; Kokkino, A.J.; Warnick, R.E.; Tew, J.M., Jr.; von Deimling, A.; Menon, A.G. Role of genomic instability in meningioma progression. Genes Chromosomes Cancer 1996, 16, 265-269, doi:10.1002/(SICI)1098-2264(199608)16:4<265::AID-GCC7>3.0.CO;2-W.

227. Wechsler, D.S.; Shelly, C.A.; Dang, C.V. Genomic organization of human MXI1, a putative tumor suppressor gene. Genomics 1996, 32, 466-470, doi:10.1006/geno.1996.0144. 
228. Eagle, L.R.; Yin, X.; Brothman, A.R.; Williams, B.J.; Atkin, N.B.; Prochownik, E.V. Mutation of the MXI1 gene in prostate cancer. Nat Genet 1995, 9, 249-255, doi:10.1038/ng0395-249.

229. Kawamata, N.; Park, D.; Wilczynski, S.; Yokota, J.; Koeffler, H.P. Point mutations of the Mxil gene are rare in prostate cancers. Prostate 1996, 29, 191-193, doi:10.1002/1097-0045(199609)29:3<191::aidpros2990290305>3.0.co;2-1.

230. Li, X.J.; Wang, D.Y.; Zhu, Y.; Guo, R.J.; Wang, X.D.; Lubomir, K.; Mukai, K.; Sasaki, H.; Yoshida, H.; Oka, T., et al. Mxi1 mutations in human neurofibrosarcomas. Jpn J Cancer Res 1999, 90, 740-746, doi:10.1111/j.1349-7006.1999.tb00809.x.

231. Kuczyk, M.A.; Serth, J.; Bokemeyer, C.; Schwede, J.; Herrmann, R.; Machtens, S.; Grünewald, V.; Höfner, K.; Jonas, U. The MXI1 tumor suppressor gene is not mutated in primary prostate cancer. Oncology Reports 1998, 10.3892/or.5.1.213, doi:10.3892/or.5.1.213.

232. Long, Q.; Xu, J.; Osunkoya, A.O.; Sannigrahi, S.; Johnson, B.A.; Zhou, W.; Gillespie, T.; Park, J.Y.; Nam, R.K.; Sugar, L., et al. Global transcriptome analysis of formalin-fixed prostate cancer specimens identifies biomarkers of disease recurrence. Cancer Res 2014, 74, 3228-3237, doi:10.1158/0008-5472.CAN-132699.

233. Rao, U.N.; Bakker, A.; Swalsky, P.A.; Finkelstein, S.D. Max interacting protein 1: loss of heterozygosity is frequent in desmoplastic melanoma. Mod Pathol 1999, 12, 344-350.

234. Fults, D.; Pedone, C.A.; Thompson, G.E.; Uchiyama, C.M.; Gumpper, K.L.; Iliev, D.; Vinson, V.L.; Tavtigian, S.V.; Perry, W.L., 3rd. Microsatellite deletion mapping on chromosome $10 \mathrm{q}$ and mutation analysis of MMAC1, FAS, and MXI1 in human glioblastoma multiforme. Int J Oncol 1998, 12, 905-910, doi:10.3892/ijo.12.4.905.

235. Wang, D.Y.; Xiang, Y.Y.; Li, X.J.; Hashimoto, M.; Tanaka, M.; Sugimura, H. Mxi1 is a potential cellular target of carcinogens and frequently mutated in experimental rat tumors and tumor cell lines. Pathol Int 2000, 50, 373-383, doi:10.1046/j.1440-1827.2000.01057.x.

236. Johnson, A.F.; Nguyen, H.T.; Veitia, R.A. Causes and effects of haploinsufficiency. Biol Rev Camb Philos Soc 2019, 94, 1774-1785, doi:10.1111/brv.12527.

237. Sedic, M.; Kuperwasser, C. BRCA1-hapoinsufficiency: Unraveling the molecular and cellular basis for tissue-specific cancer. Cell Cycle 2016, 15, 621-627, doi:10.1080/15384101.2016.1141841.

238. Schreiber-Agus, N.; Meng, Y.; Hoang, T.; Hou, H., Jr.; Chen, K.; Greenberg, R.; Cordon-Cardo, C.; Lee, H.W.; DePinho, R.A. Role of Mxi1 in ageing organ systems and the regulation of normal and neoplastic growth. Nature 1998, 393, 483-487, doi:10.1038/31008.

239. Kurbegovic, A.; Trudel, M. The master regulators Myc and p53 cellular signaling and functions in polycystic kidney disease. Cell Signal 2020, 71, 109594, doi:10.1016/j.cellsig.2020.109594.

240. Yoo, K.H.; Sung, Y.H.; Yang, M.H.; Jeon, J.O.; Yook, Y.J.; Woo, Y.M.; Lee, H.W.; Park, J.H. Inactivation of Mxi1 induces II-8 secretion activation in polycystic kidney. Biochem Biophys Res Commun 2007, 356, 8590, doi:10.1016/j.bbrc.2007.02.103.

241. Grantham, J.J.; Ye, M.; Davidow, C.; Holub, B.; Sharma, M. Evidence for a potent lipid secretagogue in the cyst fluids of patients with autosomal dominant polycystic kidney disease. J Am Soc Nephrol 1995, 6, 1242-1249, doi:10.1681/ASN.V641242.

242. Nichols, M.T.; Gidey, E.; Matzakos, T.; Dahl, R.; Stiegmann, G.; Shah, R.J.; Grantham, J.J.; Gregory Fitz, J.; Brian, R. Secretion of cytokines and growth factors into autosomal dominant polycystic kidney disease liver cyst fluid. Hepatology 2004, 40, 836-846, doi:10.1002/hep.1840400413.

243. Lubarsky, B.; Krasnow, M.A. Tube morphogenesis: making and shaping biological tubes. Cell 2003, 112, 19-28, doi:10.1016/s0092-8674(02)01283-7.

244. Song, S.A.; Yoo, K.H.; Ko, J.Y.; Kim, B.H.; Yook, Y.J.; Park, J.H. Over-expression of Mxi1 represses renal epithelial tubulogenesis through the reduction of matrix metalloproteinase 9. Biochem Biophys Res Commun 2012, 419, 459-465, doi:10.1016/j.bbrc.2012.02.002.

245. Liu, Z.; Greco, A.J.; Hellman, N.E.; Spector, J.; Robinson, J.; Tang, O.T.; Lipschutz, J.H. Intracellular signaling via ERK/MAPK completes the pathway for tubulogenic fibronectin in MDCK cells. Biochem Biophys Res Commun 2007, 353, 793-798, doi:10.1016/j.bbrc.2006.12.106.

246. Ye, P.; Habib, S.L.; Ricono, J.M.; Kim, N.H.; Choudhury, G.G.; Barnes, J.L.; Abboud, H.E.; Arar, M.Y. Fibronectin induces ureteric bud cells branching and cellular cord and tubule formation. Kidney Int 2004, 66, 1356-1364, doi:10.1111/j.1523-1755.2004.00897.x. 
247. Hydbring, P.; Larsson, L.G. Cdk2: a key regulator of the senescence control function of Myc. Aging (Albany NY) 2010, 2, 244-250, doi:10.18632/aging.100140.

248. Hydbring, P.; Castell, A.; Larsson, L.G. MYC Modulation around the CDK2/p27/SKP2 Axis. Genes (Basel) 2017, 8, 174, doi:10.3390/genes8070174.

249. Lee, T.C.; Ziff, E.B. Mxi1 is a repressor of the c-Myc promoter and reverses activation by USF. J Biol Chem 1999, 274, 595-606, doi:10.1074/jbc.274.2.595.

250. Taj, M.M.; Tawil, R.J.; Engstrom, L.D.; Zeng, Z.; Hwang, C.; Sanda, M.G.; Wechsler, D.S. Mxi1, a Myc antagonist, suppresses proliferation of DU145 human prostate cells. Prostate 2001, 47, 194-204, doi:10.1002/pros.1063.

251. Manni, I.; Tunici, P.; Cirenei, N.; Albarosa, R.; Colombo, B.M.; Roz, L.; Sacchi, A.; Piaggio, G.; Finocchiaro, G. Mxi1 inhibits the proliferation of U87 glioma cells through down-regulation of cyclin B1 gene expression. Br J Cancer 2002, 86, 477-484, doi:10.1038/sj.bjc.6600065.

252. Yin, X.Y.; Grove, L.; Datta, N.S.; Long, M.W.; Prochownik, E.V. C-myc overexpression and p53 loss cooperate to promote genomic instability. Oncogene 1999, 18, 1177-1184, doi:10.1038/sj.onc.1202410.

253. Prochownik, E.V. c-Myc: linking transformation and genomic instability. Curr Mol Med 2008, 8, 446-458, doi:10.2174/156652408785747988.

254. Ganem, N.J.; Storchova, Z.; Pellman, D. Tetraploidy, aneuploidy and cancer. Curr Opin Genet Dev 2007, 17, 157-162, doi:10.1016/j.gde.2007.02.011.

255. Hayashi, M.T.; Karlseder, J. DNA damage associated with mitosis and cytokinesis failure. Oncogene 2013, 32, 4593-4601, doi:10.1038/onc.2012.615.

256. Margolis, R.L. Tetraploidy and tumor development. Cancer Cell 2005, 8, 353-354, doi:10.1016/j.ccr.2005.10.017.

257. Potapova, T.A.; Zhu, J.; Li, R. Aneuploidy and chromosomal instability: a vicious cycle driving cellular evolution and cancer genome chaos. Cancer Metastasis Rev 2013, 32, 377-389, doi:10.1007/s10555-0139436-6.

258. Juergens, K.; Rust, B.; Pieler, T.; Henningfeld, K.A. Isolation and comparative expression analysis of the Myc-regulatory proteins Mad1, Mad3, and Mnt during Xenopus development. Dev Dyn 2005, 233, 15541559, doi:10.1002/dvdy.20470.

259. Kenney, A.M.; Cole, M.D.; Rowitch, D.H. Nmyc upregulation by sonic hedgehog signaling promotes proliferation in developing cerebellar granule neuron precursors. Development 2003, 130, 15-28, doi:10.1242/dev.00182.

260. Li, P.; Du, F.; Yuelling, L.W.; Lin, T.; Muradimova, R.E.; Tricarico, R.; Wang, J.; Enikolopov, G.; Bellacosa, A.; Wechsler-Reya, R.J., et al. A population of Nestin-expressing progenitors in the cerebellum exhibits increased tumorigenicity. Nat Neurosci 2013, 16, 1737-1744, doi:10.1038/nn.3553.

261. Oliver, T.G.; Grasfeder, L.L.; Carroll, A.L.; Kaiser, C.; Gillingham, C.L.; Lin, S.M.; Wickramasinghe, R.; Scott, M.P.; Wechsler-Reya, R.J. Transcriptional profiling of the Sonic hedgehog response: a critical role for Nmyc in proliferation of neuronal precursors. Proc Natl Acad Sci U S A 2003, 100, 7331-7336, doi:10.1073/pnas.0832317100.

262. Yun, J.S.; Rust, J.M.; Ishimaru, T.; Diaz, E. A novel role of the Mad family member Mad3 in cerebellar granule neuron precursor proliferation. Mol Cell Biol 2007, 27, 8178-8189, doi:10.1128/MCB.00656-06.

263. Fox, E.J.; Wright, S.C. S-phase-specific expression of the Mad3 gene in proliferating and differentiating cells. Biochem J 2001, 359, 361-367, doi:10.1042/0264-6021:3590361.

264. Fox, E.J.; Wright, S.C. The transcriptional repressor gene Mad3 is a novel target for regulation by E2F1. Biochem J 2003, 370, 307-313, doi:10.1042/BJ20021583.

265. Gore, Y.; Lantner, F.; Hart, G.; Shachar, I. Mad3 negatively regulates B cell differentiation in the spleen by inducing Id2 expression. Mol Biol Cell 2010, 21, 1864-1871, doi:10.1091/mbc.E09-09-0813.

266. Barisone, G.A.; Satake, N.; Lewis, C.; Duong, C.; Chen, C.; Lam, K.S.; Nolta, J.; Diotaaz, E. Loss of MXD3 induces apoptosis of Reh human precursor B acute lymphoblastic leukemia cells. Blood Cells Mol Dis 2015, 54, 329-335, doi:10.1016/j.bcmd.2014.12.002.

267. Barisone, G.A.; Yun, J.S.; Diaz, E. From cerebellar proliferation to tumorigenesis: new insights into the role of Mad3. Cell Cycle 2008, 7, 423-427, doi:10.4161/cc.7.4.5413.

268. Ngo, T.; Barisone, G.A.; Lam, K.S.; Diotaaz, E. MXD3 regulation of DAOY cell proliferation dictated by time course of activation. BMC Cell Biol 2014, 15, 30, doi:10.1186/1471-2121-15-30. 
269. Ngo, T.; Corrales, A.; Bourne, T.; Elmojahid, S.; Lam, K.S.; Diaz, E. Alternative Splicing of MXD3 and Its Regulation of MXD3 Levels in Glioblastoma. Front Mol Biosci 2019, 6, 5, doi:10.3389/fmolb.2019.00005.

270. Belle, I.; Zhuang, Y. E proteins in lymphocyte development and lymphoid diseases. Curr Top Dev Biol 2014, 110, 153-187, doi:10.1016/B978-0-12-405943-6.00004-X.

271. Ogiwara, H.; Sasaki, M.; Mitachi, T.; Oike, T.; Higuchi, S.; Tominaga, Y.; Kohno, T. Targeting p300 Addiction in CBP-Deficient Cancers Causes Synthetic Lethality by Apoptotic Cell Death due to Abrogation of MYC Expression. Cancer Discov 2016, 6, 430-445, doi:10.1158/2159-8290.CD-15-0754.

272. de The, H. Differentiation therapy revisited. Nat Rev Cancer 2018, 18, 117-127, doi:10.1038/nrc.2017.103.

273. Pirozzi, C.J.; Yan, H. The implications of IDH mutations for cancer development and therapy. Nat Rev Clin Oncol 2021, 18, 645-661, doi:10.1038/s41571-021-00521-0.

274. Kime, L.; Wright, S.C. Mad4 is regulated by a transcriptional repressor complex that contains Miz-1 and c-Myc. Biochem J 2003, 370, 291-298, doi:10.1042/BJ20021679.

275. Coppola, J.A.; Cole, M.D. Constitutive c-myc oncogene expression blocks mouse erythroleukaemia cell differentiation but not commitment. Nature 1986, 320, 760-763, doi:10.1038/320760a0.

276. Prochownik, E.V.; Kukowska, J. Deregulated expression of c-myc by murine erythroleukaemia cells prevents differentiation. Nature 1986, 322, 848-850, doi:10.1038/322848a0.

277. Boros, K.; Lacaud, G.; Kouskoff, V. The transcription factor Mxd4 controls the proliferation of the first blood precursors at the onset of hematopoietic development in vitro. Exp Hematol 2011, 39, 1090-1100, doi:10.1016/j.exphem.2011.07.007.

278. Mateyak, M.K.; Obaya, A.J.; Sedivy, J.M. c-Myc regulates cyclin D-Cdk4 and -Cdk6 activity but affects cell cycle progression at multiple independent points. Mol Cell Biol 1999, 19, 4672-4683, doi:10.1128/MCB.19.7.4672.

279. Yang, W.; Shen, J.; Wu, M.; Arsura, M.; FitzGerald, M.; Suldan, Z.; Kim, D.W.; Hofmann, C.S.; Pianetti, S.; Romieu-Mourez, R., et al. Repression of transcription of the p27(Kip1) cyclin-dependent kinase inhibitor gene by c-Myc. Oncogene 2001, 20, 1688-1702, doi:10.1038/sj.onc.1204245.

280. Marcotte, R.; Chen, J.M.; Huard, S.; Wang, E. c-Myc creates an activation loop by transcriptionally repressing its own functional inhibitor, hMad4, in young fibroblasts, a loop lost in replicatively senescent fibroblasts. J Cell Biochem 2005, 96, 1071-1085, doi:10.1002/jcb.20503.

281. Meroni, G.; Reymond, A.; Alcalay, M.; Borsani, G.; Tanigami, A.; Tonlorenzi, R.; Lo Nigro, C.; Messali, S.; Zollo, M.; Ledbetter, D.H., et al. Rox, a novel bHLHZip protein expressed in quiescent cells that heterodimerizes with Max, binds a non-canonical E box and acts as a transcriptional repressor. EMBO J 1997, 16, 2892-2906, doi:10.1093/emboj/16.10.2892.

282. Wahlström, T.; Henriksson, M. Mnt Takes Control as Key Regulator of the Myc/Max/Mxd Network. In Advances in Cancer Research, Elsevier: 2007; 10.1016/s0065-230x(06)97003-1pp 61-80.

283. Lafita-Navarro, M.C.; Liano-Pons, J.; Quintanilla, A.; Varela, I.; Blanco, R.; Ourique, F.; Bretones, G.; Aresti, J.; Molina, E.; Carroll, P., et al. The MNT transcription factor autoregulates its expression and supports proliferation in MYC-associated factor X (MAX)-deficient cells. J Biol Chem 2020, 295, 2001-2017, doi:10.1074/jbc.RA119.010389.

284. Popov, N.; Wahlstrom, T.; Hurlin, P.J.; Henriksson, M. Mnt transcriptional repressor is functionally regulated during cell cycle progression. Oncogene 2005, 24, 8326-8337, doi:10.1038/sj.onc.1208961.

285. Nilsson, J.A.; Maclean, K.H.; Keller, U.B.; Pendeville, H.; Baudino, T.A.; Cleveland, J.L. Mnt loss triggers Myc transcription targets, proliferation, apoptosis, and transformation. Mol Cell Biol 2004, 24, 15601569, doi:10.1128/MCB.24.4.1560-1569.2004.

286. Evan, G.I.; Littlewood, T.D. The role of c-myc in cell growth. Curr Opin Genet Dev 1993, 3, 44-49, doi:10.1016/s0959-437x(05)80339-9.

287. Pelengaris, S.; Khan, M.; Evan, G. c-MYC: more than just a matter of life and death. Nat Rev Cancer 2002, 2, 764-776, doi:10.1038/nrc904.

288. Zhuang, D.; Mannava, S.; Grachtchouk, V.; Tang, W.H.; Patil, S.; Wawrzyniak, J.A.; Berman, A.E.; Giordano, T.J.; Prochownik, E.V.; Soengas, M.S., et al. C-MYC overexpression is required for continuous suppression of oncogene-induced senescence in melanoma cells. Oncogene 2008, 27, 6623-6634, doi:10.1038/onc.2008.258. 
289. Dezfouli, S.; Bakke, A.; Huang, J.; Wynshaw-Boris, A.; Hurlin, P.J. Inflammatory disease and lymphomagenesis caused by deletion of the Myc antagonist Mnt in T cells. Mol Cell Biol 2006, 26, 20802092, doi:10.1128/MCB.26.6.2080-2092.2006.

290. Felsher, D.W.; Bishop, J.M. Reversible tumorigenesis by MYC in hematopoietic lineages. Mol Cell 1999, 4, 199-207, doi:10.1016/s1097-2765(00)80367-6.

291. Link, J.M.; Ota, S.; Zhou, Z.Q.; Daniel, C.J.; Sears, R.C.; Hurlin, P.J. A critical role for Mnt in Myc-driven Tcell proliferation and oncogenesis. Proc Natl Acad Sci U S A 2012, 109, 19685-19690, doi:10.1073/pnas.1206406109.

292. Campbell, K.J.; Vandenberg, C.J.; Anstee, N.S.; Hurlin, P.J.; Cory, S. Mnt modulates Myc-driven lymphomagenesis. Cell Death Differ 2017, 24, 2117-2126, doi:10.1038/cdd.2017.131.

293. Smith, D.P.; Bath, M.L.; Harris, A.W.; Cory, S. T-cell lymphomas mask slower developing B-lymphoid and myeloid tumours in transgenic mice with broad haemopoietic expression of MYC. Oncogene 2005, 24, 3544-3553, doi:10.1038/sj.onc.1208399.

294. Toyo-oka, K.; Bowen, T.J.; Hirotsune, S.; Li, Z.; Jain, S.; Ota, S.; Escoubet-Lozach, L.; Garcia-Bassets, I.; Lozach, J.; Rosenfeld, M.G., et al. Mnt-deficient mammary glands exhibit impaired involution and tumors with characteristics of myc overexpression. Cancer Res 2006, 66, 5565-5573, doi:10.1158/00085472.CAN-05-2683.

295. Hutchinson, J.N.; Muller, W.J. Transgenic mouse models of human breast cancer. Oncogene 2000, 19, 6130-6137, doi:10.1038/sj.onc.1203970.

296. Cornelis, R.S.; Vanvliet, M.; Vos, C.B.J.; Cletonjansen, A.M.; Vandevijver, M.J.; Peterse, J.L.; Khan, P.M.; Borresen, A.L.; Cornelisse, C.J.; Devilee, P. Evidence for a Gene on 17p13.3, Distal to Tp53, as a Target for Allele Loss in Breast-Tumors without P53 Mutations. Cancer Research 1994, 54, 4200-4206, doi:10.1016/0165-4608(94)90315-8.

297. Hoff, C.; Seranski, P.; Mollenhauer, J.; Korn, B.; Detzel, T.; Reinhardt, R.; Ramser, J.; Poustka, A. Physical and transcriptional mapping of the $17 \mathrm{p} 13.3$ region that is frequently deleted in human cancer. Genomics 2000, 70, 26-33, doi:10.1006/geno.2000.6353.

298. Lo Nigro, C.; Venesio, T.; Reymond, A.; Meroni, G.; Alberici, P.; Cainarca, S.; Enrico, F.; Stack, M.; Ledbetter, D.H.; Liscia, D.S., et al. The human ROX gene: genomic structure and mutation analysis in human breast tumors. Genomics 1998, 49, 275-282, doi:10.1006/geno.1998.5241.

299. Zhang, Z.; Sun, H.; Dai, H.; Walsh, R.M.; Imakura, M.; Schelter, J.; Burchard, J.; Dai, X.; Chang, A.N.; Diaz, R.L., et al. MicroRNA miR-210 modulates cellular response to hypoxia through the MYC antagonist MNT. Cell Cycle 2009, 8, 2756-2768, doi:10.4161/cc.8.17.9387.

300. Karenko, L.; Hahtola, S.; Paivinen, S.; Karhu, R.; Syrja, S.; Kahkonen, M.; Nedoszytko, B.; Kytola, S.; Zhou, Y.; Blazevic, V., et al. Primary cutaneous T-cell lymphomas show a deletion or translocation affecting NAV3, the human UNC-53 homologue. Cancer Res 2005, 65, 8101-8110, doi:10.1158/0008-5472.CAN04-0366.

301. Kari, L.; Loboda, A.; Nebozhyn, M.; Rook, A.H.; Vonderheid, E.C.; Nichols, C.; Virok, D.; Chang, C.; Horng, W.H.; Johnston, J., et al. Classification and prediction of survival in patients with the leukemic phase of cutaneous T cell lymphoma. J Exp Med 2003, 197, 1477-1488, doi:10.1084/jem.20021726.

302. Mao, X.; Orchard, G.; Lillington, D.M.; Russell-Jones, R.; Young, B.D.; Whittaker, S.J. Amplification and overexpression of JUNB is associated with primary cutaneous T-cell lymphomas. Blood 2003, 101, 15131519, doi:10.1182/blood-2002-08-2434.

303. van Doorn, R.; Dijkman, R.; Vermeer, M.H.; Out-Luiting, J.J.; van der Raaij-Helmer, E.M.; Willemze, R.; Tensen, C.P. Aberrant expression of the tyrosine kinase receptor EphA4 and the transcription factor twist in Sezary syndrome identified by gene expression analysis. Cancer Res 2004, 64, 5578-5586, doi:10.1158/0008-5472.CAN-04-1253.

304. Vermeer, M.H.; van Doorn, R.; Dijkman, R.; Mao, X.; Whittaker, S.; van Voorst Vader, P.C.; Gerritsen, M.J.; Geerts, M.L.; Gellrich, S.; Soderberg, O., et al. Novel and highly recurrent chromosomal alterations in Sezary syndrome. Cancer Res 2008, 68, 2689-2698, doi:10.1158/0008-5472.CAN-07-6398.

305. Boonk, S.E.; Zoutman, W.H.; Marie-Cardine, A.; van der Fits, L.; Out-Luiting, J.J.; Mitchell, T.J.; Tosi, I.; Morris, S.L.; Moriarty, B.; Booken, N., et al. Evaluation of Immunophenotypic and Molecular Biomarkers for Sezary Syndrome Using Standard Operating Procedures: A Multicenter Study of 59 Patients. J Invest Dermatol 2016, 136, 1364-1372, doi:10.1016/j.jid.2016.01.038. 
306. Edelmann, J.; Holzmann, K.; Miller, F.; Winkler, D.; Buhler, A.; Zenz, T.; Bullinger, L.; Kuhn, M.W.; Gerhardinger, A.; Bloehdorn, J., et al. High-resolution genomic profiling of chronic lymphocytic leukemia reveals new recurrent genomic alterations. Blood 2012, 120, 4783-4794, doi:10.1182/blood-2012-04423517.

307. Aref, S.; Fouda, M.; El-Dosoky, E.; Menessy, A.; Mabed, M.; Saleeb, M.; Zalata, K. c-Myc oncogene and Cdc25A cell activating phosphatase expression in non-Hodgkin's lymphoma. Hematology 2003, 8, 183190, doi:10.1080/1024533031000090829.

308. Huh, Y.O.; Lin, K.I.; Vega, F.; Schlette, E.; Yin, C.C.; Keating, M.J.; Luthra, R.; Medeiros, L.J.; Abruzzo, L.V. MYC translocation in chronic lymphocytic leukaemia is associated with increased prolymphocytes and a poor prognosis. Br J Haematol 2008, 142, 36-44, doi:10.1111/j.1365-2141.2008.07152.x.

309. Nagy, B.; Lundan, T.; Larramendy, M.L.; Aalto, Y.; Zhu, Y.; Niini, T.; Edgren, H.; Ferrer, A.; Vilpo, J.; Elonen, E., et al. Abnormal expression of apoptosis-related genes in haematological malignancies: overexpression of MYC is poor prognostic sign in mantle cell lymphoma. Br J Haematol 2003, 120, 434441, doi:10.1046/j.1365-2141.2003.04121.x.

310. Zhang, W.; Kater, A.P.; Widhopf, G.F., 2nd; Chuang, H.Y.; Enzler, T.; James, D.F.; Poustovoitov, M.; Tseng, P.H.; Janz, S.; Hoh, C., et al. B-cell activating factor and v-Myc myelocytomatosis viral oncogene homolog (c-Myc) influence progression of chronic lymphocytic leukemia. Proc Natl Acad Sci U S A 2010, 107, 18956-18960, doi:10.1073/pnas.1013420107.

311. Lavin, D.P.; Abassi, L.; Inayatullah, M.; Tiwari, V.K. Mnt Represses Epithelial Identity To Promote Epithelial-to-Mesenchymal Transition. Mol Cell Biol 2021, 41, e0018321, doi:10.1128/MCB.00183-21.

312. Christiansen, J.J.; Rajasekaran, A.K. Reassessing epithelial to mesenchymal transition as a prerequisite for carcinoma invasion and metastasis. Cancer Res 2006, 66, 8319-8326, doi:10.1158/0008-5472.CAN06-0410.

313. Jang, M.H.; Kim, H.J.; Kim, E.J.; Chung, Y.R.; Park, S.Y. Expression of epithelial-mesenchymal transitionrelated markers in triple-negative breast cancer: ZEB1 as a potential biomarker for poor clinical outcome. Hum Pathol 2015, 46, 1267-1274, doi:10.1016/j.humpath.2015.05.010.

314. Thompson, E.W.; Newgreen, D.F.; Tarin, D. Carcinoma invasion and metastasis: a role for epithelialmesenchymal transition? Cancer Res 2005, 65, 5991-5995; discussion 5995, doi:10.1158/00085472.CAN-05-0616.

315. Nguyen, H.V.; Vandenberg, C.J.; Ng, A.P.; Robati, M.R.; Anstee, N.S.; Rimes, J.; Hawkins, E.D.; Cory, S. Development and survival of MYC-driven lymphomas require the MYC antagonist MNT to curb MYCinduced apoptosis. Blood 2020, 135, 1019-1031, doi:10.1182/blood.2019003014.

316. Vasilevsky, N.A.; Ruby, C.E.; Hurlin, P.J.; Weinberg, A.D. OX40 engagement stabilizes Mxd4 and Mnt protein levels in antigen-stimulated T cells leading to an increase in cell survival. Eur J Immunol 2011, 41, 1024-1034, doi:10.1002/eji.201040449.

317. Kuzyk, A.; Mai, S. c-MYC-induced genomic instability. Cold Spring Harb Perspect Med 2014, 4, a014373, doi:10.1101/cshperspect.a014373.

318. Basu, A.; Haldar, S. The relationship between $\mathrm{Bcl} 2$, Bax and p53: consequences for cell cycle progression and cell death. Mol Hum Reprod 1998, 4, 1099-1109, doi:10.1093/molehr/4.12.1099.

319. Sebe-Pedros, A.; Ruiz-Trillo, I. Evolution and Classification of the T-Box Transcription Factor Family. In Curr Top Dev Biol, Elsevier: 2017; 10.1016/bs.ctdb.2016.06.004pp 1-26.

320. Blum, M.; Chang, H.Y.; Chuguransky, S.; Grego, T.; Kandasaamy, S.; Mitchell, A.; Nuka, G.; Paysan-Lafosse, T.; Qureshi, M.; Raj, S., et al. The InterPro protein families and domains database: 20 years on. Nucleic Acids Res 2021, 49, D344-D354, doi:10.1093/nar/gkaa977.

321. Kispert, A.; Herrmann, B.G. The Brachyury Gene Encodes a Novel DNA-Binding Protein. Embo Journal 1993, 12, 3211-3220, doi:DOI 10.1002/j.1460-2075.1993.tb05990.x.

322. Muller, C.W.; Herrmann, B.G. Crystallographic structure of the T domain-DNA complex of the Brachyury transcription factor. Nature 1997, 389, 884-888, doi:10.1038/39929.

323. Papaioannou, V.E. The T-box gene family: emerging roles in development, stem cells and cancer. Development 2014, 141, 3819-3833, doi:10.1242/dev.104471.

324. Wilson, V.; Conlon, F.L. The T-box family. Genome Biol 2002, 3, REVIEWS3008, doi:10.1186/gb-2002-3-6reviews3008. 
325. Burn, S.F.; Washkowitz, A.J.; Gavrilov, S.; Papaioannou, V.E. Postimplantation Mga expression and embryonic lethality of two gene-trap alleles. Gene Expr Patterns 2018, 27, 31-35, doi:10.1016/j.gep.2017.10.006.

326. Washkowitz, A.J.; Schall, C.; Zhang, K.; Wurst, W.; Floss, T.; Mager, J.; Papaioannou, V.E. Mga is essential for the survival of pluripotent cells during peri-implantation development. Development 2015, 142, 3140, doi:10.1242/dev.111104.

327. De Paoli, L.; Cerri, M.; Monti, S.; Rasi, S.; Spina, V.; Bruscaggin, A.; Greco, M.; Ciardullo, C.; Fama, R.; Cresta, S., et al. MGA, a suppressor of MYC, is recurrently inactivated in high risk chronic lymphocytic leukemia. Leuk Lymphoma 2013, 54, 1087-1090, doi:10.3109/10428194.2012.723706.

328. Takahashi, K.; Hu, B.; Wang, F.; Yan, Y.; Kim, E.; Vitale, C.; Patel, K.P.; Strati, P.; Gumbs, C.; Little, L., et al. Clinical implications of cancer gene mutations in patients with chronic lymphocytic leukemia treated with lenalidomide. Blood 2018, 131, 1820-1832, doi:10.1182/blood-2017-11-817296.

329. Jiang, L.; Gu, Z.H.; Yan, Z.X.; Zhao, X.; Xie, Y.Y.; Zhang, Z.G.; Pan, C.M.; Hu, Y.; Cai, C.P.; Dong, Y., et al. Exome sequencing identifies somatic mutations of DDX3X in natural killer/T-cell lymphoma. Nat Genet 2015, 47, 1061-1066, doi:10.1038/ng.3358.

330. Montes-Mojarro, I.A.; Chen, B.J.; Ramirez-Ibarguen, A.F.; Quezada-Fiallos, C.M.; Perez-Baez, W.B.; Duenas, D.; Casavilca-Zambrano, S.; Ortiz-Mayor, M.; Rojas-Bilbao, E.; Garcia-Rivello, H., et al. Mutational profile and EBV strains of extranodal NK/T-cell lymphoma, nasal type in Latin America. Mod Pathol 2020, 33, 781-791, doi:10.1038/s41379-019-0415-5.

331. Amin, N.A.; Seymour, E.; Saiya-Cork, K.; Parkin, B.; Shedden, K.; Malek, S.N. A Quantitative Analysis of Subclonal and Clonal Gene Mutations before and after Therapy in Chronic Lymphocytic Leukemia. Clin Cancer Res 2016, 22, 4525-4535, doi:10.1158/1078-0432.CCR-15-3103.

332. Campbell, J.D.; Alexandrov, A.; Kim, J.; Wala, J.; Berger, A.H.; Pedamallu, C.S.; Shukla, S.A.; Guo, G.; Brooks, A.N.; Murray, B.A., et al. Distinct patterns of somatic genome alterations in lung adenocarcinomas and squamous cell carcinomas. Nat Genet 2016, 48, 607-616, doi:10.1038/ng.3564.

333. Cooke, S.L.; Shlien, A.; Marshall, J.; Pipinikas, C.P.; Martincorena, I.; Tubio, J.M.; Li, Y.; Menzies, A.; Mudie, L.; Ramakrishna, M., et al. Processed pseudogenes acquired somatically during cancer development. Nat Commun 2014, 5, 3644, doi:10.1038/ncomms4644.

334. Jo, Y.S.; Kim, M.S.; Yoo, N.J.; Lee, S.H. Somatic mutation of a candidate tumour suppressor MGA gene and its mutational heterogeneity in colorectal cancers. Pathology 2016, 48, 525-527, doi:10.1016/j.pathol.2016.04.010.

335. Llabata, P.; Mitsuishi, Y.; Choi, P.S.; Cai, D.; Francis, J.M.; Torres-Diz, M.; Udeshi, N.D.; Golomb, L.; Wu, Z.; Zhou, J., et al. Multi-Omics Analysis Identifies MGA as a Negative Regulator of the MYC Pathway in Lung Adenocarcinoma. Mol Cancer Res 2020, 18, 574-584, doi:10.1158/1541-7786.MCR-19-0657.

336. Madan, V.; Han, L.; Hattori, N.; Teoh, W.W.; Mayakonda, A.; Sun, Q.Y.; Ding, L.W.; Nordin, H.B.M.; Lim, S.L.; Shyamsunder, P., et al. ASXL2 regulates hematopoiesis in mice and its deficiency promotes myeloid expansion. Haematologica 2018, 103, 1980-1990, doi:10.3324/haematol.2018.189928.

337. Mathsyaraja, H.; Catchpole, J.; Freie, B.; Eastwood, E.; Babaeva, E.; Geuenich, M.; Cheng, P.F.; Ayers, J.; $\mathrm{Yu}, \mathrm{M}$.; Wu, N., et al. Loss of MGA repression mediated by an atypical polycomb complex promotes tumor progression and invasiveness. Elife 2021, 10, e64212, doi:10.7554/eLife.64212.

338. Park, C.; Ha, S.Y.; Kim, S.T.; Kim, H.C.; Heo, J.S.; Park, Y.S.; Lauwers, G.; Lee, J.; Kim, K.M. Identification of the BRAF V600E mutation in gastroenteropancreatic neuroendocrine tumors. Oncotarget 2016, 7, 40244035, doi:10.18632/oncotarget.6602.

339. Stratmann, S.; Yones, S.A.; Mayrhofer, M.; Norgren, N.; Skaftason, A.; Sun, J.; Smolinska, K.; Komorowski, J.; Herlin, M.K.; Sundstrom, C., et al. Genomic characterization of relapsed acute myeloid leukemia reveals novel putative therapeutic targets. Blood Adv 2021, 5, 900-912, doi:10.1182/bloodadvances.2020003709.

340. Sun, Q.Y.; Ding, L.W.; Tan, K.T.; Chien, W.; Mayakonda, A.; Lin, D.C.; Loh, X.Y.; Xiao, J.F.; Meggendorfer, M.; Alpermann, T., et al. Ordering of mutations in acute myeloid leukemia with partial tandem duplication of MLL (MLL-PTD). Leukemia 2017, 31, 1-10, doi:10.1038/leu.2016.160.

341. Veeramachaneni, R.; Walker, T.; Revil, T.; Weck, A.; Badescu, D.; O'Sullivan, J.; Higgins, C.; Elliott, L.; Liloglou, T.; Risk, J.M., et al. Analysis of head and neck carcinoma progression reveals novel and relevant 
stage-specific changes associated with immortalisation and malignancy. Sci Rep 2019, 9, 11992, doi:10.1038/s41598-019-48229-7.

342. Zhang, Y.; Ma, Y.; Li, Y.; Shen, X.; Yu, Y.; Pan, Y.; Zhang, Y.; Zheng, D.; Zhao, Y.; Ye, T., et al. Comparative analysis of co-occurring mutations of specific tumor suppressor genes in lung adenocarcinoma between Asian and Caucasian populations. J Cancer Res Clin Oncol 2019, 145, 747-757, doi:10.1007/s00432-01802828-5.

343. Ohanian, M.; Rozovski, U.; Kanagal-Shamanna, R.; Abruzzo, L.V.; Loghavi, S.; Kadia, T.; Futreal, A.; Bhalla, K.; Zuo, Z.; Huh, Y.O., et al. MYC protein expression is an important prognostic factor in acute myeloid leukemia. Leuk Lymphoma 2019, 60, 37-48, doi:10.1080/10428194.2018.1464158.

344. Basit, F.; Andersson, M.; Hultquist, A. The Myc/Max/Mxd Network Is a Target of Mutated Flt3 Signaling in Hematopoietic Stem Cells in Flt3-ITD-Induced Myeloproliferative Disease. Stem Cells Int 2018, 2018, 3286949, doi:10.1155/2018/3286949.

345. Lee, M.J.; Koff, J.L.; Switchenko, J.M.; Jhaney, C.I.; Harkins, R.A.; Patel, S.P.; Dave, S.S.; Flowers, C.R. Genome-defined African ancestry is associated with distinct mutations and worse survival in patients with diffuse large B-cell lymphoma. Cancer 2020, 126, 3493-3503, doi:10.1002/cncr.32866.

346. Reddy, A.; Zhang, J.; Davis, N.S.; Moffitt, A.B.; Love, C.L.; Waldrop, A.; Leppa, S.; Pasanen, A.; Meriranta, L.; Karjalainen-Lindsberg, M.L., et al. Genetic and Functional Drivers of Diffuse Large B Cell Lymphoma. Cell 2017, 171, 481-494 e415, doi:10.1016/j.cell.2017.09.027.

347. Morkel, M.; Wenkel, J.; Bannister, A.J.; Kouzarides, T.; Hagemeier, C. An E2F-like repressor of transcription. Nature 1997, 390, 567-568, doi:10.1038/37507.

348. Scelfo, A.; Fernandez-Perez, D.; Tamburri, S.; Zanotti, M.; Lavarone, E.; Soldi, M.; Bonaldi, T.; Ferrari, K.J.; Pasini, D. Functional Landscape of PCGF Proteins Reveals Both RING1A/B-Dependent-and RING1A/BIndependent-Specific Activities. Mol Cell 2019, 74, 1037-1052 e1037, doi:10.1016/j.molcel.2019.04.002.

349. Stielow, B.; Finkernagel, F.; Stiewe, T.; Nist, A.; Suske, G. MGA, L3MBTL2 and E2F6 determine genomic binding of the non-canonical Polycomb repressive complex PRC1.6. PLoS Genet 2018, 14, e1007193, doi:10.1371/journal.pgen.1007193.

350. Trojer, P.; Cao, A.R.; Gao, Z.; Li, Y.; Zhang, J.; Xu, X.; Li, G.; Losson, R.; Erdjument-Bromage, H.; Tempst, P., et al. L3MBTL2 protein acts in concert with PcG protein-mediated monoubiquitination of $\mathrm{H} 2 \mathrm{~A}$ to establish a repressive chromatin structure. Mol Cell 2011, 42, 438-450, doi:10.1016/j.molcel.2011.04.004.

351. van Wijnen, A.J.; Bagheri, L.; Badreldin, A.A.; Larson, A.N.; Dudakovic, A.; Thaler, R.; Paradise, C.R.; Wu, Z. Biological functions of chromobox (CBX) proteins in stem cell self-renewal, lineage-commitment, cancer and development. Bone 2021, 143, 115659, doi:10.1016/j.bone.2020.115659.

352. Donehower, L.A.; Harvey, M.; Slagle, B.L.; McArthur, M.J.; Montgomery, C.A., Jr.; Butel, J.S.; Bradley, A. Mice deficient for p53 are developmentally normal but susceptible to spontaneous tumours. Nature 1992, 356, 215-221, doi:10.1038/356215a0.

353. Jackson, E.L.; Willis, N.; Mercer, K.; Bronson, R.T.; Crowley, D.; Montoya, R.; Jacks, T.; Tuveson, D.A. Analysis of lung tumor initiation and progression using conditional expression of oncogenic K-ras. Genes Dev 2001, 15, 3243-3248, doi:10.1101/gad.943001.

354. Sanchez-Rivera, F.J.; Papagiannakopoulos, T.; Romero, R.; Tammela, T.; Bauer, M.R.; Bhutkar, A.; Joshi, N.S.; Subbaraj, L.; Bronson, R.T.; Xue, W., et al. Rapid modelling of cooperating genetic events in cancer through somatic genome editing. Nature 2014, 516, 428-431, doi:10.1038/nature13906.

355. Suzuki, A.; Hirasaki, M.; Hishida, T.; Wu, J.; Okamura, D.; Ueda, A.; Nishimoto, M.; Nakachi, Y.; Mizuno, Y.; Okazaki, Y., et al. Loss of MAX results in meiotic entry in mouse embryonic and germline stem cells. Nat Commun 2016, 7, 11056, doi:10.1038/ncomms11056.

356. Gao, Z.; Zhang, J.; Bonasio, R.; Strino, F.; Sawai, A.; Parisi, F.; Kluger, Y.; Reinberg, D. PCGF homologs, CBX proteins, and RYBP define functionally distinct PRC1 family complexes. Mol Cell 2012, 45, 344-356, doi:10.1016/j.molcel.2012.01.002.

357. Kawaguchi, T.; Takenoshita, M.; Kabashima, T.; Uyeda, K. Glucose and cAMP regulate the L-type pyruvate kinase gene by phosphorylation/dephosphorylation of the carbohydrate response element binding protein. Proc Natl Acad Sci U S A 2001, 98, 13710-13715, doi:10.1073/pnas.231370798. 
358. O'Callaghan, B.L.; Koo, S.H.; Wu, Y.; Freake, H.C.; Towle, H.C. Glucose regulation of the acetyl-CoA carboxylase promoter PI in rat hepatocytes. J Biol Chem 2001, 276, 16033-16039, doi:10.1074/jbc.M101557200.

359. Ishii, S.; lizuka, K.; Miller, B.C.; Uyeda, K. Carbohydrate response element binding protein directly promotes lipogenic enzyme gene transcription. Proc Natl Acad Sci U S A 2004, 101, 15597-15602, doi:10.1073/pnas.0405238101.

360. Rufo, C.; Teran-Garcia, M.; Nakamura, M.T.; Koo, S.H.; Towle, H.C.; Clarke, S.D. Involvement of a unique carbohydrate-responsive factor in the glucose regulation of rat liver fatty-acid synthase gene transcription. J Biol Chem 2001, 276, 21969-21975, doi:10.1074/jbc.M100461200.

361. Shih, H.M.; Towle, H.C. Definition of the carbohydrate response element of the rat S14 gene. Evidence for a common factor required for carbohydrate regulation of hepatic genes. J Biol Chem 1992, 267, 13222-13228, doi:10.1016/s0021-9258(18)42198-9.

362. Li, M.V.; Chen, W.; Poungvarin, N.; Imamura, M.; Chan, L. Glucose-mediated transactivation of carbohydrate response element-binding protein requires cooperative actions from Mondo conserved regions and essential trans-acting factor 14-3-3. Mol Endocrinol 2008, 22, 1658-1672, doi:10.1210/me.2007-0560.

363. Merla, G.; Howald, C.; Antonarakis, S.E.; Reymond, A. The subcellular localization of the ChoRE-binding protein, encoded by the Williams-Beuren syndrome critical region gene 14, is regulated by 14-3-3. Hum Mol Genet 2004, 13, 1505-1514, doi:10.1093/hmg/ddh163.

364. Sakiyama, H.; Wynn, R.M.; Lee, W.R.; Fukasawa, M.; Mizuguchi, H.; Gardner, K.H.; Repa, J.J.; Uyeda, K. Regulation of nuclear import/export of carbohydrate response element-binding protein (ChREBP): interaction of an alpha-helix of ChREBP with the 14-3-3 proteins and regulation by phosphorylation. $J$ Biol Chem 2008, 283, 24899-24908, doi:10.1074/jbc.M804308200.

365. Falcicchio, M.; Ward, J.A.; Macip, S.; Doveston, R.G. Regulation of p53 by the 14-3-3 protein interaction network: new opportunities for drug discovery in cancer. Cell Death Discov 2020, 6, 126, doi:10.1038/s41420-020-00362-3.

366. Pennington, K.L.; Chan, T.Y.; Torres, M.P.; Andersen, J.L. The dynamic and stress-adaptive signaling hub of 14-3-3: emerging mechanisms of regulation and context-dependent protein-protein interactions. Oncogene 2018, 37, 5587-5604, doi:10.1038/s41388-018-0348-3.

367. Grompe, M.; Lindstedt, S.; al-Dhalimy, M.; Kennaway, N.G.; Papaconstantinou, J.; Torres-Ramos, C.A.; Ou, C.N.; Finegold, M. Pharmacological correction of neonatal lethal hepatic dysfunction in a murine model of hereditary tyrosinaemia type I. Nat Genet 1995, 10, 453-460, doi:10.1038/ng0895-453.

368. Lindqvist, L.M.; Tandoc, K.; Topisirovic, I.; Furic, L. Cross-talk between protein synthesis, energy metabolism and autophagy in cancer. Curr Opin Genet Dev 2018, 48, 104-111, doi:10.1016/j.gde.2017.11.003.

369. Metukuri, M.R.; Zhang, P.; Basantani, M.K.; Chin, C.; Stamateris, R.E.; Alonso, L.C.; Takane, K.K.; Gramignoli, R.; Strom, S.C.; O'Doherty, R.M., et al. ChREBP mediates glucose-stimulated pancreatic betacell proliferation. Diabetes 2012, 61, 2004-2015, doi:10.2337/db11-0802.

370. Ran, H.; Lu, Y.; Zhang, Q.; Hu, Q.; Zhao, J.; Wang, K.; Tong, X.; Su, Q. MondoA Is Required for Normal Myogenesis and Regulation of the Skeletal Muscle Glycogen Content in Mice. Diabetes Metab J 2021, 45, 439-451, doi:10.4093/dmj.2019.0212.

371. Eilers, A.L.; Sundwall, E.; Lin, M.; Sullivan, A.A.; Ayer, D.E. A novel heterodimerization domain, CRM1, and 14-3-3 control subcellular localization of the MondoA-Mlx heterocomplex. Mol Cell Biol 2002, 22, 8514-8526, doi:10.1128/MCB.22.24.8514-8526.2002.

372. Minn, A.H.; Hafele, C.; Shalev, A. Thioredoxin-interacting protein is stimulated by glucose through a carbohydrate response element and induces beta-cell apoptosis. Endocrinology 2005, 146, 2397-2405, doi:10.1210/en.2004-1378.

373. Lu, J.; Holmgren, A. The thioredoxin antioxidant system. Free Radic Biol Med 2014, 66, 75-87, doi:10.1016/j.freeradbiomed.2013.07.036.

374. Chen, Y.; Ning, J.; Cao, W.; Wang, S.; Du, T.; Jiang, J.; Feng, X.; Zhang, B. Research Progress of TXNIP as a Tumor Suppressor Gene Participating in the Metabolic Reprogramming and Oxidative Stress of Cancer Cells in Various Cancers. Front Oncol 2020, 10, 568574, doi:10.3389/fonc.2020.568574. 
375. Jeon, J.H.; Lee, K.N.; Hwang, C.Y.; Kwon, K.S.; You, K.H.; Choi, I. Tumor suppressor VDUP1 increases p27(kip1) stability by inhibiting JAB1. Cancer Res 2005, 65, 4485-4489, doi:10.1158/0008-5472.CAN-042271.

376. Arakaki, A.K.S.; Pan, W.A.; Wedegaertner, H.; Roca-Mercado, I.; Chinn, L.; Gujral, T.S.; Trejo, J. alphaArrestin ARRDC3 tumor suppressor function is linked to GPCR-induced TAZ activation and breast cancer metastasis. J Cell Sci 2021, 134, jcs254888, doi:10.1242/jcs.254888.

377. Xiao, J.; Shi, Q.; Li, W.; Mu, X.; Peng, J.; Li, M.; Chen, M.; Huang, H.; Wang, C.; Gao, K., et al. ARRDC1 and ARRDC3 act as tumor suppressors in renal cell carcinoma by facilitating YAP1 degradation. Am J Cancer Res 2018, 8, 132-143.

378. Rhein, P.; Scheid, S.; Ratei, R.; Hagemeier, C.; Seeger, K.; Kirschner-Schwabe, R.; Moericke, A.; Schrappe, M.; Spang, R.; Ludwig, W.D., et al. Gene expression shift towards normal B cells, decreased proliferative capacity and distinct surface receptors characterize leukemic blasts persisting during induction therapy in childhood acute lymphoblastic leukemia. Leukemia 2007, 21, 897-905, doi:10.1038/sj.leu.2404613.

379. Parmenter, T.J.; Kleinschmidt, M.; Kinross, K.M.; Bond, S.T.; Li, J.; Kaadige, M.R.; Rao, A.; Sheppard, K.E.; Hugo, W.; Pupo, G.M., et al. Response of BRAF-mutant melanoma to BRAF inhibition is mediated by a network of transcriptional regulators of glycolysis. Cancer Discov 2014, 4, 423-433, doi:10.1158/21598290.CD-13-0440.

380. Bollag, G.; Hirth, P.; Tsai, J.; Zhang, J.; Ibrahim, P.N.; Cho, H.; Spevak, W.; Zhang, C.; Zhang, Y.; Habets, G., et al. Clinical efficacy of a RAF inhibitor needs broad target blockade in BRAF-mutant melanoma. Nature 2010, 467, 596-599, doi:10.1038/nature09454.

381. Carlino, M.S.; Saunders, C.A.; Haydu, L.E.; Menzies, A.M.; Martin Curtis, C., Jr.; Lebowitz, P.F.; Kefford, R.F.; Long, G.V. (18)F-labelled fluorodeoxyglucose-positron emission tomography (FDG-PET) heterogeneity of response is prognostic in dabrafenib treated BRAF mutant metastatic melanoma. Eur $J$ Cancer 2013, 49, 395-402, doi:10.1016/j.ejca.2012.08.018.

382. McArthur, G.A.; Puzanov, I.; Amaravadi, R.; Ribas, A.; Chapman, P.; Kim, K.B.; Sosman, J.A.; Lee, R.J.; Nolop, K.; Flaherty, K.T., et al. Marked, homogeneous, and early [18F]fluorodeoxyglucose-positron emission tomography responses to vemurafenib in BRAF-mutant advanced melanoma. J Clin Oncol 2012, 30, 1628-1634, doi:10.1200/JCO.2011.39.1938.

383. Zheng, J. Energy metabolism of cancer: Glycolysis versus oxidative phosphorylation (Review). Oncol Lett 2012, 4, 1151-1157, doi:10.3892/ol.2012.928.

384. Goetzman, E.S.; Prochownik, E.V. The Role for Myc in Coordinating Glycolysis, Oxidative Phosphorylation, Glutaminolysis, and Fatty Acid Metabolism in Normal and Neoplastic Tissues. Front Endocrinol (Lausanne) 2018, 9, 129, doi:10.3389/fendo.2018.00129.

385. Vander Heiden, M.G.; Cantley, L.C.; Thompson, C.B. Understanding the Warburg effect: the metabolic requirements of cell proliferation. Science 2009, 324, 1029-1033, doi:10.1126/science.1160809.

386. Altman, B.J.; Stine, Z.E.; Dang, C.V. From Krebs to clinic: glutamine metabolism to cancer therapy. Nat Rev Cancer 2016, 16, 773, doi:10.1038/nrc.2016.131.

387. Yang, G.; Hurlin, P.J. MNT and Emerging Concepts of MNT-MYC Antagonism. Genes (Basel) 2017, 8, 83, doi:10.3390/genes8020083.

388. Yang, L.; Venneti, S.; Nagrath, D. Glutaminolysis: A Hallmark of Cancer Metabolism. Annu Rev Biomed Eng 2017, 19, 163-194, doi:10.1146/annurev-bioeng-071516-044546.

389. Graves, J.A.; Wang, Y.; Sims-Lucas, S.; Cherok, E.; Rothermund, K.; Branca, M.F.; Elster, J.; Beer-Stolz, D.; Van Houten, B.; Vockley, J., et al. Mitochondrial structure, function and dynamics are temporally controlled by c-Myc. PLoS One 2012, 7, e37699, doi:10.1371/journal.pone.0037699.

390. Hsieh, A.L.; Walton, Z.E.; Altman, B.J.; Stine, Z.E.; Dang, C.V. MYC and metabolism on the path to cancer. Semin Cell Dev Biol 2015, 43, 11-21, doi:10.1016/j.semcdb.2015.08.003.

391. Shim, H.; Dolde, C.; Lewis, B.C.; Wu, C.S.; Dang, G.; Jungmann, R.A.; Dalla-Favera, R.; Dang, C.V. c-Myc transactivation of LDH-A: implications for tumor metabolism and growth. Proc Natl Acad Sci U S A 1997, 94, 6658-6663, doi:10.1073/pnas.94.13.6658.

392. Meroni, G.; Cairo, S.; Merla, G.; Messali, S.; Brent, R.; Ballabio, A.; Reymond, A. Mlx, a new Max-like bHLHZip family member: the center stage of a novel transcription factors regulatory pathway? Oncogene 2000, 19, 3266-3277, doi:10.1038/sj.onc.1203634. 
393. Lytle, N.K.; Barber, A.G.; Reya, T. Stem cell fate in cancer growth, progression and therapy resistance. Nat Rev Cancer 2018, 18, 669-680, doi:10.1038/s41568-018-0056-x.

394. Nedachi, T.; Kadotani, A.; Ariga, M.; Katagiri, H.; Kanzaki, M. Ambient glucose levels qualify the potency of insulin myogenic actions by regulating SIRT1 and FoxO3a in C2C12 myocytes. Am J Physiol Endocrinol Metab 2008, 294, E668-678, doi:10.1152/ajpendo.00640.2007.

395. Hunt, L.C.; Xu, B.; Finkelstein, D.; Fan, Y.; Carroll, P.A.; Cheng, P.F.; Eisenman, R.N.; Demontis, F. The glucose-sensing transcription factor MLX promotes myogenesis via myokine signaling. Genes Dev 2015, 29, 2475-2489, doi:10.1101/gad.267419.115.

396. Rai, M.; Demontis, F. Systemic Nutrient and Stress Signaling via Myokines and Myometabolites. Annu Rev Physiol 2016, 78, 85-107, doi:10.1146/annurev-physiol-021115-105305.

397. Falcone, G.; Tato, F.; Alema, S. Distinctive effects of the viral oncogenes myc, erb, fps, and src on the differentiation program of quail myogenic cells. Proc Natl Acad Sci US A 1985, 82, 426-430, doi:10.1073/pnas.82.2.426.

398. Donato, M.; Hamidian Jahromi, A.; Andrade, A.I.; Kim, R.; Chaudhery, S.I.; Sangster, G. Hepatic adenomatosis: a rare but important liver disease with severe clinical implications. Int Surg 2015, 100, 903-907, doi:10.9738/INTSURG-D-14-00161.1.

399. Karim, S.; Adams, D.H.; Lalor, P.F. Hepatic expression and cellular distribution of the glucose transporter family. World J Gastroenterol 2012, 18, 6771-6781, doi:10.3748/wjg.v18.i46.6771.

400. Torbenson, M. Hepatic Adenomas: Classification, Controversies, and Consensus. Surg Pathol Clin 2018, 11, 351-366, doi:10.1016/j.path.2018.02.007.

401. Brunt, E.M.; Wong, V.W.; Nobili, V.; Day, C.P.; Sookoian, S.; Maher, J.J.; Bugianesi, E.; Sirlin, C.B.; Neuschwander-Tetri, B.A.; Rinella, M.E. Nonalcoholic fatty liver disease. Nat Rev Dis Primers 2015, 1, 15080, doi:10.1038/nrdp.2015.80.

402. Marengo, A.; Rosso, C.; Bugianesi, E. Liver Cancer: Connections with Obesity, Fatty Liver, and Cirrhosis. Annu Rev Med 2016, 67, 103-117, doi:10.1146/annurev-med-090514-013832.

403. Edmunds, L.R.; Otero, P.A.; Sharma, L.; D'Souza, S.; Dolezal, J.M.; David, S.; Lu, J.; Lamm, L.; Basantani, M.; Zhang, P., et al. Abnormal lipid processing but normal long-term repopulation potential of myc-/hepatocytes. Oncotarget 2016, 7, 30379-30395, doi:10.18632/oncotarget.8856.

404. Croce, C.M. Oncogenes and cancer. N Engl J Med 2008, 358, 502-511, doi:10.1056/NEJMra072367.

405. Mandel, J.; Avula, R.; Prochownik, E.V. Sequential analysis of transcript expression patterns improves survival prediction in multiple cancers. BMC Cancer 2020, 20, 297, doi:10.1186/s12885-020-06756-x.

406. Mandel, J.; Wang, H.; Normolle, D.P.; Chen, W.; Yan, Q.; Lucas, P.C.; Benos, P.V.; Prochownik, E.V. Expression patterns of small numbers of transcripts from functionally-related pathways predict survival in multiple cancers. BMC Cancer 2019, 19, 686, doi:10.1186/s12885-019-5851-6.

407. Dolezal, J.M.; Dash, A.P.; Prochownik, E.V. Diagnostic and prognostic implications of ribosomal protein transcript expression patterns in human cancers. BMC Cancer 2018, 18, 275, doi:10.1186/s12885-0184178-z.

408. de Pretis, S.; Kress, T.R.; Morelli, M.J.; Sabo, A.; Locarno, C.; Verrecchia, A.; Doni, M.; Campaner, S.; Amati, B.; Pelizzola, M. Integrative analysis of RNA polymerase II and transcriptional dynamics upon MYC activation. Genome Res 2017, 27, 1658-1664, doi:10.1101/gr.226035.117.

409. Price, D.H. Regulation of RNA polymerase II elongation by c-Myc. Cell 2010, 141, 399-400, doi:10.1016/j.cell.2010.04.016.

410. Rahl, P.B.; Lin, C.Y.; Seila, A.C.; Flynn, R.A.; McCuine, S.; Burge, C.B.; Sharp, P.A.; Young, R.A. c-Myc regulates transcriptional pause release. Cell 2010, 141, 432-445, doi:10.1016/j.cell.2010.03.030.

411. Zhou, Z.Q.; Hurlin, P.J. The interplay between Mad and Myc in proliferation and differentiation. Trends in Cell Biology 2001, 11, S10-S14, doi:Doi 10.1016/S0962-8924(01)02121-3.

412. Mermel, C.H.; Schumacher, S.E.; Hill, B.; Meyerson, M.L.; Beroukhim, R.; Getz, G. GISTIC2.0 facilitates sensitive and confident localization of the targets of focal somatic copy-number alteration in human cancers. Genome Biol 2011, 12, R41, doi:10.1186/gb-2011-12-4-r41.

413. Gu, Z.; Eils, R.; Schlesner, M. Complex heatmaps reveal patterns and correlations in multidimensional genomic data. Bioinformatics 2016, 32, 2847-2849, doi:10.1093/bioinformatics/btw313. 